Higor Aparecido Vieira Alves

\title{
Oncogrid: Uma Grade Computacional Para a Integração e Compartilhamento de Dados Médicos em Oncologia
}

Dissertação de mestrado apresentado à Escola Politécnica da Universidade de São Paulo para obtenção do título de Mestre em Engenharia Elétrica 
Higor Aparecido Vieira Alves

\section{Oncogrid: Uma Grade Computacional Para a Integração e Compartilhamento de Dados Médicos em Oncologia}

Dissertação de mestrado apresentado à Escola Politécnica da Universidade de São Paulo para obtençao do título de Mestre em Engenharia Elétrica

Área de Concentração: Sistemas Eletrônicos

Orientador: Prof. Dr. Marcelo Knörich Zuffo

São Paulo 
A minha família pelo apoio. 


\section{Agradecimentos}

Agradeço aos meus pais, Francicleston e Ivanilde, minha irmã Helen e meus familiares pelo apoio, incentivo e confiança.

Agradeço ao Ulysses Pereira de Almeida Neto e Anne Picorone, pelo apoio, incentivo e confiança.

Agradeço a coordenação da Escola Politécnica da USP e do Laboratório de Sistemas Integráveis pelo apoio oferecido.

Agradeço a Profa. Dra. Magdala de Araújo Novaes, Hermano Brandão e toda a equipe do NUTES-UFPE pelo apoio no desenvolvimento do projeto piloto do da arquitetura do Oncogrid e da aplicação de validação.

Agradeço ao Prof. Dr. Marcelo Marcelo Knörich Zuffo, pela orientação, amizade e oportunidade de trabalharmos em conjunto.

Agradeço ao Dr. André Nebel e Prof. Dr. Vicente Odone Filho, pelo apoio e colaboração na área médica.

Agradeço a todos meus colegas do Núcleo de Saúde Digital do LSI pelas contribuições neste trabalho: Francisco Fernandes, Moacir Campos, Thiago Petersen, Marcelo Arbore, Felipe, Ilana Souza, Marcio Almeida, Marcio Hatano, Celina, Ana Alcaltra, Edvaldo, Marcia Kondo, Maryana Alegro, Claudinei Sanches, Natanael Santos, Cicero da Conceição, Henrique Calazans, Emerson Moretto, Eduardo, Sandra Segalo, Rodrigo Alves. E a todos aqueles que colaboraram de forma indireta para a realização deste trabalho.

Agradeço ao amigo Msc. Adilson Hira, gerente do núcleo do Telessaúde do Laboratório de Sistemas Integráveis pelo apoio, incentivo, cobranças e auxílio nas revisões desta dissertação e publicações realizadas, pois foram de extrema importância para a consolidação deste trabalho. 


\section{Resumo}

No Brasil as informações sobre o câncer estão distribuídas entre diferentes instituições que realizam o seu tratamento, nesse contexto são necessárias ferramentas para o levantamento do cenário nacional que possa auxiliar na atenção a doença. Este contexto motivou a criação do Oncogrid, que é uma grade computacional para integração e compartilhamento de dados médicos em oncologia e permitirá à comunidade médica a análise dos tratamentos aplicados com reflexos na gestão do câncer. Foi realizada uma pesquisa analizando as diferentes arquiteturas e componentes utilizados em projetos de grade voltados à saúde, a fim de propor uma arquitetura flexível, modular e escalável para o Oncogrid, em conformidade com as necessidades brasileiras. Realizou-se um projeto piloto entre o LSI/EPUSP e o NUTES/UFPE o qual implementou uma aplicação para geração de curvas de sobrevida utilizando o método Kaplan-Meier e serviu para avaliar a arquitetura do Oncogrid. Os resultados obtidos comprovaram a viabilidade da arquitetura utilizada e o potencial da proposta de uma grade computacional como um novo paradigma para a integração e compartilhamento de informações. O Oncogrid mostrou-se uma arquitetura computacional interessante para a realidade brasileira, especialmente no acesso as informações distribuídas, o que pode fornecer maiores subsídios para a evolução dos tratamentos e desenvolvimento de novas frentes de pesquisas. 


\section{Abstract}

In Brazil the cancer information is distributed among several institutions that accomplish your treatment, in this context we are need tools to build a national scenery that can be aid the cancer care. This context motivated the Oncogrid creation that is a grid computing for integration and sharing medical data in oncology and will allow the medical community to analise the applied treatments with reflection in cancer management.A study was done to analise the several architectures and components used in grid projects to health care, making possible to propose a flexible, modular and scalable architecture to the Oncogrid accordingly with the brazilian reality. An initial project between LSI/EPUSP and NUTES/UFPE that was developed an application to plot the survival curve using the Kaplan-Meier method and allow the evaluation of the Oncogrid architecture. The results achieved confirm the architecture viability used and the proposal potentiality of a grid computing with a new paradigm to the integration and sharing informations. The Oncogrid shows a viable computing architecture to Brazil, especially to access distributed information that can be prove great contributions to treatment evolution and to develop new research areas. 


\section{Lista de Figuras}

1.1 Gráfico da distribuição dos casos de câncer por Tipo/Região . . . . . . . . 2

1.2 Gráfico da distribuição dos casos de câncer por Região . . . . . . . . . . . 3

2.1 Visão de alto nível do relacionamento entre OGSI e OGSA . . . . . . . . 16

2.2 Interfaces OGSI . . . . . . . . . . . . . . . . . . . 17

2.3 Modelo organizacional do GME . . . . . . . . . . . . . . . . . . . . 23

2.4 Federação de dados com o VMako . . . . . . . . . . . . . . . . . . . . . . . 24

2.5 Serviço do Mobius de Tradução de Esquema . . . . . . . . . . . . . . . . 25

2.6 Modelo de Integração do OGSA-DAI . . . . . . . . . . . . . . . . . . . . 26

2.7 Modelo de Integração do OGSA-DQP . . . . . . . . . . . . . . . . . . . . 28

2.8 Ferramenta CAS . . . . . . . . . . . . . . . . . . 31

2.9 Ferramenta VOMS . . . . . . . . . . . . . . . . . . . . 32

2.10 Ferramenta MyProxy . . . . . . . . . . . . . . . . 34

2.11 Visão de Alto Nível da Arquitetura do Shibboleth . . . . . . . . . . . . 35

3.1 Backbone da Rede Ipê . . . . . . . . . . . . . . . . . . . . . . . . 46

3.2 Camadas Funcionais do Oncogrid . . . . . . . . . . . . . . . . . . 48

3.3 Processo de Assinatura de Certificado . . . . . . . . . . . . . . . . . . . . . 49

3.4 Processo de Autenticação e Delegação de Certificado . . . . . . . . . . . . 50

3.5 Processo de Monitoramento de Serviços e Recursos . . . . . . . . . . . . . 52

3.6 Processo de Utilização dos Serviços de Dados . . . . . . . . . . . . . . . . 53

4.1 Curva de Sobrevida pelo método Kaplan-Meier (IARC, 1991) . . . . . . . . 57

4.2 Implementação Inicial do Oncogrid . . . . . . . . . . . . . . . . . . . . 61

4.3 Modelo de autenticação e delegação . . . . . . . . . . . . . . . . . . . . 62 
4.4 Modelo de Integração de Dados . . . . . . . . . . . . . . . . . . . . 63

4.5 Curvas do Kaplan-Meier geradas no Oncogrid . . . . . . . . . . . . . . 65

4.6 Modelo do Gerenciador de Credencial de Grade . . . . . . . . . . . . . . . 70 


\section{Lista de Tabelas}

1.1 Estimativa de câncer por tumor. Fonte: INCA . . . . . . . . . . . . . . . 2

1.2 Sobrevida dos pacientes após 5 anos de tratamento. Fonte: INCA . . . . . 4

4.1 Componentes Físicos do Oncogrid . . . . . . . . . . . . . . . . . . . 60 


\section{Lista de Siglas}

AC Autoridade Certificadora

AMBIT Acquiring Medical and Biological Information from Text

ANL Argonne National Laboratory

ANSP Academic Network at São Paulo

API Application Programming Interface

AR Autoridade Registradora

BOINC Berkeley Open Infrastructure for Network Computing

caBIG The Cancer Biomedical Informatics Grid

Caltech California Institute of Technology

CAS Community Authorization Service

DAISGR Data Access and Integration Service Group Registry

DAIS-WG Data Access and Integration Services - Work Group

DTS Data Translation Service

EDG European Data Grid

EGA Enterprise Grid Alliance

EPSRC Engineering and Physical Sciences Research Council

EVS Enterprise Vocabulary Services

GAARDS Grid Authentication and Authorization with Realiaby Distributed Services

GDQS Grid Distributed Query Service

GDS Grid Data Service 
GDSF Grid Data Service Factory

GGF Global Grid Form

GME Global Model Exchange

GQES Grid Query Evaluation Service

GT Globus Toolkit

GTS Grid Trust Service

GRAM Grid Resource Allocation and Management

GSH Grid Service Handle

GSI Grid Security Infrastructure

GSR Grid Service Reference

ICP Infra-estrutura de Chaves Públicas

iRods $i$ Rule Oriented Data Systems

LSI-EPUSP Laboratório de Sistemas Integráveis da Escola Politécnica da Universidade de São Paulo

MDS Monitoring and Discovery System

NCSA National Center for Supercomputing Applications

NESS Network for Earthquake Engineering Simulation

NUTES-UFPE Núcleo de Telessaúde da Universidade Federal de Pernambuco

OASIS Organization for the Advancement of Structured Information Standards

OGF Open Grid Forum

OGSA Open Grid Services Architecture

OGSA-DAI Open Grid Services Architecture - Data Access and Integration

OGSA-DQP Open Grid Services Architecture - Distributed Query Processing

OGSI Open Grid Services Infrastructure 
OSG Open Sciences Grid

OV Organização Virtual

POP Ponto de Presença

RCT Rede Catarinense de Tecnologia

RGMA Relational Grid Monitoring Architecture

RNP Rede Nacional de Ensino e Pesquisa

SAML Security Assertion Markup Language

SDSC San Diego Supercomputer Center

SOAP Simple Object Access Protocol

SPRACE São Paulo Regional Analysis Center

SRB Storage Resource Broker

SSL Security Socket Layer

SUS Sístema Único de Saúde

TLS Transport Layer Security

UML Unified Modeling Language

US-NDMA United States - National Digital Mammogram Archive

VOMS Virtual Organization Membership Service

XML eXtensible Markup Language

W3C World Wide Web Consortium

WSDL Web Service Definition Language 


\section{Sumário}

1 Introdução 1

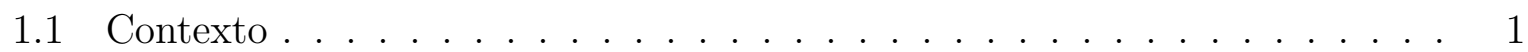

1.2 Relevância . . . . . . . . . . . . . . . . . . . 6

1.3 Justificativa . . . . . . . . . . . . . . . . . . . . . 7

1.4 Motivação . . . . . . . . . . . . . . . . . . . . . 8

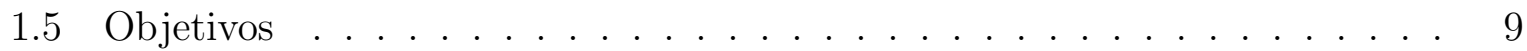

1.6 Metodologia . . . . . . . . . . . . . . . . . . . . . . 9 9

1.7 Estrutura da Dissertação . . . . . . . . . . . . . . . . . . . . . . . . 10

2 Computação em Grade na Área da Saúde $\quad 12$

2.1 Introdução . . . . . . . . . . . . . . . . . . . . . . . 12

2.2 Histórico das Grades Computacionais . . . . . . . . . . . . . . . . . . . . . 14

2.3 Padrões e Especificações para Grades Computacionais . . . . . . . . . . . . 15

2.3.1 Especificações da Infra-estrutura Aberta de Serviços de Grade . . . 16

2.3.2 Especificações da Arquitetura Aberta de Serviços de Grade . . . . . 18

2.4 Ferramentas Base para Grade Computacional . . . . . . . . . . . . . . . . 19

2.4.1 A Ferramenta ${ }^{m y}$ Grid . . . . . . . . . . . . . . . . . . . . 19

2.4 .2 A Ferramenta MyGrid . . . . . . . . . . . . . . . . . 20

2.4 .3 A Ferramenta OurGrid . . . . . . . . . . . . . . . . 20

2.4.4 A Ferramenta Berkeley Open Infrastructure for Network

Computing ......................... 21

2.4.5 A Ferramenta Globus Toolkit ................. 21 
2.5 Ferramentas para Acesso e Integração de Dados em Grade Computacional 22

2.5.1 A Ferramenta Mobius . . . . . . . . . . . . . . 23

2.5.2 A Ferramenta Open Grid Services Architecture - Data Access and Integration . . . . . . . . . . . . . . . . . 24

2.5.3 A Ferramenta Open Grid Services Architecture - Distributed Query Processing . . . . . . . . . . . . . . . . 27

2.6 Ferramentas para Segurança em Grade Computacional . . . . . . . . . . . 27

2.6.1 O Serviço de Infra-estrutura de Chave Pública . . . . . . . . . . . . 29

2.6.2 A Ferramenta Serviço de Autorização Comunitária . . . . . . . . . 30

2.6.3 A Ferramenta Virtual Organization Membership Service . . . . . . 31

2.6.4 A Ferramenta GridMap . . . . . . . . . . . . . . . 32

2.6.5 A Ferramenta MyProxy . . . . . . . . . . . . . . . . 33

2.6.6 A Ferramenta Shibboleth . . . . . . . . . . . . . . . 34

2.7 Ferramentas para Monitoração e Informação em Grade Computacional . 34

2.7 .1 A Ferramenta Ganglia . . . . . . . . . . . . . . . 35

2.7 .2 A Ferramenta Hawkeye . . . . . . . . . . . . . . . 36

2.7.3 A Ferramenta Arquitetura Relacional de Monitoramento de Grade . 36

2.7.4 A Ferramenta Sistema de Monitoramento e Descoberta . . . . . . . 37

2.8 Projetos Similares em Grade para Saúde . . . . . . . . . . . . . . . . . . . 38

2.8.1 Cancer Biomedical Informatics Grid . . . . . . . . . . . . . . 38

2.8.2 Diagnostic Mammography National Database . . . . . . . . . . . . . 39

2.8.3 BioSimGrid . . . . . . . . . . . . . . . . . . . . . . . 39

2.9 Resumo do Capítulo . . . . . . . . . . . . . . . . . . . . . . . . . 39

3 Proposta de Arquitetura de Grade Computacional para Integração e Compartilhamento de Dados Médicos $\quad 41$

3.1 Introdução . . . . . . . . . . . . . . . . . . . . . . . . . . . . 41

3.2 Requisitos do Oncogrid . . . . . . . . . . . . . . . . . . . . 42 
3.2.1 Requisitos Funcionais . . . . . . . . . . . . . . . . . 42

3.2 .2 Requisitos Não Funcionais . . . . . . . . . . . . . . . . . . . . . 43

3.3 Aplicabilidade no Meio Médico . . . . . . . . . . . . . . . . . 45

3.4 Rede Nacional de Ensino e Pesquisa . . . . . . . . . . . . . . . . . . . . 45

3.5 Arquitetura do Oncogrid . . . . . . . . . . . . . . . . . . 47

3.5.1 Camada de Segurança . . . . . . . . . . . . . . . . 47

3.5.2 Camada de Acesso do Usuário . . . . . . . . . . . . . . . . . . . . . 49

3.5.3 Camada de Serviços de Aplicação . . . . . . . . . . . . . . . . . . . 51

3.5.4 Camada de Serviços de Grade . . . . . . . . . . . . . . . . . . 51

3.5.5 Camada de Serviços de Conexão de Dados . . . . . . . . . . . . . . 52

3.5.6 Camada de Recursos . . . . . . . . . . . . . . . . . . . 53

3.6 Proposta de Validação do Oncogrid . . . . . . . . . . . . . . . . 53

3.7 Resumo do Capítulo . . . . . . . . . . . . . . . . 54

4 Implementação e Análise dos Resultados $\quad 56$

4.1 Introdução . . . . . . . . . . . . . . . . . . . . . . . 56

4.2 Estudo de Caso: Kaplan-Meier f . . . . . . . . . . . . . . . . . 57

4.3 Inclusão dos dados . . . . . . . . . . . . . . . . . . . . . . . . 58

4.4 Implementação Inicial da Arquitetura . . . . . . . . . . . . . . . . . 58

4.4 .1 Processo de Autenticação . . . . . . . . . . . . . . . . . . . 61

4.4 .2 Processo de Integração de Dados . . . . . . . . . . . . . . . . . . . 63

4.4 .3 Integração do Ambiente . . . . . . . . . . . . . . . . . . . 63

4.4 .4 Resultados Obtidos . . . . . . . . . . . . . . . . 64

4.4.5 Análise dos Resultados . . . . . . . . . . . . . . . . . . 65

4.5 Estudo de Alternativas na Camada de Segurança . . . . . . . . . . . 67

4.5 .1 MyProxy CA . . . . . . . . . . . . . . . 68

4.5.2 Gerenciador de Credencial de Grade . . . . . . . . . . . . . . . . . 69 
4.5.3 Análise das soluções . . . . . . . . . . . . . . . . . . . . . . . . . 72

4.6 Resumo do Capítulo . . . . . . . . . . . . . . . . . . 73

5 Conclusão, Trabalhos Futuros e Contribuições $\quad 75$

5.1 Introdução . . . . . . . . . . . . . . . . . . . . . 75

5.2 Conclusão . . . . . . . . . . . . . . . . . . . . . . 75

5.3 Contribuições . . . . . . . . . . . . . . . . . . 76

5.4 Trabalhos Futuros . . . . . . . . . . . . . . . . . . 77

$\begin{array}{lr}\text { Referências Bibliográficas } & 80\end{array}$ 


\section{Introdução}

O câncer é uma doença de nível celular que pode eventualmente induzir tumores em diversas regiões do corpo humano, e possui crescente incidência na população mundial, sendo estimado 15 milhões de novos casos no mundo em 2020 pela Organização Mundial de Saúde (OMS), e 60\% destes casos estarão em países em desenvolvimento (INCA, 2007).

Como estes tumores não possuem uma cura específica, é necessário em alguns casos a intervenção cirúrgica ou terapias de tratamento com compostos químicos (quimioterapia) ou radioativos (radioterapia), mas o melhor prognóstico no tratamento de um câncer é a detecção precoce da existência do tumor.

Esforços para encontrar uma cura ou melhores métodos de tratamento para a doença, movimentam a comunidade científica a promover pesquisas que vão da genética a melhores métodos para vigilância da doença, pois $1 / 3$ dos novos casos podem ser prevenidos (INCA, 2007).

Para auxiliar o desenvolvimento destas pesquisas é necessário a utilização de plataformas computacionais que possibilitam processamento e armazenamento de uma grande massa de dados, que podem abranger informações genéticas ou sobre o tratamento de pacientes e dentre as tecnologias utilizadas estão as grades computacionais.

As grades computacionais são utilizadas para o desenvolvimento de aplicações nas mais diversas áreas através da Internet e redes de alta velocidade; particularmente na área de saúde, esta tecnologia é utilizada para oferecer uma infra-estrutura colaborativa distribuída para pesquisas e oferta de serviços à prática médica.

\section{$1.1 \quad$ Contexto}

As estatisticas de incidência do câncer no país para os anos de 2008 e 2009 são apresentados pelo periódico Estimativa 2008 - Incidência do Câncer no Brasil publicado pelo Instituto Nacional do Câncer(INCA), estas informações mostram que estão previs- 
tos 466.730 novos casos, distribuídos conforme a Tabela 1.1, atingindo 231.860 homens e 234.870 mulheres (INCA, 2007).

\begin{tabular}{|l|c|}
\hline Tipo do tumor & Estimativa de casos \\
\hline Pele não melanoma & $115 \mathrm{mil}$ \\
\hline Próstata & $49 \mathrm{mil}$ \\
\hline Mama feminino & $49 \mathrm{mil}$ \\
\hline Pulmão & $27 \mathrm{mil}$ \\
\hline Cólon e Reto & $27 \mathrm{mil}$ \\
\hline Estômago & $22 \mathrm{mil}$ \\
\hline Colo do útero & $19 \mathrm{mil}$ \\
\hline
\end{tabular}

Tabela 1.1: Estimativa de câncer por tumor. Fonte: INCA

Além das estimativas de incidência apresentadas por esta publicação, é apresentado a distribuição dos tipos de tumores por região, como ilustrado na Figura 1.1, a qual permite concluir que no Sul e Sudeste ocorrerão os maiores níveis de incidência e o Norte e Nordeste os menores, como ilustrado na Figura 1.2.

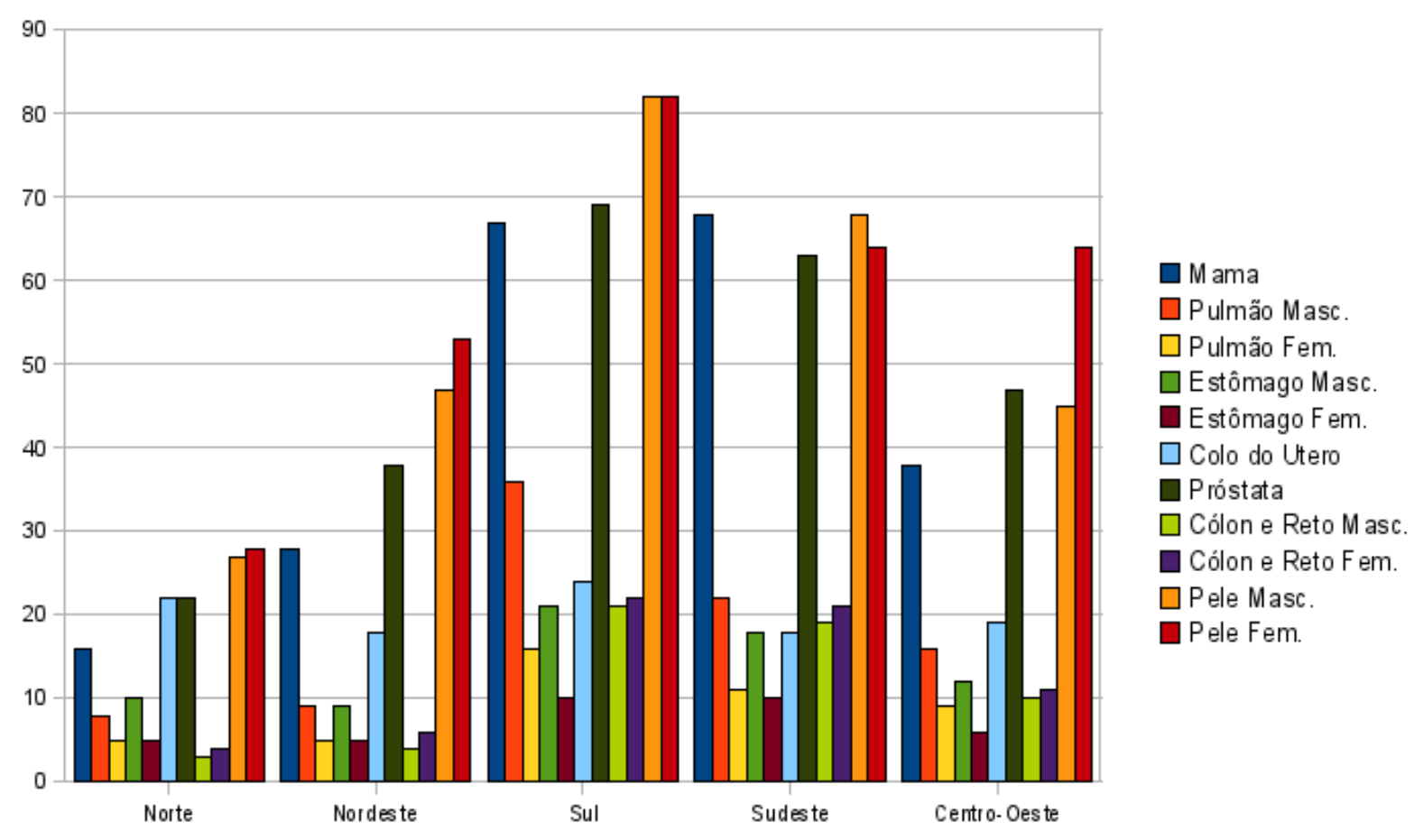

Figura 1.1: Gráfico da distribuição dos casos de câncer por Tipo/Região

Por se tratar de uma doença que depende de sua detecção precoce para obter melhores níveis de cura, a vigilância da doença torna-se uma estratégia importante para avaliar fatores como a eficiência dos programas de controle e prevenção, detecção precoce e o impacto do câncer na população (INCA, 2007). 


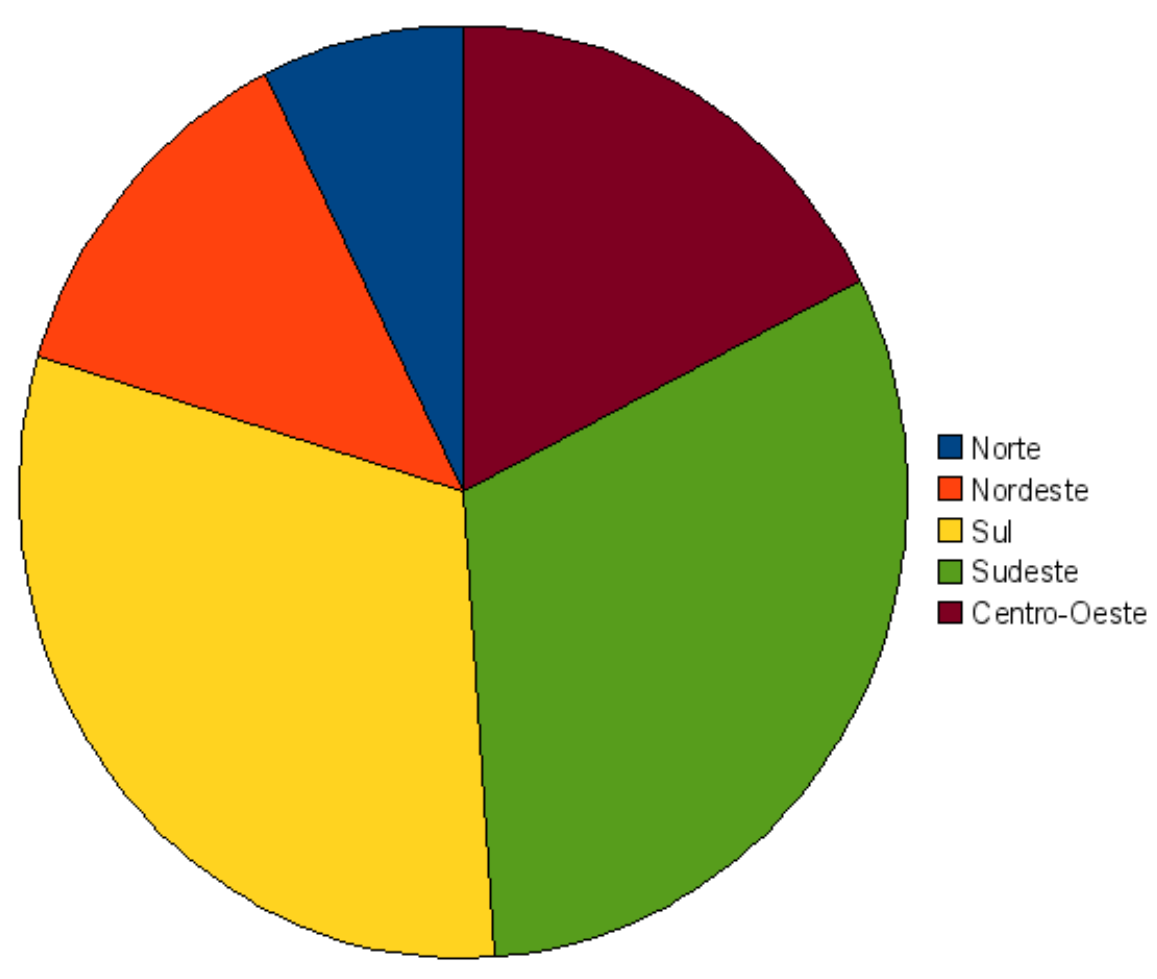

Figura 1.2: Gráfico da distribuição dos casos de câncer por Região

Segundo a Agência Internacional de Pesquisa sobre o Câncer, do inglês International Agency for Research on Cancer, a principal ferramenta para um programa eficiente de controle do câncer é o registro dos casos de incidência (IARC, 1991). Os registros de câncer no Brasil são gerenciados pelo INCA através do Registro Hospitalar de Câncer (RHC) e o Registro de Câncer de Base Populacional (RCBP), possibilitando a geração de estimativas da doença (INCA, 2007).

As estimativas da doença no país utilizam as informações contidas no RCBP e o Sistemas de Informações sobre Mortalidade (SIM). A qualidade das estimativas geradas no país não podem ser consideradas ótimas para a real compreensão da magnitude do problema, devido as diferenças entres os vários tipos de câncer, onde os tumores com maior taxa de mortalidade permitem uma aproximação do que seria a incidência, diferente com o que acontece com tumores de melhor prognóstico (INCA, 2007).

A dificuldade de obter estimativas mais próximas da realidade deve-se também ao fato da defasagem em aproximadamente 2 anos da base do Sistema de Informação sobre Mortalidade e a qualidade de suas informações, pois existe alto índice de óbitos classificados como "Causas mal definidas" em alguns estados. Apesar das dificuldades, as mesmas auxiliam as políticas governamentais na vigilância, gestão do SUS, pesquisa e prevenções primárias (prevenção da ocorrência) e secundária (detecção precoce). 
O cálculo das estimativas utilizando o Método de Black, onde as taxas de incidência de uma região são iguais a multiplicação da taxa observada de mortalidade da região, pela razão entres os valores de incidência e mortalidade da localidade que haja RCBP. A Fórmula 1.1 ilustra o Método de Black (INCA, 2007)

$$
T I_{L}=T M_{L} \frac{I_{O}}{M_{R}}
$$

Sendo:

- $\mathrm{TI}_{L}$ : Taxa de incidência estimada para a UF ou Capital

- $\mathrm{TM}_{L}$ : Taxa de motalidade estimada pela série histórica de mortalidade para UF ou Capital

- $\mathrm{I}_{R}$ : Número de casos novos do RCBP (1998/2002)

- $\mathrm{M}_{O}$ : Número de óbitos nas regiões com RCBP (1998/2002)

No Brasil, os orgãos responsáveis pela gestão do câncer no país produzem duas publicações, uma é sobre as estimativas de incidência do tumor, citado anteriormente, o qual possui informações detalhadas sobre os tumores adultos e estimativa geral para os tumores infantis, esta publicação é bienal. Outro livro é produzido, o Atlas de Mortalidade de Câncer, a última edição abrange o período de 1979 a 1999 e foi publicado em 2002.

Estes livros devem auxiliar as ações governamentais no controle e tratamento do câncer, mas outros índices podem auxiliar estas ações: a Taxa de Sobrevida e a Expectativa de Vida. O Livro de estimativas publicado pelos órgãos governamentais não apresentam estes índices para os tumores no país e sim índices mundiais após 5 anos do diagnóstico da doença, como apresentado na Tabela 1.2) (INCA, 2007).

\begin{tabular}{|l|c|}
\hline Tipo do tumor & Sobrevida \\
\hline Pele não melanoma & $56 \%$ a $73 \%$ Mundo \\
\hline Próstata & $58 \%$ Mundo \\
\hline Mama feminino & $61 \%$ Mundo \\
\hline Pulmão & $7 \%$ a $13 \%$ Mundo \\
\hline Cólon e Reto & $40 \%$ a $50 \%$ Mundo \\
\hline Estômago & $<20 \%$ Mundo e $60 \%$ Japão \\
\hline Colo do útero & $49 \%$ a $69 \%$ Mundo \\
\hline
\end{tabular}

Tabela 1.2: Sobrevida dos pacientes após 5 anos de tratamento. Fonte: INCA 
Os levantamentos estatísticos do câncer infantil também abordado nestas literaturas, não apresenta detalhes sobre a incidência dos diferentes tipos de tumor que podem ocorrer em crianças. São estimados 9.890 novos casos de câncer infantil em 2008, aproximadamente 3\% das bases do RCBP (INCA, 2007). Assim como os índices para o câncer adulto, o infantil baseia-se em taxas apresentadas nos EUA (77\%) e na Europa (Norte $77 \%$ e Leste $67 \%)$.

O desconhecimento destes índices para os portadores de câncer, impossibilita uma avaliação mais concreta da realidade da doença no país e da qualidade e eficiência dos métodos de tratamento oferecidos à população.

A qualidade dos dados utilizados nestas estimativas é influenciada pela divergência de ferramentas que são utilizadas pelos hospitais que não implementam padrões para prover compatibilidade entre elas e por ferramentas complexas para serem utilizadas pela classe médica.

Além das ferramentas, existem soluções que utilizam arquiteturas cliente/servidor para oferecer serviços de auxílio ao tratamento de câncer a hospitais espalhados pelo território nacional ou para consolidar dados de tratamento que estão em hospitais caracterizados como Centros de Alta Complexidade em Oncologia (CACON) para geração destas estatísticas.

O uso desta arquitetura para oferecer serviços de saúde implica no desenvolvimento de um ambiente com alta disponibilidade nos serviços, servidores e meios de conexão, pois se um destes componentes falhar, influenciará diretamente no tratamento do paciente.

A consolidação de informações contidas nos hospitais necessita que os responsáveis dos hospitais gerem os relatórios ou organizem os dados em um formato pré-definido e enviem para serem concentrados e centralizados, possibilitando realizar as análises desejadas. A integridade dos dados, o sigilo das informações dos pacientes são desafios encontrados nesta abordagem, pois segundo a legislação médica os dados do paciente só devem ser acessados pelo médico responsável pelo seu tratamento.

Outra questão identificada sobre o tratamento do câncer foi apresentada em conversa com o Dr. Odone Vicente Filho do Institudo da Criança da Facudade de Medicina da USP. Nesta reunião foi relatado que na Oncologia Pediátrica, existem envolvimento total ou parcial de instituições em 17 estados da federação que utilizam os protocolos de tratamento referenciados pela Sociedade Brasileira de Oncologia Pediátrica (SOPOBE). Apesar da utilização destes protocolos, em dezembro de 2007, segundo o Dr. Odone, apenas 3 
instituições, cada qual particularmente interessada em um protocolo diferente, possuia um profissional para a sistematização dos dados e a comparação entre eles.

Os dois cenários apresentados, mostram a necessidade do desenvolvimento de soluções que auxiliem na gestão do câncer no país, pois atualmente não existe uma forma eficiente para identificar a qualidade dos tratamentos oferecidos a população, seja pela falta de profissionais ou má qualidade das informações utilizadas para a geração das estimativas.

\subsection{Relevância}

O desenvolvimento de uma estrutura de computação em grade à área da saúde, possibilita o desenvolvimento de sistemas descentralizados, permitindo integrar e compartilhar os dados obtidos pelas instituições de saúde com segurança e garantindo a privacidade das informações.

O acesso aos dados geograficamente distribuídos de forma homogênea e o oferecimento de um ambiente computacional para o desenvolvimento de novas pesquisas, permite a oferta de novos serviços na área de saúde e uma plataforma para prover meios de interoperabilidade entre sistemas já utilizados no legado dos hospitais.

Diversas áreas da saúde vem se beneficiando das tecnologias de computação em grade, seja auxiliando na gestão e no diagnósticos de tumores como no Projeto eDiaMoND que será abordado na Seção 2.8.2 ou fornecendo um ambiente interoperável no qual a comunidade científica possa compartilhar recursos remotos ou integrar dados de diversos institutos médicos ou de pesquisa como o projeto CaBIG que será abordado na Seção 2.8.1.

Quando olhamos para o cenário brasileiro, que possui os serviços de saúde pública como hospitais e postos de saúde sobrecarregados e necessitando de recursos como médicos e novos equipamentos, a oferta de uma arquitetura de grade computacional de baixo custo, interoperável e adaptável a realidade nacional é importante para que esta tecnologia seja difundida, pois permite sua utilização independente da quantidade de investimento financeiro disponível e das plataformas utilizadas. Estes requisitos são obtidos através de padronização e a utilização de software de código aberto ou livre.

A interoperabilidade em um ambiente geograficamente distribuído é essencial, pois simplifica a troca de informações entre as organizações participantes. Isto é possível devido a utilização de padrões abertos e bem definidos. A normatização e padronização 
desta tecnologia é realizada pelo Fórum Aberto de Grade, em inglês Open Grid Forum (OGF), onde participam instituições de pesquisa, universidades e empresas.

Além da questão de interoperabilidade e custos, o uso destas plataformas computacionais no projeto e desenvolvimento de ambientes distribuídos, faz-se necessário a utilização de uma infra-estrutura de interconexão rápida. Em muitos países, existem soluções governamentais de redes de alta velocidade e pontos de comutação entre essas redes, possibilitando o desenvolvimento de uma rede com abrangência mundial.

O Brasil possui redes de alta velocidades providas pela RNP, que possibilita desenvolvimento de ambientes de grades voltados a projetos de pesquisa e iniciativas governamentais para integração de conteúdo.

Alguns exemplos de iniciativas de projetos brasileiros que se beneficiariam da utilização desta tecnologia auxiliada pela infra-estrutura provida pela RNP são: os Projetos Oncopediatria (HIRA, 2005) e o Registro Hospitalar de Câncer (INCA, 2008; ALEGRO et al., 2006), os quais, já utilizam a RNP e o Cadastro Nacional de Usuários e Estabelecimentos do Sistema Único de Saúde (SUS) Brasileiro (CADSUS, 2008; DATASUS, 2008).

Algumas destas aplicações citadas utilizam arquitetura cliente/servidor que centralizam dados de várias instituições de saúde em um único servidor de armazenamento de dados, podendo possuir pontos únicos de falhas, sejam eles nos componentes físicos dos servidores, nos serviços oferecidos ou nas redes de comunicação.

\subsection{Justificativa}

Os sistemas de saúde quando possuem seus dados centralizados, podem gerar pontos únicos de falha, influenciando diretamente na qualidade dos serviços oferecidos. Quando abordado o cenário brasileiro, a oferta contínua dos serviços providos por estas ferramentas é de extrema relevância social devido ao tamanho territorial do país, permitindo manter a qualidade no atendimento a população.

Além das questões territoriais e da qualidade dos serviços de saúde ofertados no tratamento de doenças como o câncer, a Legislação Médica Brasileira atribui a responsabilidade pela coleta e guarda dos dados do registro de câncer como responsabilidade das unidades hospitalares: "Os Centros devem dispor e manter em funcionamento o Registro Hospitalar de Câncer", conforme as normas técnico-operacionais preconizadas pelo Ministério da 
Saúde - Portaria No 3.535, DE 2 DE SETEMBRO DE 1998 - Anexo 1 - parágrafo 2.3 (BRASIL, 1998). Caracterizando a necessidade de uma infra-estrutura para acesso aos dados distribuídos geograficamente.

O desenvolvimento de uma estrutura de computação em grade à área da saúde, irá possibilitar o desenvolvimento de sistemas descentralizados, respeitando a legislação existente, pois através das grades de dados será possível integrar e compartilhar os dados obtidos pelas instituições médicas com segurança e garantindo a privacidade das informações.

A gestão da saúde será beneficiada, pois poderá utilizar as tecnologias de depósito de dados (Data WareHouse) e mineração de dados (Data Mining) nas bases distribuídas através da grade, conseguindo informações com maior eficácia e maior auxílio na tomada de decisões e melhor distribuição dos recursos.

A prática médica irá se beneficiar com a oferta de ferramentas que através da utilização dos recursos disponíveis pelas grades podem, por exemplo, gerar diagnósticos mais precisos a partir da comparação com outros exames disponíveis no ambiente, permitirá a oferta de aplicações para segunda opinião médica com maior grau de colaboração, abrangência e as pesquisas biomédicas poderão utilizar o poder computacional disponível para o processamento de genes e proteínas.

\subsection{Motivação}

Como pude observar nas informações apresentadas nas publicações do INCA, o melhor prognóstico no tratamento de um câncer está diretamente ligado a detecção precoce da existência do tumor e tendo o conhecimento das estimativas de incidências da doença, é necessário utilizar a tecnologia para o desenvolvimento de soluções que auxiliem a detecção da doença ou o acompanhamento da eficiência dos métodos de tratamento existentes.

A interação com o Prof. Dr. Vicente Odone Filho do Instituto da Criança da Faculdade de Medicina da USP, mostrou que apesar da existência de trabalhos colaborativos para aprimorar e avaliar os métodos de tratamento aplicados ao tratamento de um câncer, existe carência em ferramentas que auxiliem na gestão destas informações para que elas possam retornar para a comunidade médica possibilitando uma retroalimentação da qualidade obtida com o tratamento atual.

Tendo estes dois cenários, pesquisar e propor um ambiente computacional para que 
estas informações possam ser geridas, permitindo que os resultados obtidos com a utilizaçãos dos métodos de tratamentos sejam analisados e aprimorados, oferecendo para a população um tratamento mais eficaz e propor ao Oncogrid (ALVES et al., 2008; JR. et al., 2006), uma arquitetura de grade computacional que possa integrar e compartilhar estas informações de tratamento, é a motivação deste trabalho, o qual complementa o trabalho desenvolvido por Moacir Alves de Campos Júnior o qual implementa o suporte a processamento em larga escala ao Oncogrid.

\subsection{Objetivos}

Este projeto de pesquisa tem como objetivo investigar e propor uma infra-estrutura de computação em grade para a integração e compartilhamento de dados médicos no cenário brasileiro, permitindo que novas aplicações e serviços de alto desempenho sejam desenvolvidas e oferecidos a área da saúde.

Os objetivos específicos deste trabalho de pesquisa serão:

a. Pesquisar e comparar com a literatura os projetos de ambientes que utilizam grades computacionais

b. Especificar os componentes de uma arquitetura de grade computacional para a integração de dados distribuídos;

c. Desenvolver bibliotecas para facilitar que novas aplicações sejam oferecidas ou portadas para à grade;

d. Especificar os padrões a serem utilizados para manter a interoperabilidade entre softwares e outras iniciativas de grade.

\subsection{Metodologia}

A metodologia utilizada nesta proposta de pesquisa consiste:

a. No levantamento do estado da arte na tecnologia de grade de dados, identificando os requisitos e componentes necessários no compartilhamento de dados, segurança e monitoração de recursos a serem aplicados nesta proposta;

b. Especificação dos padrões de interoperabilidade a serem utilizados; 
c. Na avaliação dos conceitos envolvidos na proposta através do desenvolvimento de um ambiente de testes entre o Laboratório de Sistemas Integráveis da Escola Politécnica da Universidade de São Paulo (LSIEPUSP) e o Núcleo de Telessaúde da Universidade Federal de Pernambuco (NUTES-UFPE), para os testes dos componentes a serem estudados;

d. Levantamento da Legislação Médica Brasileira ou dos requisitos de uma grade para saúde, auxiliando na especificação do ambiente;

e. Especificação dos componentes de grade computacional a serem utilizados na concepção da arquitetura;

f. Desenvolvimento de uma infra-estrutura, contendo os componentes especificados;

g. Implementação de bibliotecas para o desenvolvimento de aplicações à grade proposta;

h. Implementação de uma aplicação web para validação da arquitetura.

A avaliação final da proposta irá utilizar um ambiente de grade computacional, que possuirá ferramentas para monitoramento e autorização. Uma aplicação será desenvolvida para avaliar todas as funcionalidades propostas pela grade, que irá possuir mais de duas bases de dados disponíveis.

\subsection{Estrutura da Dissertação}

Esta dissertação está dividida em seis capítulos que abordarão: o estado da arte, a proposta de pesquisa, o desenvolvimento do trabalho, análise dos resultados obtidos, conclusão e trabalhos futuros.

O Capítulo 2, apresenta a pesquisa do estado da arte descrevendo os componentes e os padrões de interoperabilidade utilizados para o desenvolvimento de uma grade computacional, e os trabalhos correlatos de arquiteturas de grades computacionais voltadas para a área da saúde.

No Capítulo 3, apresenta a proposta dissertação de mestrado e a metodologia que será utilizada em seu desenvolvimento, apresentando um modelo da infra-estrutura que será proposta por este trabalho de pesquisa, mostrando como será a integração dos softwares utilizados. 
O Capítulo 4 apresenta o desenvolvimento desta pesquisa, abordando o trabalho realizado no desenvolvimento de um projeto piloto da arquitetura, permitindo a validação e ajustes no modelo a ser especificado.

O Capítulo 5, apresenta as análises do trabalho realizado no projeto piloto e de desempenho e comportamento do ambiente especificado. Por fim, o Capítulo 6 apresenta as conclusões, trabalhos futuros e contribuições. 


\section{Computação em Grade na Área da Saúde}

O objetivo deste capítulo é apresentar a pesquisa realizada para identificar os componentes e padrões utilizados para o desenvolvimento de uma grade computacional, através do estudo de trabalhos correlatos existentes na literatura. Permitindo desenvolver uma solução de grade computacional para a integração e compartilhamento de informações médicas em oncologia para a realidade brasileira.

\subsection{Introdução}

A Computação em Grade consiste no compartilhamento de recurso entre organizações virtuais à resolução de problemas de forma dinâmica e colaborativa. Esta arquitetura computacional deve fornecer uma infra-estrutura padronizada com componentes que possibilitem segurança, processamento distribuído, monitoramento de recursos, acesso a dados distribuídos, bibliotecas e ferramentas para desenvolvimento.

Os componentes de segurança devem fornecer métodos para controlar quem, como e quando acessar os recursos disponíveis no ambiente. Estas funcionalidades são conseguidas através de ferramentas que ofereçam suporte para autenticação, autorização e delegação.

Para o desenvolvimento de aplicações para processamento distribuído, são necessários componentes que realizam o escalonamento de tarefas, gerenciamento e alocação de recursos disponibilizados pelas organizações participantes.

O acesso a dados distribuídos permite que as instituições compartilhem informações como resultado de simulações e bases de dados específicos, permitindo o desenvolvimento de projetos que possuem interesses comuns.

Com a diversidade de recursos existentes nestes ambientes distribuídos são necessários componentes que monitorem sua disponibilidade, informando aos usuários quais estão 
acessíveis quando necessário e permitindo aos administradores da grade obter conhecimento e tomar ações preventivas em caso de falha de algum recurso.

Além de oferecer todos os componentes necessários para a composição de uma grade computacional, a infra-estrutura proposta deve possuir bibliotecas de desenvolvimento e protocolos que permitam as aplicações desenvolvidas nestas plataformas interagir com todos os componentes utilizados.

O uso de diversos componentes à composição de uma plataforma de Grade, possibilita a proposta de sistemas que integram alguns desses componentes e suas bibliotecas de desenvolvimento em um conjunto comum de ferramentas, oferecendo métodos com maior simplicidade e eficácia à implantação de uma grade computacional.

Dentre os projetos encontrados na literatura estão o NESSgrid (JR. et al., 2004) e o TeraGrid (CATLETT, 2002). O Projeto NESSgrid utiliza a rede Internet2 criando um ambiente para a integração de sistemas no projeto (NESS, 2008), ligando pesquisadores através dos Estados Unidos da América (EUA) aos recursos computacionais e equipamento de pesquisa. As ferramentas disponíveis possibilitam a simulação de terremotos oferecendo um ambiente para os pesquisadores desenvolverem modelos complexos, detalhados e exatos de como os diferentes tipos de estruturas irão responder durante um abalo sísmico.

Neste ambiente, o modelo de Computação em Grade adotado é o colaborativo, permitindo que pesquisadores, espalhados pelos EUA, possam compartilhar acesso a equipamentos e dados experimentais, tornando eficiente a comunicação entre os pesquisadores e disponibilizando um espaço colaborativo para modelagem e simulação.

O TeraGrid (PENNINGTON, 2001; TERAGRID, 2008) oferece uma plataforma que fornece novas potencialidades computacionais, armazenamento de dados e visualização. Dentro desses novos recursos fornecidos, estão a renderização e visualização remota (NEFEDOVA et al., 2006), acoplamento de sensores e instrumentos remotos, acesso e correlação de dados distribuídos, aplicações distribuídas através de múltiplos sistemas (acesso a aplicações e dados remotos) e grande poder de processamento computacional agregado. Esta grade computacional foi desenvolvida, inicialmente, nos EUA, integrando recursos de quatro localidades (Caltech, NCSA, ANL, SDSC) através das redes Abilene, QWest, I-WIRE e através da StarLight, foi possível integrar sítios no Reino Unido e outros países da Europa ao ambiente.

Existem projetos em que as instituições estão espalhadas por diversos países e con- 
tinentes, necessitando a utilização de diversas redes para a troca de informações. Este é o caso do projeto Open Sciences Grid (OSG, 2008b) que possui instituições presentes na América, Europa e Ásia. Dentre as redes utilizadas podemos citar a Energy Sciences Network (EUA), ANSP e Rede Ipê (Brasil) e as redes continentais GEANT (Europa) e AMPATH (América), fornecendo um ambiente para pesquisas de computação de alto desempenho e gerenciamento de dados, do qual, fazem parte o Instituto de Física da Universidade de São Paulo, o São Paulo Regional Analysis Center (SPRACE) e a Universidade Estadual do Rio de Janeiro (UERJ) (OSG, 2008b, 2008a).

\subsection{Histórico das Grades Computacionais}

O termo Computação em Grade foi criado em meados de 1990, denotando uma infraestrutura de computação distribuída, destinada a aplicações de ciências avançadas e engenharia (FOSTER; KESSELMAN, 1999). A definição mais recente desta tecnologia data do ano 2000, sendo descrita por Kesselman, Foster e Turcke (2001) como um conjunto de recursos computacionais compartilhados e coordenados, voltados a solucionar problemas de forma dinâmica e colaborativa em organizações virtuais multi-institucionais.

Com a evolução desta tecnologia, vertentes foram criadas dando origem a uma taxionomia (KRAUTER; BUYYA; MAHESWARAN, 2002; MINOLI, ), classificando as grades em:

a. COMPUTACIONAIS: esta classificação é utilizada para oferecer poder computacional no processamento de grandes massas de dados. Utiliza servidores de alto desempenho ou a alocação de processadores. Este tipo é utilizado para aplicações como simulações nucleares e de Monte Carlo, modelagem climática e dobra de proteína;

b. SERVIÇOS: são utilizadas para oferecer serviços que não podem ser fornecidos por uma única máquina. Esta classificação de computação em grade se divide em colaborativo, multimídia ou sob-demanda, permitindo o desenvolvimento de ambientes voltados para trabalhos de grupos colaborativos ou plataformas e ambientes que se ajustem conforme a necessidade de um recurso como, por exemplo, a alocação de mais recursos computacionais para processamento quando uma determinada aplicação necessitar ou ambientes que utilizam aplicações multimídia em tempo real; 
c. DADOS: é utilizada para disponibilizar um meio de acesso unificado para todos os repositórios de dados em uma organização, que permite busca, gerenciamento e segurança no armazenamento. Não importa para o usuário, onde o dado está localizado, garantindo acesso a informação através de múltiplas organizações. Este modelo permite compartilhamento de arquivos contidos no disco rígido e de bases de dados relacionais ou XML.

Como apresentado na motivação, a pesquisa realizada neste mestrado é desenvolver uma arquitetura de grade computacional para a integração e compartilhamento de informações médicas em oncologia, para isto o foco desta proposta será a utilização da metodologia da Grade de Dados.

\subsection{Padrões e Especificações para Grades Computa- cionais}

A evolução da tecnologia de Grade Computacional no cenário de pesquisa internacional levou a criação do Global Grid Forum (GGF), através da união dos fóruns existentes nos EUA, Europa e Ásia; o GGF é responsável por propor muitos dos padrões e especificações utilizados pela comunidade de Computação em Grade. No ano 2006, surgiu o Open Grid Forum (OGF), através da fusão entre o GGF e a Enterprise Grid Alliance (EGA) (OGF, 2008).

Assim como a Internet, a Computação em Grade utiliza padrões e especificações abertas, permitindo manter interoperabilidade entre as plataformas que são desenvolvidas, sejam elas por empresas ou universidades (BASNEY; HUMPHREY; WELCH, 2005).

Dentre as especificações definidas pelo OGF encontramos a Infra-estrutura Aberta de Serviços de Grade, do inglês Open Grid Services Infrastructure (OGSI) e a Arquitetura Aberta de Serviços de Grade, do inglês Open Grid Services Architecture (OGSA), que definem a infra-estrutura e a arquitetura de serviços de uma Grade Computacional, padronizando um modelo de oferta de serviços através da utilização de padrões já difundidos pela indústria como Serviços Web, Protocolo Simples de Acesso a Objeto, do inglês Simple Object Access Protocol (SOAP) e Infra-estrutura de Chaves Públicas. A Figura 2.1 apresenta o modelo de relacionamento entre o OGSI e o OGSA.

Nos tópicos seguintes serão abordadas as especificações OGSI e OGSA apresentando 
Consumidor

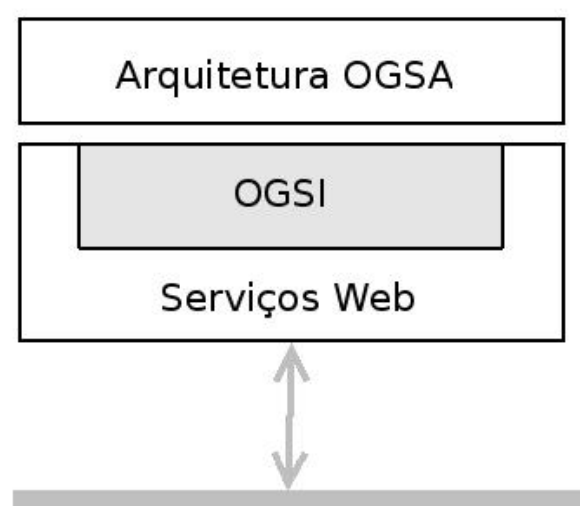

\section{Serviços de Rede}

Provedor de Serviços A

Arquitetura OGSA

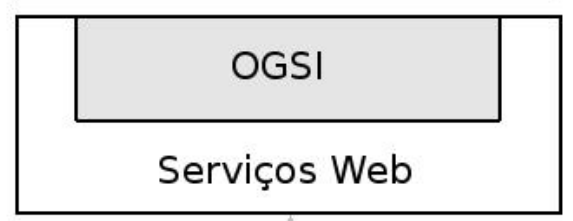

Provedor de Serviços B

Arquitetura OGSA

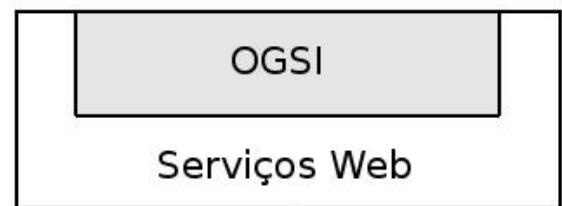

Serviços Web

Figura 2.1: Visão de alto nível do relacionamento entre OGSI e OGSA

suas funcionalidades.

\subsubsection{Especificações da Infra-estrutura Aberta de Serviços de Grade}

O OGSI é responsável por definir as extenções e interfaces utilizados pelos serviços de grade, possibilitando que aplicações e serviços desenvolvidos com estas especificações sejam interoperáveis entre si, independente da linguagem de programação utilizada em seu desenvolvimento (MINOLI, ; TUECKE et al., 2003).

A infra-estrutura dos serviços de grades propostos pelo OGSI é baseado em mecanismos de serviços web como o XML e o WSDL para especificar interfaces padrões, comportamento e interação entre todos os serviços na grade.

Além das interfaces dos serviços de grade, o OGSI disponibiliza outras interfaces para descoberta, ciclo de vida, gerenciamento de estado, criação e remoção, notificação de eventos e gerenciamento de referências (MINOLI, ). Estas interfaces são ilustradas na Figura 2.2 e apresentadas abaixo. 


\section{Arquitetura OGSA}

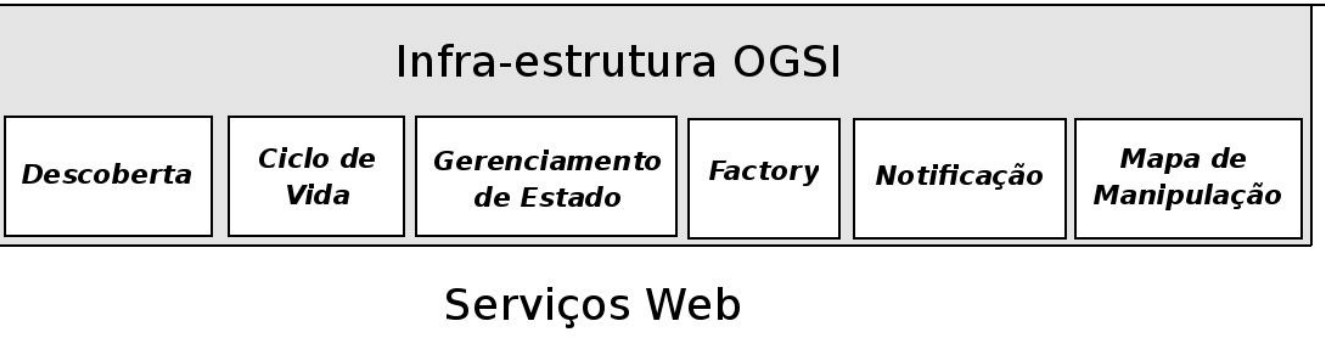

Figura 2.2: Interfaces OGSI

a. Factory: Interface para criar novos serviços de grade, possibilita a criação de serviços temporários com funções limitadas como, por exemplo, um escalonador que cria um serviço para representar a execução de uma determinada tarefa;

b. Ciclo de vida: É um mecanismo para prevenir que os serviços de grade não irão consumir recursos indefinidamente, sendo responsável pelo gerenciamento do tempo de vida dos serviços de grade. Seu comportamento é semelhante a um "coletor de lixo"como utilizado pela linguagem de programação Java, liberando os recursos que não são mais utilizados;

c. Gerenciamento de estado: O OGSI especifica um arcabouço para representação do estado dos serviços de grade, chamado serviço de dados e um mecanismo para inspeção e modificação deste estado, chamado Find/SetSeviceData, requisitando que todos os serviços de grade suportem uma quantidade mínima de estados nos elementos de serviço de dados e que implementem uma portType para o Find/SetSeviceData;

d. Grupos de Serviços: Os grupos de serviços são coleções de serviços de grade indexados, usando o serviço de dados, para algum propósito específico;

e. Notificação: Provê um mecanismo através das interfaces NotificationSource e NotificationSink para a troca de mensagens entre os serviços de grade;

f. Mapas de manipulação: Quando as Factories são usadas para criar uma nova instância de um serviço de grade, a Factory retorna a identidade do novo serviço instanciado. Esta identidade é composta por duas partes: 
um Grid Service Handle (GSH) e um Grid Service Reference (GSR). O GSH provê uma referência de um serviço de grade e o GSR pode fazer alterações no tempo de vida do serviço.

As especificações de serviços definidas pelo OGSI servem de base para que o OGSA possa especificar uma infra-estrutura de serviços de grade interoperável (MINOLI, ; TUECKE et al., 2003)

\subsubsection{Especificações da Arquitetura Aberta de Serviços de Grade}

O OGSA é responsável por integrar as tecnologias de computação em grade com mecanismos Web Services para criar um arcabouço de sistema distribuído baseados no OGSI (MINOLI, ) tendo como objetivo:

a. Gerenciar recursos em plataformas heterogêneas distribuídas;

b. Prover serviços como autorização, controle de acesso e delegação;

c. Prover uma base comum para gerenciamento autônomo;

d. Definir interfaces e protocolos abertos para a interoperabilidade entre diversos recursos e serviços;

e. Utilizar padronizações já existentes quando possível, como por exemplo as propostas pelo W3C e OASIS.

A arquitetura do OGSA é dividida em quatro camadas funcionais (MINOLI, ). Sendo elas:

a. Camada de aplicações de grade: É responsável por suportar as aplicações dos usuários, sendo a única camada da grade visível por eles;

b. Camada de serviços de grade especificados pelo OGSA: Os serviços desta camada são baseados em Web Services, possuindo serviços que contemplam a Descoberta, o Ciclo de vida, o Gerenciamento de estado, os Grupos de serviços, a Fabrica de serviços, a Notificação e o Mapa de manipulação;

c. Camada de Web Services: É a camada de Web Services definida pelo OGSI através da utilização de padrões como WSDL e XML, especificando interfaces, comportamentos e interações padrões para os recursos de grade; 
d. Camada de recursos físicos e lógicos: Provê os recursos para a grade sendo os recursos físicos compostos de servidores, storages e redes. Os recursos lógicos oferecem funcionalidades adicionais para os recursos físicos, como virtualização e agregação de recursos.

As especificações propostas pelo OGSA são adotadas em muitas ferramentas para manter a interoperabilidade dentro de uma Grade Computacional.

\subsection{Ferramentas Base para Grade Computacional}

Existem conjuntos de ferramentas integradas para o desenvolvimento de ambientes de grade. Para o desenvolvimento deste trabalho foram estudadas diversas ferramentas, dando preferência para as que possuem código aberto e sigam as especificações propostas pelo OGSI e OGSA possibilitando que sejam desenvolvidos projetos de integração entre grades computacionais.

Este trabalho avaliou o ${ }^{m y}$ Grid, Ourgrid/MyGrid, Berkeley Open Infrastructure for Network Computing (BOINC) e Globus Toolkit (GT) para definir qual será utilizado para compor a infra-estrutura base do Oncogrid.

\subsubsection{A Ferramenta ${ }^{\text {my }}$ Grid}

O ${ }^{\text {my }}$ Grid é um conjunto de ferramentas orquestradas pelo Engineering and Physical Sciences Research Council (EPSRC) para o desenvolvimento de um ambiente de grade para simulação de experimentos biológicos, utilizando dados que estão armazenados em repositórios distribuídos, possiblitando que os usuários busquem, compartilhem e executem experimentos disponíveis (GOBLE et al., 2003; STEVENS; GOBLE, 2004).

A arquitetura do ${ }^{m y}$ Grid é composto de quatro camadas contendo aplicações, serviços para gerenciamento dos experimentos e notificações no ambiente, acesso a dados distribuídos e serviços web internos e externos, que constituem as fontes de informações disponíveis (GOBLE et al., 2003).

Os serviços externos fornecem informações biológicas a ferramentas de análise como EMBOSS, MEDLINE, SRS e OMIM; ferramentas para alinhamento de sequências como NCBI BLASTe WU BLAST; e ferramentas para extração de textos como AMBIT (GOBLE et al., 2003). 
Para o acesso as informações disponíveis pelos serviços web é utilizado o Open Grid Services Architecture - Data Access and Integration e o Open Grid Services Architecture - Distributed Query Processing. Para a execução dos experimentos é utilizado o FreeFluo (GOBLE et al., 2003).

O ${ }^{m y}$ Grid é utilizado em diversos projetos de bioinformática como para anotação de genoma e proteoma, integração de dados biológicos, análise de microarray (MYGRID, 2008).

\subsubsection{A Ferramenta MyGrid}

O MyGrid é um sistema de Computação em Grade desenvolvido pela Universidade Federal de Campina Grande para o processamento de pacotes de tarefas com o objetivo de ser facilmente utilizado pelo usuário (CIRNE et al., 2003).

A arquitetura do MyGrid consiste em uma máquina chamada "máquina casa", do inglês "home machine" que será responsável por coordenar o envio das tarefas que o usuário submeteu para processamento e a "máquina grade", do inglês "grid machine" que será responsável pelo processamento das tarefas (CIRNE et al., 2003; COSTA et al., 2004).

Não é possível integrar outras ferramentas neste ambiente, pois ele não implementa as especificações do OGSI e OGSA, impossibilitando a interoperabilidade com outras ferramentas (CIRNE et al., 2003).

O MyGrid pode ser utilizado em aplicações de pacotes de tarefas como data mining, buscas massivas, simulações e biologia computacional (COSTA et al., 2004).

\subsubsection{A Ferramenta OurGrid}

O OurGrid é desenvolvido pela Universidade Federal de Campina Grande utilizando o MyGrid e o $S W A N$ para oferecer um ambiente de processamento distribuído através de redes ponto a ponto (ANDRADE et al., 2005; OURGRID, 2008). A arquitetura desta ferramenta consiste em três componentes:

a. OurGrid Peer: Responsável pela comunicação entre os outros pontos da grade, e informação dos recursos disponíveis;

b. MyGrid: Será o ponto de entrada dos usuários na grade, será responsável pela submissão das tarefas a serem processadas; 
c. SWAN: Proverá acesso seguro aos recursos.

No OurGrid o MyGrid foi modificado para suportar as especificações do OGSI e OGSA, possibilitando a integração com outros ambientes através da utilização de serviços de grade (ARAúJO; CIRNE; MENDES, 2004), sendo utilizado em projetos como GerpavGrid da Pontifícia Universidade Católica do Rio Grande do Sul, GridVida da Universidade Federal de Pernambuco e o BioPaua do Laboratório Nacional de Computação Científica (OURGRID, 2008).

\subsubsection{A Ferramenta Berkeley Open Infrastructure for Network Computing}

O Berkeley Open Infrastructure for Network Computing (BOINC) se beneficia do aumento no número de computadores pessoais para oferecer iniciativas de Computação de Recursos Públicos, também conhecida como Computação Ponto a Ponto, fornecendo capacidade de processamento e armazenamento superior ao encontrado em super computadores como o Earth Simulator e sistemas de armazenamento centralizados (ANDERSON, 2004).

O BOINC é uma plataforma aberta de computação de recursos públicos, desenvolvida pelo Laboratório de Sistemas Espaciais da Universidade de Berkeley, que permite pesquisadores com conhecimento moderado em computação, desenvolver projetos que utilizem processamento e armazenamento através de recursos públicos (ANDERSON, 2004).

Esta plataforma é utilizada pro projetos como SETI@Home, Folding@home e projetos para simulação climática como Climateprediction.net e Climate@home (ANDERSON, 2004; BOINC, 2008).

\subsubsection{A Ferramenta Globus Toolkit}

O Globus Toolkit (GT) é um sistema de computação em grade modular que permite o desenvolvimento gradual de uma plataforma ou aplicações. A arquitetura deste sistema contem diversos componentes, que estão divididos em camadas funcionais (MINOLI, ; FERREIRA et al., 2003; FOSTER, , 2005):

a. Segurança: fornece componentes para autenticação, gerenciamento de credenciais, delegação e diferentes níveis de autorização; 
b. Gerenciamento de dados: fornece componentes para movimentação de dados, localização de réplica, replicação e acesso e integração de dados;

c. Gerenciamento de execução: fornece componentes para gerenciamento e alocação de recursos para execução de tarefas;

d. Serviços de informação: fornece componentes para monitoramento e informações de recursos;

e. Execução Comum: fornece bibliotecas e ferramentas para desenvolvimento.

A integração dos componentes utilizados pelo Globus é realizada através da utilização de serviços web e a implementação das especificações OGSI a OGSA, possibilitando a integração entre diferentes plataformas de grade, sejam elas voltadas às pesquisas ou empresas (MINOLI, ).

Com a diversidade de componentes oferecidos por esta ferramenta, possibilita sua utilização no desenvolvimento de diferentes iniciativas de pesquisas, caracterizando flexibilidade na plataforma. Novos serviços de grade podem ser desenvolvidos para atender as necessidades destas pesquisas, sendo facilmente integrados ao sistema.

O GT é utilizado em grades como Cancer Bioinformatics Grid (caBIG) (CABIG, 2006; SALTZ et al., 2006a; LANGELLA et al., 2007; OSTER et al., 2007), China National Grid (CNGRID, 2008), TeraGrid (TERAGRID, 2008; NEFEDOVA et al., 2006; CATLETT, 2002; PENNINGTON, 2001), Open Sciences Grid (OSG, 2008b, 2008a) e UK National Grid Services (UKNGS, 2008).

\subsection{Ferramentas para Acesso e Integração de Dados em Grade Computacional}

Para desenvolver esta especificação foram estudadas ferramentas de código aberto que se propõem a fornecer recursos para acesso a dados distribuídos e que utilizem as padronizações definidas pelo OGF através do OGSA, OGSI e do Data Access and Integration Services-Work Group (DAIS-WG).

As ferramentas encontradas foram o $i$ Rule Oriented Data Systems (iRods) ainda em desenvolvimento, Mobius, o Open Grid Services Architecture - Data Access and Integration e o Open Grid Services Architecture - Distributed Query Processing sendo as três últimas estudadas para o desenvolvimento deste trabalho. 


\subsubsection{A Ferramenta Mobius}

O Mobius é um arcabouço baseado nas especificações do DAIS-WG para gerenciamento eficiente de dados e metadados em ambientes dinâmicos e distribuídos, através da utilização de esquemas XML pra criar e representar definições de dados e a utilização documentos XML para representação e troca de dados (HASTINGS et al., 2004; LANGELLA et al., 2004). O Mobius possui três serviços base: o Global Model Exchange (GME), o Mako e o Data Translation Service (DTS) (MOBIUS, 2008) .

O Serviço GME é responsável por armazenar e articular os modelos de dados definidos em um ambiente distribuído, permitindo outros serviços, como publicar, recuperar, descobrir e remover definições de metadados. Esta ferramenta dispõe seus serviços em uma estrutura hierárquica, semelhante a arquitetura utilizada pelos servidores Domain Name System (DNS) e fornece métodos para gerenciamento das dependências entre modelos de dados, possibilitando o intercâmbio entre versões do modelo (HASTINGS et al., 2004; LANGELLA et al., 2004). O modelo de organização deste serviço é ilustrado na Figura 2.3 (MOBIUS, 2008).

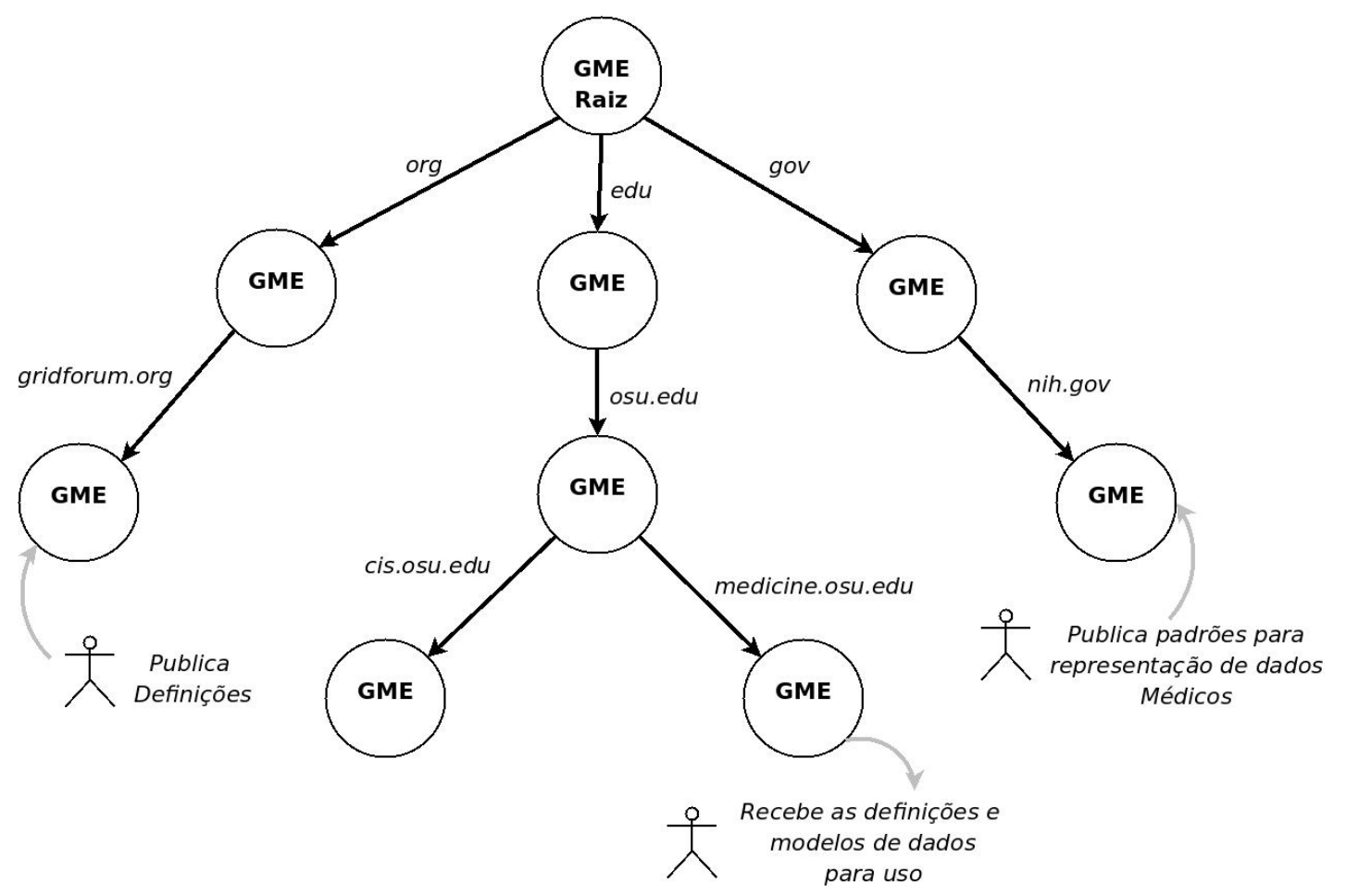

Figura 2.3: Modelo organizacional do GME

No Serviço Mako são providos os serviços para armazenamento e busca de dados que estão armazenados em bases de dados relacionais ou XML e sistemas de arquivos na grade. A arquitetura do Mako possibilita que os clientes utilizem protocolos como o Security 
Socket Layer ou o Globus Security Infrastructure para comunicar com as instâncias de serviços. A federação de bases de dados, pode ser realizada através do VMako, que atua como uma interface para o as instâncias remotas, reduzindo a complexidade no desenvolvimento de aplicações (HASTINGS et al., 2004; LANGELLA et al., 2004). A federação de dados oferecida por este serviço é ilustrada na Figura 2.4 (MOBIUS, 2008).

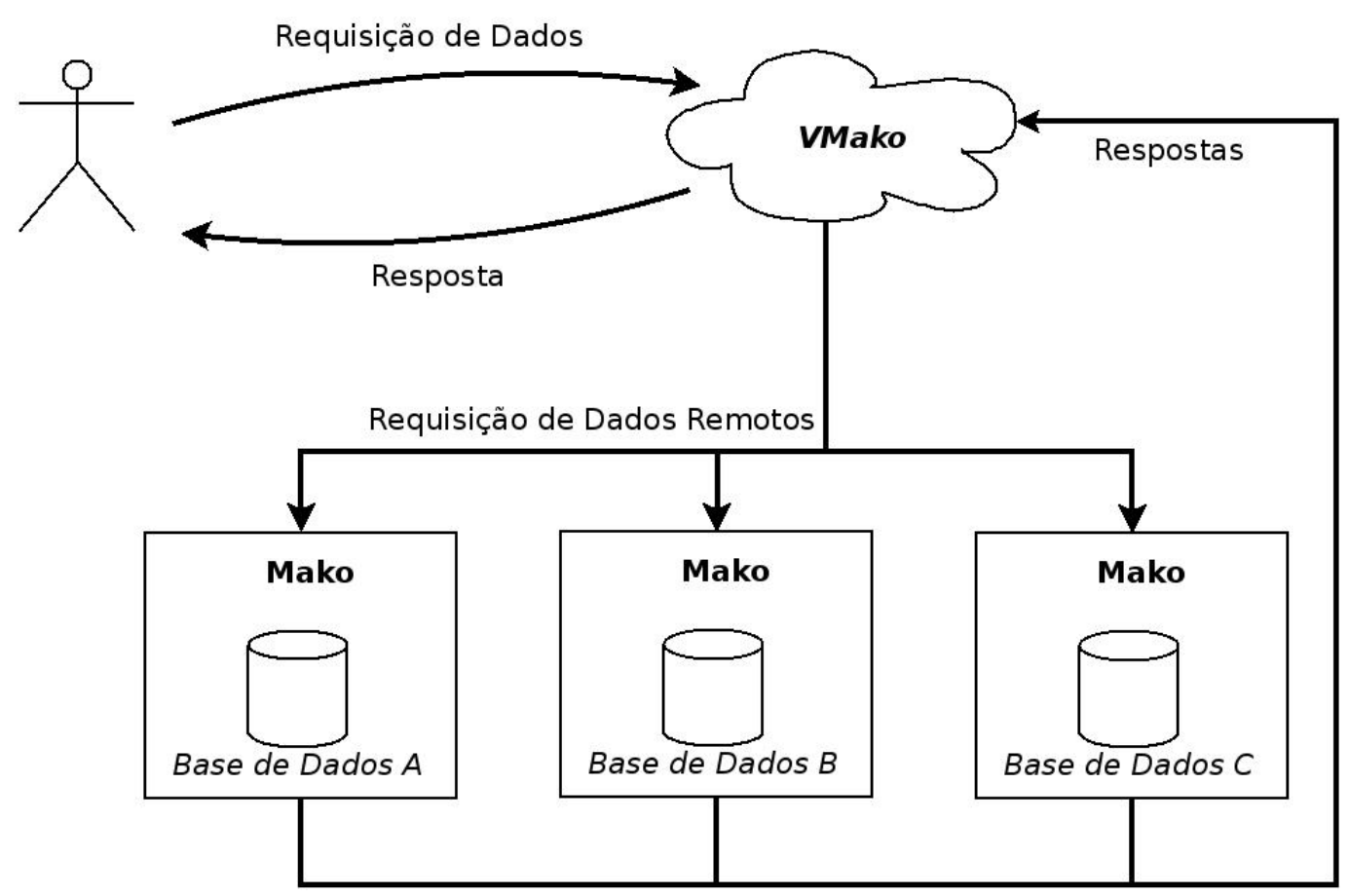

Figura 2.4: Federação de dados com o VMako

O DTS é responsável por gerenciar a tradução de entre tipos de dados, através da utilização de um serviço de mapeamento remoto que oferece o emparelhamento da tradução entre os elementos, possibilitando a interpretação de informações existentes em modelos de dados que possuem conteúdo semântico similar, mas em estrutura variáveis (HASTINGS et al., 2004). A Figura 2.5 (MOBIUS, 2008) ilustra o funcionamento deste serviço.

No sítio do projeto Mobius (MOBIUS, 2008) podemos encontrar referências de projetos de pesquisa que utilizam esta ferramenta.

\subsubsection{A Ferramenta Open Grid Services Architecture - Data Access and Integration}

O projeto Open Grid Services Architecture - Data Access and Integration (OGSADAI) desenvolveu um middleware para acesso uniforme aos dados distribuídos em uma grade computacional podendo ter suas funcionalidades integradas ao Globus, ela suporta diferentes tipos de recursos de dados como bases de dados relacionais: MySQL, DB2, 


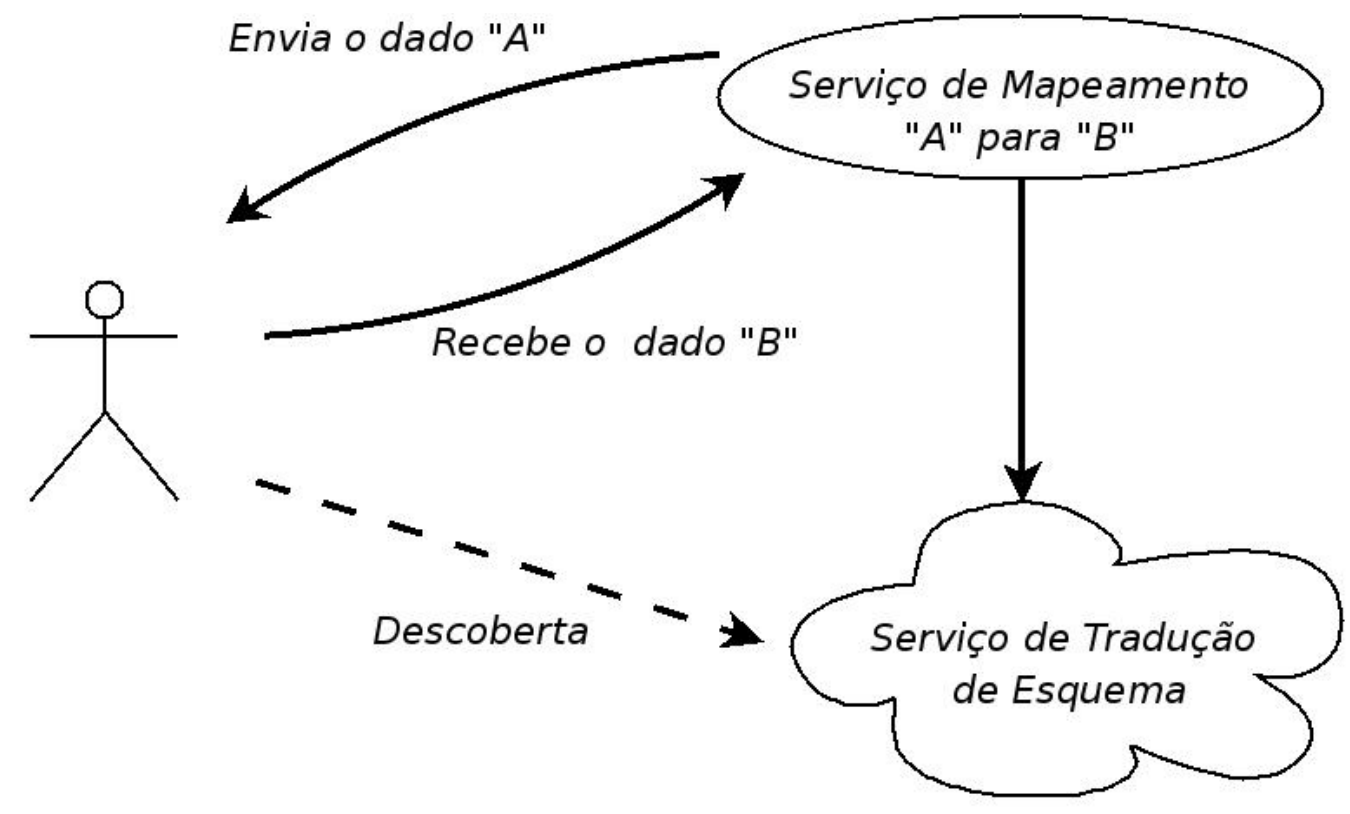

Figura 2.5: Serviço do Mobius de Tradução de Esquema

Oracle, PostgreSQL, SQLServer, Derby; bases de dados XML: Xindice e utiliza padrões definidos pelo OGSA, OGSI e DAIS-WG (ANTONIOLETTI et al., 2004; JACKSON; LLOYD; SLOAN, 2005). Esta ferramenta oferece três serviços base: Data Access and Integration Service Group Registry (DAISGR), Grid Data Service Factory (GDSF) e o Grid Data Service (GDS) (KARASAVVAS et al., 2005; ANTONIOLETTI et al., 2005).

a. DAISGR: Permite que os serviços da grade publiquem metadados sobre algum recurso de dados, os quais podem ser consultados pelos usuários para encontrar provedores de recursos que satisfazem suas necessidades. O DAISGR utiliza a padronização do OGSI definido as OGSA-DAI portTypes de comunicação (KARASAVVAS et al., 2005);

b. GDSF: Atua como um ponto de acesso persistente para os recursos de dados e contém metadados adicionais que não estão disponíveis no DAISGR. O GDSF é responsável por criar os GDSs para acesso e manipulação de recursos de dados (KARASAVVAS et al., 2005);

c. GDS: Atua como um ponto de acesso transiente para os recursos de dados, sendo através do GDS que o cliente interage com os recursos de dados, através da utilização de atividades que foram definidas pelo GDSF. As atividades podem ser classificadas em três grupos funcionais: atividades de declaração que atuam com um recurso de dados; atividades de entrega que enviam ou coletam dados de outros serviços e as atividades de trans- 
formação que realizam transformações sobre os dados enquanto ele ainda está no serviço (KARASAVVAS et al., 2005).

Uma aplicação para utilizar os recursos oferecidos pelo OGSA-DAI deve suportar a interoperabilidade com serviços web, possibilitando acessar os recursos de dados disponíveis pela ferramenta. As únicas alterações a serem realizadas na aplicação já desenvolvida para acessar um banco de dados convencional, é a forma em que ela se conecta ao banco e como submete suas consultas. A Figura 2.6 ilustra o modelo de integração entre o OGSA-DAI e a aplicação.

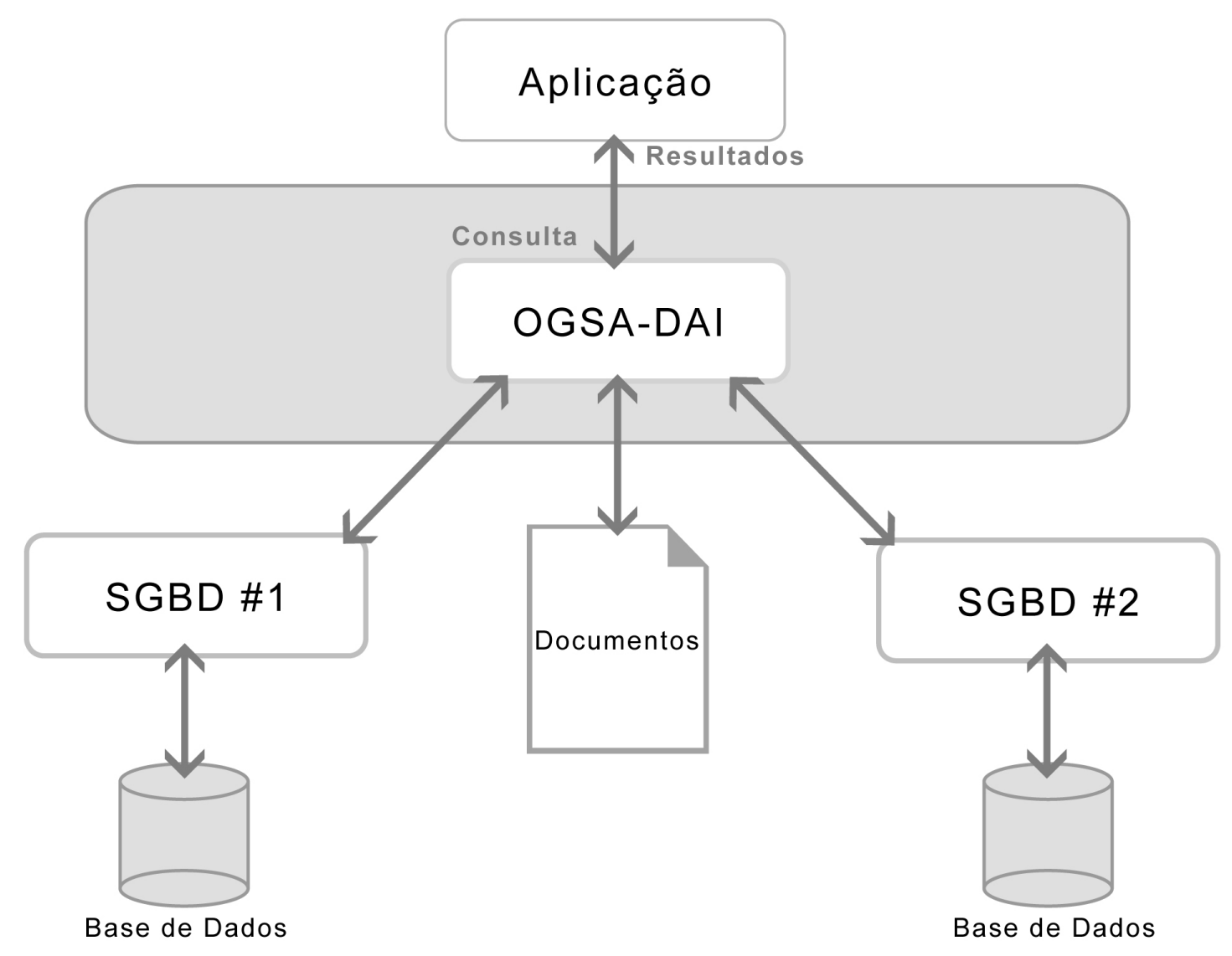

Figura 2.6: Modelo de Integração do OGSA-DAI

Na literatura encontramos o emprego do OGSA-DAI em diversos projetos de pesquisa como: caBIG (FENSTERMACHER et al., 2005; SALTZ et al., 2006b), UnitProt (TOHSATO et al., 2004), eDiaMoND (POWER et al., 2004), FirstDIG (GRAHAM et al., 2004), BIoDA (CROMPTON et al., 2005), demonstrando a aplicabilidade e estabilidade desta ferramenta. 


\subsubsection{A Ferramenta Open Grid Services Architecture - Dis- tributed Query Processing}

O Open Grid Services Architecture - Distributed Query Processing (OGSA-DQP) extendem o GDS oferecido pelo OGSA-DAI, pois esta ferramenta utiliza os GDS disponíveis para realizar processamento distribuído de consultas (ALPDEMIR et al., 2003, 2004, 2003). O OGSA-DQP adiciona dois novos serviços a arquitetura do OGSA-DAI: o Grid Distributed Query Service (GDQS) e o Grid Query Evaluation Service (GQES).

a. GDQS: Atua como um coordenador, sendo responsável por obter os metadados e as informações dos recursos computacionais de que necessitam para compilar, otimizar, particionar e agendar consultas distribuídas por vários planos de execução execução na grade;

b. GQES: Atua como um avaliador, sendo usado pelo GDQS para executar consultas geradas por um compilador, otimizador e escalonador de consultas. Cada GQES avalia uma parte de uma consulta em execução que são atribuídas por um coordenador.

Como o OGSA-DQP é uma extenção do OGSA-DAI, eles possuem os mesmos requisitos para serem suportados por uma aplicação. A Figura 2.7 ilustra o modelo de integração entre o OGSA-DQP, OGSA-DAI e a aplicação.

\subsection{Ferramentas para Segurança em Grade Computa- cional}

O compartilhamento de recursos é umas das principais características das grades computacionais, necessitando de um modelo de segurança que forneça métodos para integridade e privacidade das mensagens, autenticação, identificação, autorização, controle de acesso e delegação, garantindo a segurança do ambiente e dos recursos disponíveis (CHAKRABARTI, 2007).

As especificações definidas no OGSA, incorporaram os padrões propostos pelo Grid Security Infrastructure (GSI) que empregam a utilização de cifração de chaves públicas, certificados X.509 e protocolos seguros de comunicação para autenticação e o tráfego de dados nas redes de computadores (CHAKRABARTI, 2007). 


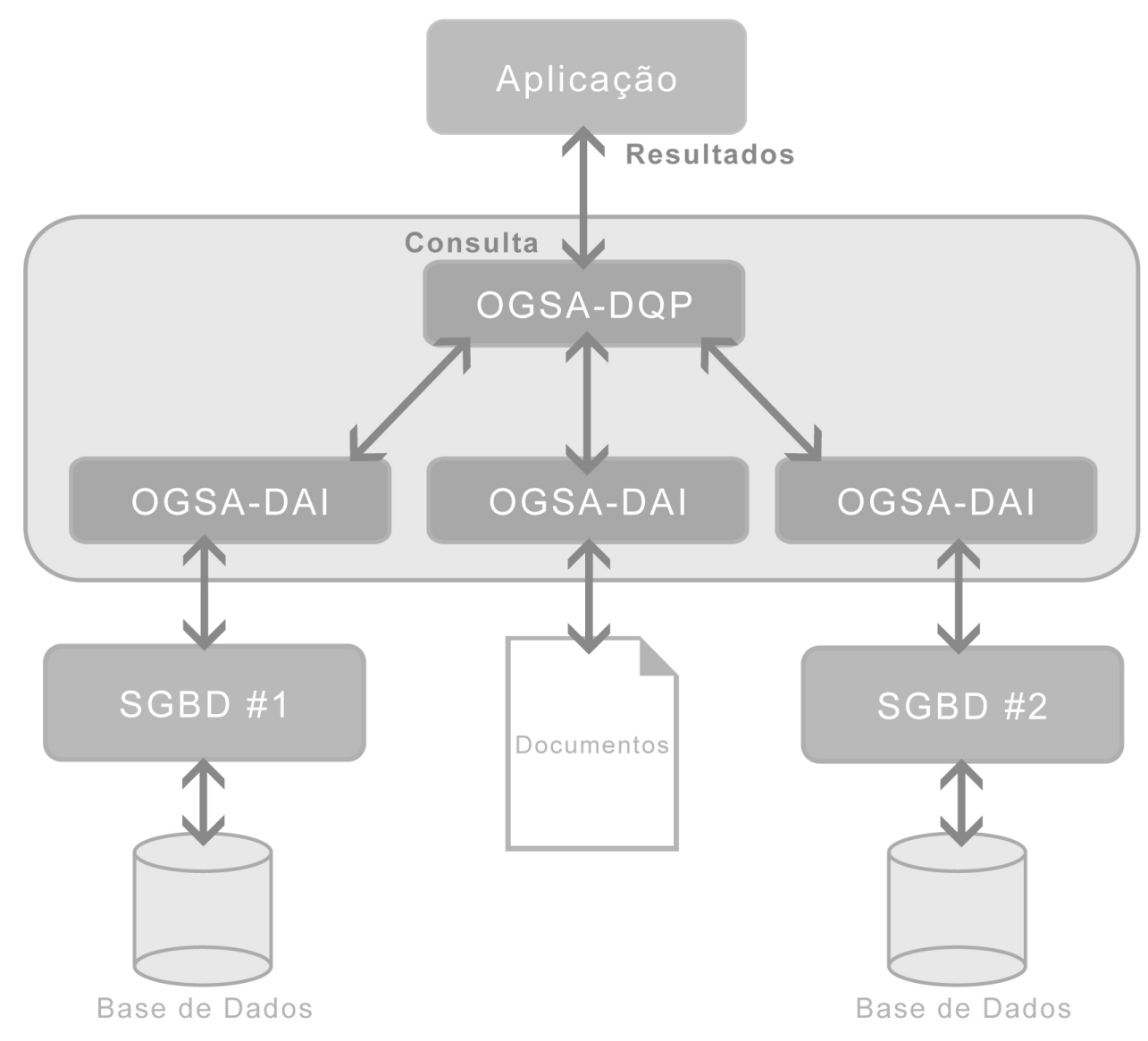

Figura 2.7: Modelo de Integração do OGSA-DQP

A cifração de chaves públicas proposta pelo GSI, basea-se na utilização de uma Infraestrutura de Chaves Públicas, que todos os usuários e máquinas possuem uma identificação única na grade, através de uma credencial de acesso que corresponde a um certificado X.509 e uma chave criptográfica (chave privada). Para autenticação e garantir a privacidade e integridade das mensagens são utilizados os protocolos Secure Socket Layer (SSL) e Transport Layer Security (TLS) (NOVOTNY; TUECKE; WELCH, 2001; CHAKRABARTI, 2007).

O GSI também oferece recursos para autenticação única e delegação através da utilização de certificados proxy, reduzindo o número de vezes que que o usuário tem que informar a sua senha quando utilizar diversos recursos (CHAKRABARTI, 2007; NOVOTNY; TUECKE; WELCH, 2001; PEARLMAN et al., 2002).

Como os recursos na computação em grade são compartilhados entre muitas organizações ou departamentos, existe a possibilidade que eles possuam algum padrão de uso já definido internamente pelo seu proprietário, necessitando de uma autorização para sua utilização. (CHAKRABARTI, 2007). 
Nas próximas seções serão apresentadas as ferramentas que são utilizadas para implementar um modelo de segurança para computação em grade.

\subsubsection{O Serviço de Infra-estrutura de Chave Pública}

A Infra-estrutura de Chaves Públicas (ICP) consiste na utilização de chaves públicas para autenticação e cifração de dados, fornecendo ao usuário um par de chaves, sendo uma pública e uma privada (MENEZES; VANSTONE; OORSCHOT, 1996)

Uma ICP é formada pela utilização de credenciais, que consistem de certificados com sua chave criptográfica privada correspondente e uma Autoridade Certificadora (AC) confiável responsável por assinar e revogar certificados que foram comprometidos. As grades computacionais utilizam certificados X.509 possuindo as seguintes informações (CHAKRABARTI, 2007):
a. A versão do protocolo x.509 utilizada;
b. Informação sobre o usuário ou a AC assinante;
c. Algoritmo utilizado para assinar o certificado;
d. O dono da chave pública que está sendo certificada (Nome Distinto);
e. A validade do certificado;
f. Informação da chave pública;
g. Campo de assinatura contendo informações sobre a chave privada da AC;
h. Extensões ou informações adicionais.

A Autoridade Certificadora é uma entidade considerada confiável por outros sistemas, é responsável por assinar os certificados de diferentes usuários assegurando a confiabilidade, autenticidade e integridade dos dados cifrados por aquele usuário. Em uma ICP existem diferentes modelos de ACs, alguns deles são (CHAKRABARTI, 2007):

a. Modelo Monopólio: Possui somente uma AC responsável pela certificação dos certificados, é o modelo mais simples de se implementar, mas não é escalável em grandes sistemas;

b. Modelo Monopólio com AR: Semelhante ao Modelo Monopólio mas a AC escolhe algumas organizações conhecidas como Autoridade Registradora (AR) para verificar as chaves públicas utilizadas, comunicando as informações para a AC; 
c. Modelo de Delegação: Este modelo possui uma AC Raiz que emite certificados para outras ACs conhecidas como AC Delegadas. Os usuário solicitam os seus certificados para estas ACs Delegadas, sendo este modelo implementado pelo Globus Toolkit.

O Globus oferece em seu pacote de ferramentas uma AC chamada simpleCA que pode ser utilizada para o gerenciamento dos certificados na grade, mas é possível utilizar uma AC externa para desempenhar esta função.

\subsubsection{A Ferramenta Serviço de Autorização Comunitária}

O Serviço de Autorização Comunitária (Community Authorization Service, CAS) é uma ferramenta que possibilita a autorização de usuários para acesso aos recursos disponíveis por uma organização. Seu desenvolvimento é realizado como parte do GT, sendo uma ferramenta que permite a autorização em nível de Organização Virtual $(\mathrm{OV})^{1}$, responsável pelo gerenciamento das políticas de acesso dos recursos e emissão de credenciais com as permissões de acesso do usuário (CHAKRABARTI, 2007).

O CAS possui informações sobre as ACs, usuários, servidores e recursos que pertencem a comunidade e aos grupos que organizam essas entidades. Ela possui as declarações das políticas que especificam "Quem"(usuário ou grupo) possui permissão, "Qual"recurso ou grupo de recursos possui permissão e que permissão é concedida. As permissões são definidas por um tipo de serviço e uma ação, onde provedores de recursos podem reconhecer diferentes tipos de serviços, mas todos os provedores que reconhecem o mesmo tipo de serviço devem compartilhar de que ação é o tipo de serviço (PEARLMAN et al., 2002).

A arquitetura desta ferramenta possui dois componentes a Base de Dados do CAS e um Servidor (CHAKRABARTI, 2007), eles possuem as seguintes funcionalidades:

a. CAS Database: É a base de dados de políticas contendo os grupos de usuários, recursos, ações e um conjunto de políticas de acesso de usuário. A declaração da política define quais usuários podem acessar qual recurso ou grupo de recursos e qual são as permissões atribuídas a este usuário. As permissões são denotadas por um conjunto de ações do tipo "escrever", "ler", "executar", etc, representando o que o usuário pode realizar em um recurso ou grupo de recursos;

\footnotetext{
${ }^{1}$ Organização Virtual é definida como uma comunidade de usuários, instituições e recursos em um mesmo domínio administrativo. (CHAKRABARTI, 2007)
} 
b. CAS Server: É responsável por receber a requisição do usuário, verificar a validade de sua credencial e gerar as permissões de acesso com base nas políticas armazenadas na base de dados. As políticas são concedidas com base nas políticas de restrição definidas através das extensões dos certificados X.509.

A interação do usuário com a ferramenta é ilustrada na Figura 2.8, onde o usuário requisita suas permissões de acesso o Servidor CAS, este verifica em sua base de dados de políticas quais são as permissões deste usuário e anexa na credencial do usuário. Possuindo sua credencial e permissões ele a envia ao recurso desejado para que possa acessá-lo.

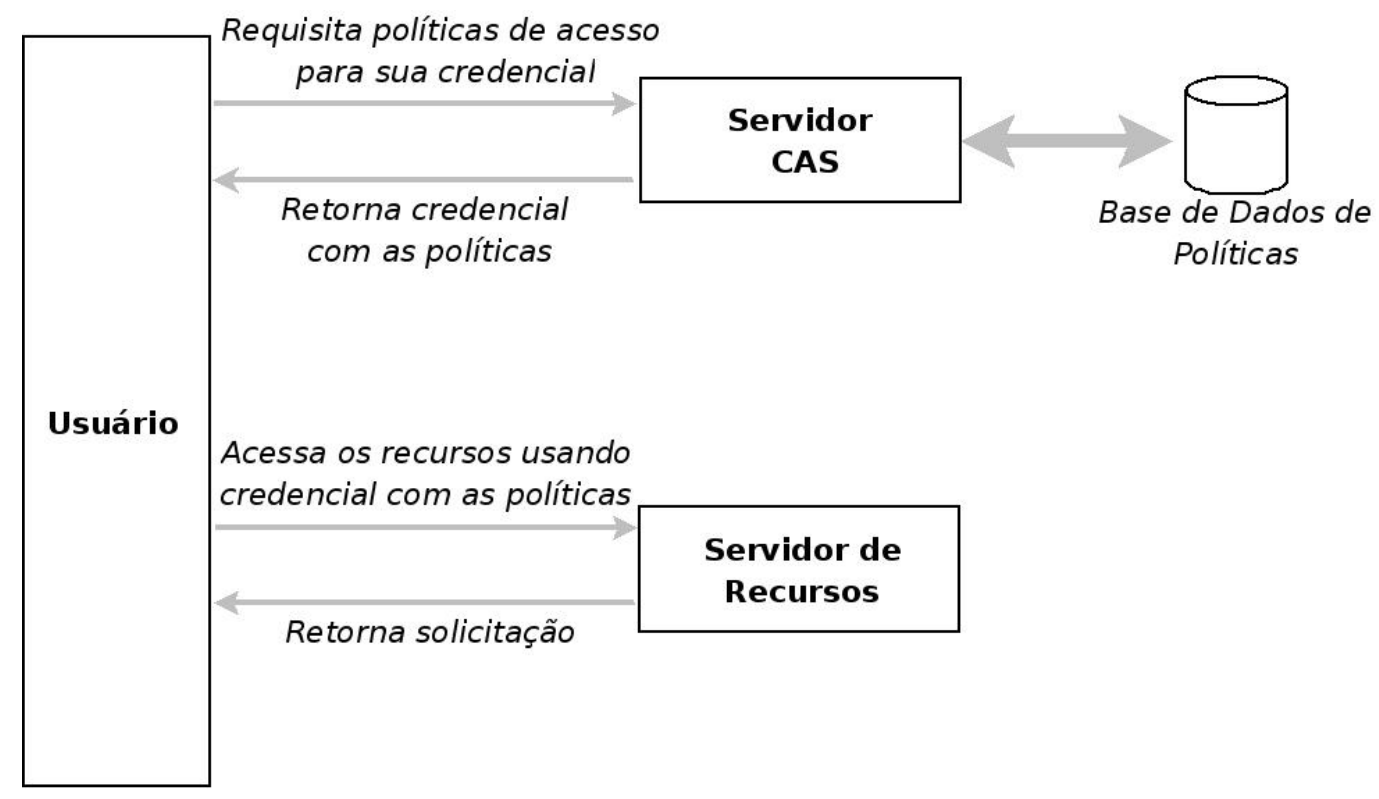

Figura 2.8: Ferramenta CAS

Para poder utilizar esta ferramenta é necessário que os recursos utilizem as permissões anexadas na credencial do usuário.

\subsubsection{A Ferramenta Virtual Organization Membership Service}

O Virtual Organization Membership Service (VOMS) é um sistema de autorização desenvolvido pelo European Data Grid (EDG), possuindo características semelhantes ao CAS, pois também usa uma base de dados para armazenar as políticas de acesso.

Apesar das semelhanças entre o CAS e esta ferramenta, implementa um mecanismo baseado em regras que permitem que um usuário possa obter múltiplas regras de diferentes OVs e utiliza credenciais com curto tempo de vida, que possuem informações do usuário, 
do servidor e período de validade, colocando os atributos dos certificados nas extenções não críticas do certificado gerado pelo usuário (CHAKRABARTI, 2007).

A Figura 2.9 ilustra a interação da ferramenta com o usuário, o qual envia sua credencial da grade para os servidores VOMS que deseja obter as permissões de acesso e depois apresentando sua credencial com as permissões para acesso aos recursos.

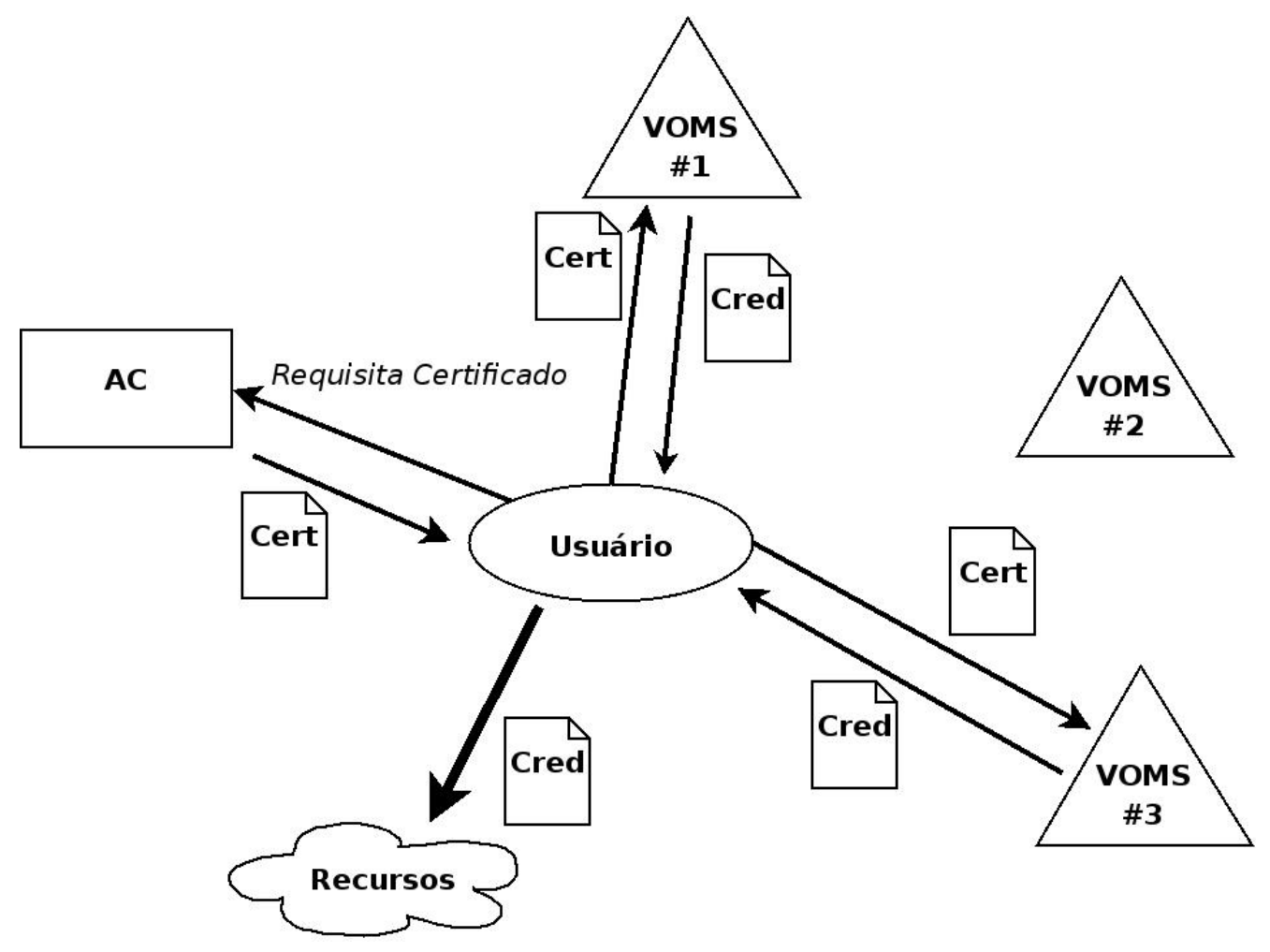

Figura 2.9: Ferramenta VOMS

Estas características oferecidas pelo VOMS possibilitam que os usuários sejam classificados em grupos ou sub-grupos de acordo com suas atividades em diversas Organizações Virtuais, mantendo a compatibilidade com outros sistemas de autorização (CHAKRABARTI, 2007).

\subsubsection{A Ferramenta GridMap}

O GridMap é utilizado para autorização em nível de recurso e foi o primeiro modelo de autorização utilizado pelo Globus antes da implementação de ferramentas mais robustas como as citadas nos tópicos 2.6.2 e 2.6.3.

O GridMap é um sistema de autorização bem simples e fácil de ser implementado, mas não é escalável em ambientes de grande porte, tornando-se de difícil administração, pois utiliza um arquivo para manter as políticas de acesso aos recursos e este arquivo precisaria 
ser alterado frequentemente, acarretando perda de desempenho e tornando complexo o gerencimento do ambiente (CHAKRABARTI, 2007).

\subsubsection{A Ferramenta MyProxy}

O MyProxy é uma ferramenta desenvolvida pela Universidade de Illinois, Urbana Champaign com o objetivo de oferecer um gerenciador de credenciais para ambientes de grade computacional. Esta ferramenta foi concebida com base na proposta de um sistema de tokens virtuais flexíveis, onde são utilizados certificados proxy para armazenar e recuperar as credenciais do usuário sem a necessidade do usuário expor sua chave privada (CHAKRABARTI, 2007).

A arquitetura do MyProxy consiste de um servidor e uma base de dados para armazenar as credenciais proxy X.509 dos usuários. Esta ferramenta através da delegação de credenciais atende as necessidades dos Portais de Grade ${ }^{2}$, permitindo o usuário utilizar todas as funcionalidades das grades computacionais através da web, mesmo que eles não possuam acesso a suas credenciais (NOVOTNY; TUECKE; WELCH, 2001; CHAKRABARTI, 2007; BASNEY; HUMPHREY; WELCH, 2005). As principais características desta ferramenta são:

a. Certificados Proxy: São certificados com um curto tempo de vida e são gerados através da derivação dos certificados X.509 do usuário e de sua chave privada. No Globus estes certificados são armazenados no sistema do usuário permitindo sua utilização para autenticação única na grade;

b. Delegação: O processo de delegação é realizado através dos certificados proxy, permitindo ao usuário delegar direitos a outras máquinas no ambiente;

c. Controle de Acesso: O MyProxy possui diferentes mecanismos de controle de acesso para gerenciar o armazenamento e a retirada de credenciais;

d. Armazenamento Seguro: O servidor MyProxy cifra as chaves privadas utilizando uma senha informada pelo usuário e o algoritmo criptográfico Triple DES no modo CBC, não armazenando a senha informada no repositório.

\footnotetext{
${ }^{2}$ Os Portais de Grade, são portais de internet que permitem o usuário acesso aos recursos disponíveis em um ambiente de grade computacional através da utilização de um navegador web padrão.
} 
A Figura 2.10 ilustra a arquitetura do MyProxy. O usuário armazena sua credencial na base de dados do servidor MyProxy, possibilitando que ele recupere ou delegue a outros recursos permitindo acesso aos servidos e recursos oferecidos pela grade computacional (BASNEY; HUMPHREY; WELCH, 2005).

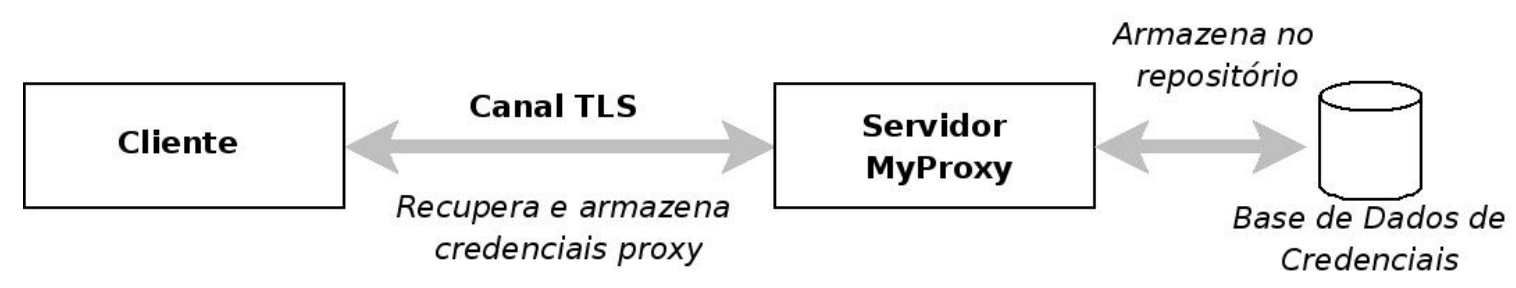

Figura 2.10: Ferramenta MyProxy

\subsubsection{A Ferramenta Shibboleth}

O Shibboleth é uma ferramenta desenvolvida pelo consórcio Internet2 que fornece um mecanismo para ser aplicado a arquitetura já existente em uma instituição, permitindo que organizações troquem informações sobre seus usuários de uma maneira segura, preservando a privacidade dos dados (CHAKRABARTI, 2007).

A arquitetura desta ferramenta consiste 3 serviços, 2 serviços para autenticação e delegação de acesso e um serviço que o usuário utiliza para informar qual a sua organização de origem, como ilustrado na Figura 2.11.

Utilizando esta ferramenta o usuário acessa o recurso desejado, verificando a credencial do usuário. Se ele não possuir uma credencial válida, é redirecionado para um serviço do Shibboleth para informar a qual organização ele pertence. Após informado a organização é redirecionado para os serviços de autenticação do Shibboleth disponíveis na organização. Feita a autenticação do usuário o Shibboleth faz o processo de delegação de acesso das credenciais do usuário entre a organização do usuário e o provedor de recursos requisitadas (SHIBBOLETH, 2008).

\subsection{Ferramentas para Monitoração e Informação em Grade Computacional}

As características transientes dos recursos disponibilizados por uma grade fazem com que estas plataformas tenham características dinâmicas, necessitando de ferramentas que coletem informações e monitorem os recursos, possibilitando que os usuários tenham con- 


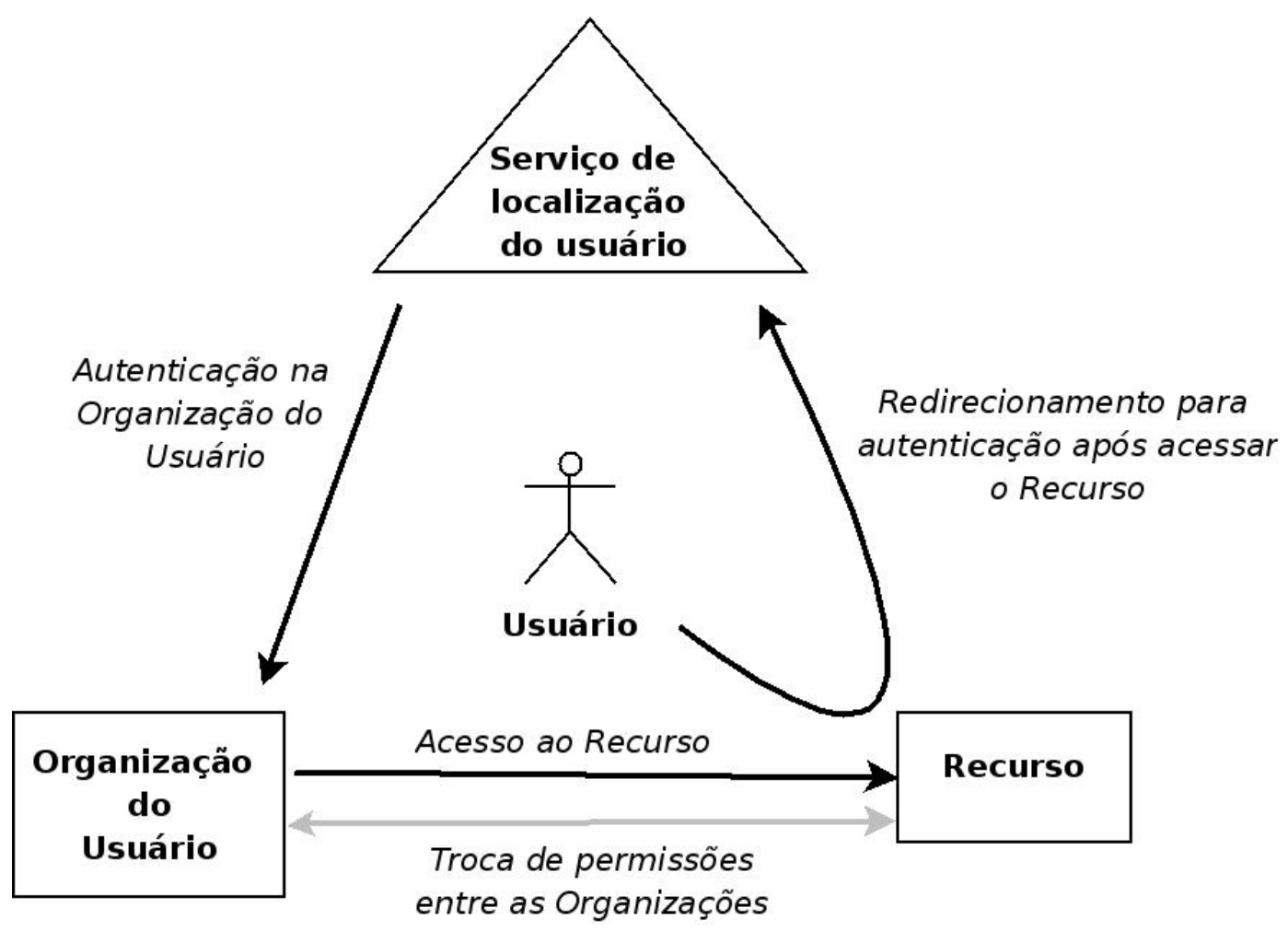

Figura 2.11: Visão de Alto Nível da Arquitetura do Shibboleth

hecimento dos recursos disponíveis quando ele necessitar e que os administradores da grade possam tomar decisões em caso de falha em algum recurso (ZANIKOLAS; SAKELLARIOU, 2005).

Este trabalho avaliou as seguintes ferramentas: Ganglia, Hawkeye, Arquitetura Relacional de Monitoramento de Grade e Sistema de Monitoramento e Descoberta.

\subsubsection{A Ferramenta Ganglia}

O Ganglia é uma ferramenta de código aberto utilizada para monitoração de aglomerados de computadores. Sendo sua arquitetura dividida em três componentes, a Monitoração Intra-cluster, federação e visualização (ZANIKOLAS; SAKELLARIOU, 2005; CHAKRABARTI, 2007).

a. Monitoração Intra-cluster: Responsável por coletar informações do sistema local, utilizando mensagens do tipo heartbeat para monitoração e redes multicast para o tráfego de informações;

b. Federação: Possibilita agregar a monitoração de múltiplos ambientes, usando o XML para tráfego de informações sob um canal TCP; 
c. Visualização: A visualização e o armazenamento das informações coletadas são realizadas através da utilização Round Robin Database (RRDTool) possibilitando analisar informações de diferentes tipos de sistemas, como aglomerados de computadores, grades, etc.

Apesar da característica hierárquica da ferramenta através da utilização de federação, esta ferramenta não é interoperável com outros sistemas de monitoramento, que dependendo dos requisitos de monitoramento, é necessário adotar outras ferramentas para trabalho conjunto (CHAKRABARTI, 2007).

\subsubsection{A Ferramenta Hawkeye}

O Hawkeye pode ser utilizado para monitorar diferentes aspectos de um sistema computacional, que podem ser um aglomerado de computadores ou uma grade, monitorando a disponibilidade dos nós, a carga do sistema, processos em execução, entre outros. Esta ferramenta é geralmente utilizada em conjunto com o escalonador de processos Condor. O Hawkeye utiliza em sua arquitetura um gerenciador central, comunicando com os clientes através de mensagens com o formato XML e armazenando as informações em bases de dados round robin (ZANIKOLAS; SAKELLARIOU, 2005; CHAKRABARTI, 2007).

\subsubsection{A Ferramenta Arquitetura Relacional de Monitoramento de Grade}

A Arquitetura Relacional de Monitoramento de Grade (Relational Grid Monitoring Architecture, R-GMA) é desenvolvido pelo projeto European Data Grid, que é um arcabouço baseado na especificação do Grid Monitoring Architecture (GMA) e combina o monitoramento em grade e serviços de informação baseados em modelo relacional (ZANIKOLAS; SAKELLARIOU, 2005; CHAKRABARTI, 2007). A arquitetura desta ferramenta utiliza o modelo de produtor/consumidor, possuindo quatro componentes:

a. Produtor: Responsável produzir as informações que vão ser coletadas, as quais enviam informações para o Registro após terem sido criados;

b. Consumidor: Responsável por coletar as informações produzidas, utilizando o Registro para identificar qual o Produtor possui as informações de seu interesse; 
c. Arquivo: Auxilia na transferência das informações contidas no Produtor para o Consumidor;

d. Registro: Responsável por fazer a conexão entre os Produtores e Consumidores.

O R-GMA é uma ferramenta interessante para o monitoramento de grades computacionais, pois implementa alguns padrões como o GSI. Esta ferramenta não possui suporte a tomada de decisão, impossibilitando realização de ações como enviar um e-mail para os a administradores, se é identificada alguma falha em algum recurso da grade (CHAKRABARTI, 2007).

\subsubsection{A Ferramenta Sistema de Monitoramento e Descoberta}

O Sistema de Monitoramento e Descoberta, do inglês Monitoring and Discovery System (MDS), é uma suíte de componentes para monitoração e descoberta de serviços e recursos na grade. A diferença entre esta ferramenta dos sistemas utilizados para monitoração em clusters como o Ganglia, é que ela não possui um mecanismo detalhado para a manipulação de eventos, ela pode se comunicar com diferentes sistemas de monitoração em múltiplos domínios administrativos (ZANIKOLAS; SAKELLARIOU, 2005; CHAKRABARTI, 2007). A arquitetura do MDS dispõe de dois serviços:

a. Serviço de Index: Este serviço coleta informações de diferentes fontes de dados através da utilização dos padrões WS-ResourceProperties e WSBaseNotification e as torna disponível para acesso através do WebMDS, que consiste de uma interface web para visualização dos dados adquiridos;

b. Serviço de Trigger: Este serviço coleta informações e compara com um conjunto de condições definidas em um arquivo de configuração, Se uma condição é encontrada, uma ação pré definida é realizada.

O MDS é uma ferramenta desenvolvida pelo GT que possibilita sua utilização em uma arquitetura hierárquica e a coleta de informações de outros sistemas. Além dessas características, é possível realizar ações em caso de falha de recursos (CHAKRABARTI, 2007). 


\subsection{Projetos Similares em Grade para Saúde}

Neste capítulo, serão apresentados trabalhos que implementam uma infra-estrutura de grades computacionais para o compartilhamento, integração e acesso a informações distribuídas, utilizando os padrões e algumas das ferramentas citadas anteriormente.

\subsubsection{Cancer Biomedical Informatics Grid}

O projeto Cancer Biomedical Informatics Grid ( $\left.c a B I G^{T M}\right)$ é desenvolvido pelo Instituto Nacional nos EUA para criar uma infra-estrutura computacional para conectar pesquisadores e instituições, permitindo a utilização de ferramentas para análise e a colaboração de dados dentre as pesquisas sobre o câncer (FENSTERMACHER et al., 2005; CABIG, 2008).

O $c a B I G^{T M}$ utiliza em sua arquitetura o Globus Toolkit, OGSA-DAI, GRAM, Mobius, caDSR e EVS para oferecer serviços como Gerenciamento de Experimentos Clínicos, Bancos de Tecidos, Ferramentas Patológicas, Vocabulários e Elementos de Dados Comum (FENSTERMACHER et al., 2005; SALTZ et al., 2006a).

A arquitetura utilizada pelo $c a B I G^{T M}$ faz a utilização de padrões como OGSA, WSRF, GSI, SAML, XML e outros padrões de serviços web, possibilitando a integração entre os componentes e outros ambientes de grades computacionais (SALTZ et al., 2006a; OSTER et al., 2007).

Para a camada de segurança, o projeto $c a B I G^{T M}$ desenvolveu o Grid Authentication and Authorization with Reliably Distributed Services (GAARDS), que implementa as especificações GSI para compatibilidade com os certificados X.509 utilizado pelo Globus; devido as diversas organizações que fazem parte do projeto, desenvolveram o Grid Trust Service (GTS) para a utilização das diversas AC envolvidas; provê serviços para gerenciamento de grupos de regras, autorização e controle de acesso dos usuários (LANGELLA et al., 2007).

O estudo da arquitetura desenvolvida pelo $c a B I G^{T M}$ auxiliará na especificação da infra-estrutura da grade computacional proposta por este trabalho, pois possui algumas funcionalidades que serão oferecidas pelo Oncogrid. 


\subsubsection{Diagnostic Mammography National Database}

O Diagnostic Mammography National Database (eDiaMoND) foi desenvolvido para auxiliar na identificação e diagnóstico de câncer de mama no Reino Unido através da comparação de imagens de mamografias com as informações contidas em banco de dados médico, reduzindo o número de biópsias para casos benignos e os custos para o Sistema Nacional de Saúde no Reino Unido (BRADY et al., 2002; EDIAMOND, 2008).

Este projeto foi desenvolvido em parceria com a IBM Hursley, que forneceu consultoria na realização do projeto, pois era semelhante ao projeto US-NDMA realizado nos EUA entra a parceria da Universidade da Pensilvânia e IBM americana. Além da consultoria, a IBM forneceu a plataforma de hardware e software utilizada pelo eDiaMoND, sendo a integração dos dados médicos realizadas através do OGSA-DAI (SOUTTER et al., 2003).

\subsubsection{BioSimGrid}

O BioSimGrid é um projeto que explora o potencial da utilização de grades computacionais na simulação de dados biomoleculares e busca resolver os desafios de análises comparativas. Ele oferece uma plataforma para que permite aos pesquisadores armazenar, recuperar e analisar dados de simulações biomoleculares (NG et al., 2006).

Dentre as ferramentas utilizadas por esta grade computacional estão o GT como middleware básico e SRB para o gerenciamento dos dados distribuídos, oferecendo serviços de mineração e análise de dados e visualização (NG et al., 2006; WU et al., 2004, 2003).

\subsection{Resumo do Capítulo}

Este capítulo apresentou os componentes utilizados para o desenvolvimento de uma grade computacional, os padrões de interoperabilidade e os projetos correlatos.

A utilização de padrões no desenvolvimento de uma grade computacional irá simplificar a integração entre componentes e outros ambientes de grades computacionais e a utilização de padrões na arquitetura do Oncogrid é fundamental para desenvolver um ambiente que possa se tornar escalável e adaptável as novas necessidades no desenvolvimento de pesquisas multi-institucionais.

Dentro os componentes estudados, podemos agrupá-los por suas funcionalidades, como Ferramentas Base, Segurança, Integração de Dados e Monitoração. 
Dentre as ferramentas bases estudadas o Globus Toolkit, mostrou-se mais completo pois seu arcabouço é fortemente baseado em padrões e possui diversos componentes que são desenvolvidos para a sua arquitetura.

As ferramentas para segurança estudadas, O GridMap, MyProxy e CAS são as ferramentas que já estão inclusas no Globus Toolkit, tornando nativa a interoperabilidade entre elas e simplificando o desenvolvimento da arquitetura. O MyProxy pode ser implantado sozinho para o gerenciamento das credenciais, podendo ser implantado com o GridMap ou o CAS para o gerenciamento de políticas de acesso.

Para a integração e compartilhamento de dados encontradas na literatura, o OGSADAI e sua extenção o OGSA-DQP oferecem recursos semelhantes quando comparado com o Mobius, o qual se destaca pelo serviço de tradução de dados, mas devido a constante desenvolvimento do OGSA-DAI e OGSA-DQP sendo citados em diversos projetos de pesquisas, mostra que a ferramenta encontra-se madura para ser aplicada em um ambiente de larga escala com abrangência nacional.

A ferramenta Sistema de Monitoramento e Descoberta, possui a vantagem de execução de ações quando ocorrer algo não previsto, como por exemplo a insdisponibilidade de um serviço e recurso, possibilitando que seja complementada com as ferramentas para o monitoramento de aglomerados como o Ganglia.

Dentre os projetos estudados para o desenvolver a proposta de integração de dados para o Oncogrid, o eDiaMoND é o projeto que mais semelhante ao escopo desta pesquisa, com uma grande diferença, o Oncogrid é totamente desenvolvido pela academia, sem a intervenção de empresas externas, possibilitando que todo o conhecimento adquirido seja revertido para própria academia. 


\section{Proposta de Arquitetura de Grade Computacional para Integração e Compartilhamento de Dados Médicos}

Este capítulo apresenta os componentes utilizados para compor a arquitetura do Oncogrid para a integração e compartilhamento de informações médicas em oncologia com base nas pesquisas realizadas no levantamento do estado da arte em grade computacional, descrevendo os componentes utilizados.

\subsection{Introdução}

A arquitetura proposta para integrar ao Oncogrid é escalável, interoperável e flexível, podendo ser aplicada a uma plataforma de hardware e software heterogênea, utilizando ferramentas e padrões abertos e a infra-estrutura de conexão da Rede Nacional de Ensino e Pesquisa para o desenvolvimento de uma Grade Computacional em Oncologia, promovendo um ambiente para auxiliar a gestão da atenção do câncer e uma plataforma colaborativa em saúde à comunidade científica brasileira, a qual poderá ser aplicada em outras áreas da saúde.

O suporte do ambiente para uma plataforma de hardware e software heterogêneo deve-se a realidade dos hospitais nos quais possuem recursos limitados, não podedendo adquirir uma conjunto de hardware e software específico, necessitando adaptações no Oncogrid para que possa ser implantado na infra-estrutura computacional já existente no hospital ou com o menor custo possível.

Nas pesquisas realizadas no levantamento do estado da arte em grades computacionais, foi feito o levantamento dos componentes utilizados na proposta de uma arquitetura de um ambiente distribuído desta tecnologia. A identificação dos componentes e a decisão de 
priorizar a utilização de componentes que implementam as padronizações definidas pelo OGF, possibilitou levantar requisitos que o Oncogrid deferá oferecer.

\subsection{Requisitos do Oncogrid}

O Oncogrid deve abranger a segurança da informação, acesso as informações (bases de dados), monitoração e descoberta de recursos e possuir flexibilidade permitindo que seja expandido para atender novas funcionalidades como o processamento de tarefas, necessitando prover componentes para alocação de recursos e a distribuição de processos, estas funcionalidades são pesquisadas por Moacir Alves de Campos Junior, para complementação da arquitetura.

Os requisitos do Oncogrid são divididos em requisitos funcionais e não funcionais. O primeiro aborda as funcionalidades que o ambiente deve prover e o segundo as características encontradas na arquitetura.

\subsubsection{Requisitos Funcionais}

Os requisitos funcionais do Oncogrid são:

1. Utilizar as redes de intercomunicação existentes como a RNP ou a internet comercial;

2. Utilizar software livre;

3. Utilizar componentes que implementem os padrões definidos pelo OGF;

4. Suportar diferentes tipos de hardware;

5. Suportar diferentes tipos de bancos de dados.

Implantar uma rede de intercomunicação dedicada para o Oncogrid se tornaria inviável, devido aos custos envolvidos e a distribuição geográfica que teria que abranger. Para viabilizar a comunicação entre as organizações participantes, não necessitando altos investimentos na construção de uma rede privada para o Oncogrid, o desenvolvimento desta plataforma é compatível com a utilização das soluções já existentes, como a RNP, Onconet e a internet comercial.

Além da viabilidade da rede de intercomunicação, é necessário pensar no investimento relativo a licensas de software, para isto o Oncogrid utiliza software livre em uma arquitetura, esta atitude é importante pois além da questão social, pois diminuirá os custos 
envolvidos com licensas de software, ele permite que as ferramentas utilizadas possam ser adaptadas para atender as necessidades encontradas durante as pesquisas.

Para garantir a interoperabilidade entre as ferramentas existentes, o Oncogrid adotou os padrões definidos pelo OGF através do OGSA o OGSI. Adotar estes padrões oferece mais que a interoperabilidade entre as aplicações permite que o Oncogrid possa colaborar com outras iniciativas de grades computacionais existentes.

O Oncogrid deve ser compatível com a infra-estrutura computacional dos hospitais, como já abordado, existem localidades que não dispõe de recursos para ser aplicados nesta área, o que poderá impossibilitar a compra de um hardware mais específico. Para contornar esta situação a arquitetura proposta deve ser modular, o que permitirá a alocação de módulos em hardwares diferentes, o que permitirá que o ambiente seja disponibilizados dentro da instituição.

Definir as redes de interconexão que devem ser utilizadas, o modelo do licenciamento do software, padrões utilizados e prover alternativas para a redução dos custos em hardware, são passos para possibilitar que o Oncogrid seja acessível. Para que tenha abrangência em sua utilização ele irá possibilitar o acesso a diferentes bancos de dados através dos componentes utilizados na Camada de Serviços de Conexão de Dados, isto vai permitir que sejam desenvolvidos novos projetos utilizando bancos de dados livres como o PostgreSQL ou compartilhar informações armazenadas em bancos de dados corporativos existentes no legado do hospital como o Oracle.

\subsubsection{Requisitos Não Funcionais}

Os requisitos não funcionais são:

1. Segurança no acesso as informações;

2. Escalabilidade;

3. Interface Web;

4. Sigilo dos Dados.

A segurança das informações é crucial para ambientes voltados para área da saúde e esta determinação está contida na legislação médica, a qual referencia a utilização de certificados de chave pública ICP Brasil para proteção das mensagens contendo dados 
dos pacientes. O Oncogrid atualmente implementa a sua segurança através de uma infraestrutura de chaves públicas própria, a qual poderá integrar ou aceitar os certificados ICP-Brasil em sua estrutura.

A determinação de não adotar a ICP-Brasil atualmente no projeto é devido a adaptação necessário para fazer o Oncogrid utilizar os serviços de Infra-estrutura de Chaves Públicas da ICP-Brasil, que é responsável pelo gerenciamento dos certificados digitais utilizados oficialmente pelo Governo Federal.

Os certificados utilizados no Oncogrid servem para permitir identificação e acesso do usuário ao ambiente, identificação de hosts e prover comunicação segura através de SSL e HTTPS no acesso aos serviços disponibilizados pelo ambiente.

Como abordado nos Requisitos Funcionais a flexibilidade e escalabilidade conseguida através da definição dos padrões, redes, softwares e hardwares, sendo fundamentais para tormar o Oncogrid adaptável e aplicável a ambientes computacionais heterogêneos, possibilitando maior integração e compartilhamento de informações médicas.

Prover uma arquitetura de grade computacional que seja flexível e escalável é tão importante para utilização do ambiente quanto disponibilizar uma interface simples e eficiente para o usuário. Não possuir este tipo de funcionalidade o Oncogrid poderá limitar sua utilização a pessoas com mais conhecimento em tecnologia, lembrando que como relatado na conversa com o Dr. Odone, somente 3 instituições possuem pessoas responsável pela sistematização e análise dos dados.

Tendo o objetivo de oferecer uma interface simples e eficiente o Oncogrid utiliza o conceito de Portal de Grade, que consiste em um Portal Web que proverá os recursos necessários para o usuário interagir com o ambiente, sem a necessidade de instalação de aplicações específicas, pois todo o acesso será realizados através de um navegador WEB padrão.

Além da utilização de certificados de chave pública para acesso ao ambiente e prover comunicação segura através de SSL e HTTPS, é necessário prover métodos que serão oferecidos pelo SDK que possibilitarão a não identificação do paciente. Esta funcionalidade atenderá a uma solicitação da Legislação Brasileira, possibilitando que dados sensíveis como Nome do paciente, Nome da mãe e endereço não sejam acessíveis pelas aplicações. 


\subsection{Aplicabilidade no Meio Médico}

Na interação com o Dr. Odone Vicente Filho, apresentou os problemas na comparação dos resultados contendo a taxa de sobrevida das instituições que fazem o tratamento do câncer. No caso da Oncologia Pediátrica, diversas instituições procuraram maximizar o nível de cooperação entre os protocolos referendados pela Sociedade Brasileira de Oncologia Pediátrica.

A operacionalização desse processo é, via de regra, imersa no contexto das atividades diárias dos grupos médicos envolvidos. Raras são as instituições que contam com profissionais dedicados exclusivamente à sistematização dos dados e a sua devida comparação ("data managers") (em dezembro de 2007, formalmente, apenas 3 instituições, cada qual particularmente interessada em um protocolo diferente, possuía esse profissional).

Segundo o Prof. Dr. Odone Vicente Filho, "a comparação de dados permitida pelo Oncogrid, não apenas viabiliza as necessárias análises de ínterim dos protocolos, como permite vislumbrar vicissitudes institucionais que possam estar especificamente prejudicando sua aplicação".

A utilização de uma plataforma que acesse dados colaborados por estas instituições possibilitaria também:

a. Comparações de dados entre regiões do país;

b. Compartilhamento de informações entre investigadores.

A necessidade de uma ferramenta que auxilie o gerenciamento destes dados, utilizada junto com a proposta aprsentada pelo Oncogrid poderá auxiliar na comparação destes resultados possibilitando melhoras nos métodos de tratamento.

\subsection{Rede Nacional de Ensino e Pesquisa}

A rede brasileira de alta velocidade disponibiliza um backbone agregado de 60.4 Gbps e está distribuída no território nacional através de ponto de presença (POP). Ao todo são 27 POPs, sendo um em cada unidade federativa e são mantidos através de parcerias com instituições federais e estaduais (RNP, 2008a). Esta rede fornece a infra-estrutura de conectividade do seu backbone para diversas iniciativas de interconexão como a Rede Onconet, a Rede Comunitária de Ensino e Pesquisa (COMEP) e para redes estaduais 
como, por exemplo, a Rede Acadêmica em São Paulo do inglês Academic Network at São Paulo (ASNP), Rede Catarinense de Tecnologia (RCT) e a Rede Rio2 (RNP, 2008b).

Ao todo, a Rede Ipê conta com, aproximadamente, 350 instituições conectadas em seu backbone. A Figura 3.1 ilustra o estado da rede em Agosto de 2007 (RNP, 2008a).

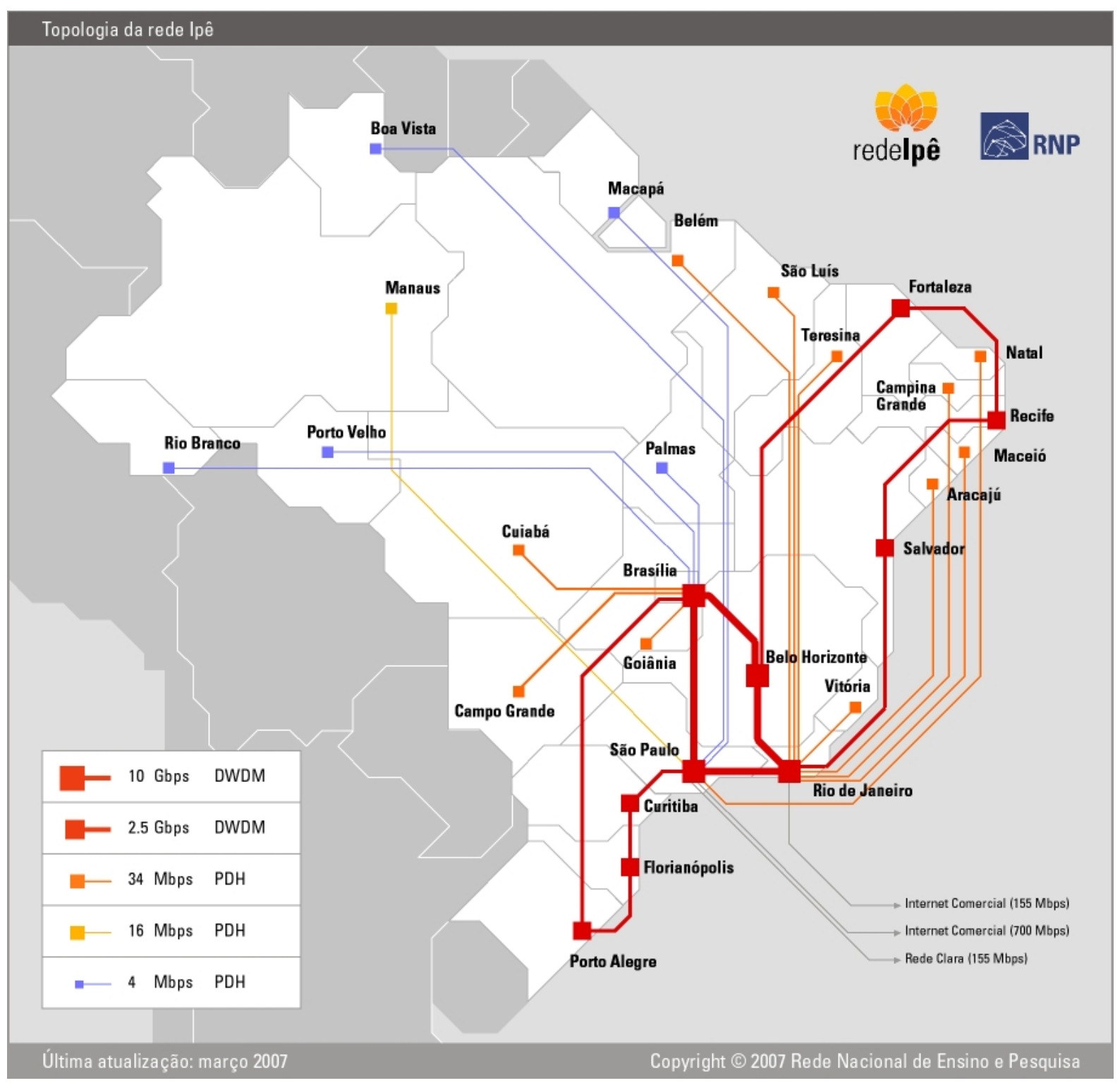

Figura 3.1: Backbone da Rede Ipê

Estas redes de alta velocidade fornecem, desde ponto de conexão primária de uma instituição, canal para vídeo conferência de alta qualidade até o desenvolvimento de projetos mais complexos como a Computação em Grade, pois oferece um ambiente de interconexão mais restrito, com maior segurança e garantia de qualidade de serviço. Devido aos recursos oferecidos por estas redes, as instituições científicas as utilizam para oferecer uma infra-estrutura de conexão necessária para o desenvolvimento de pesquisas, utilizando 
computação em grade.

\subsection{Arquitetura do Oncogrid}

A especificação da arquitetura do Oncogrid é proposta com base nas pesquisas realizadas no levantadmento do estado da arte e nos estudos de projetos de grades computacionais desenvolvidos pela comunidade científica que possibilitaram a identificação das melhores alternativas dentre os componentes existentes, para compor a especificação de uma arquitetura flexível, interoperável e escalável ao Oncogrid.

Os estudos realizados destacaram a importância da utilização de padrões difundidos mundialmente como um requisito essencial para fornecer interoperabilidade entre recursos e até ambientes de grades computacionais distintos. Os padrões que se destacam quando tratamos de grade computacional são o OGSI e o OGSA. Além da importância do uso de padrões, é necessário que as ferramentas e os compornentes escolhidas para compor a arquitetura do Oncogrid implementem estes padrões que são definidas pelo OGF.

Para criar uma arquitetura modular ao Oncogrid, é utilizado um modelo de camadas funcionais como ilustrado na Figura 3.2, o que permite que cada camada seja distribuída na infra-estrutura computacional existente na instituição, proporcionando flexibilidade e escalabilidade, pois o crescimento de cada camada é independente das outras.

As camadas propostas pelo Oncogrid são Segurança, Acesso do Usuário, Serviços de Aplicação, Serviços de Grade, Serviço de Conexão de Dados e Recursos, estas camadas possuem componentes que são interoperáveis. Nas próximas seções estas camadas serão detalhadas, apresentando suas funcionalidades e relacionamento com as demais camadas da arquitetura.

\subsubsection{Camada de Segurança}

A camada de segurança utilizada no Oncogrid oferece componentes que contemplam as funcionalidades de autenticação, autorização, delegação, proteção de mensagem, controle de acesso e o gerenciamento de certificados. Como o acesso do usuário à grade computacional é realizado através de uma portal de grade, é necessário que esta camada oferece mecanismos para autenticação única, possibilitando que o usuário tenha menor exposição de sua senha para acesso ao ambiente. 


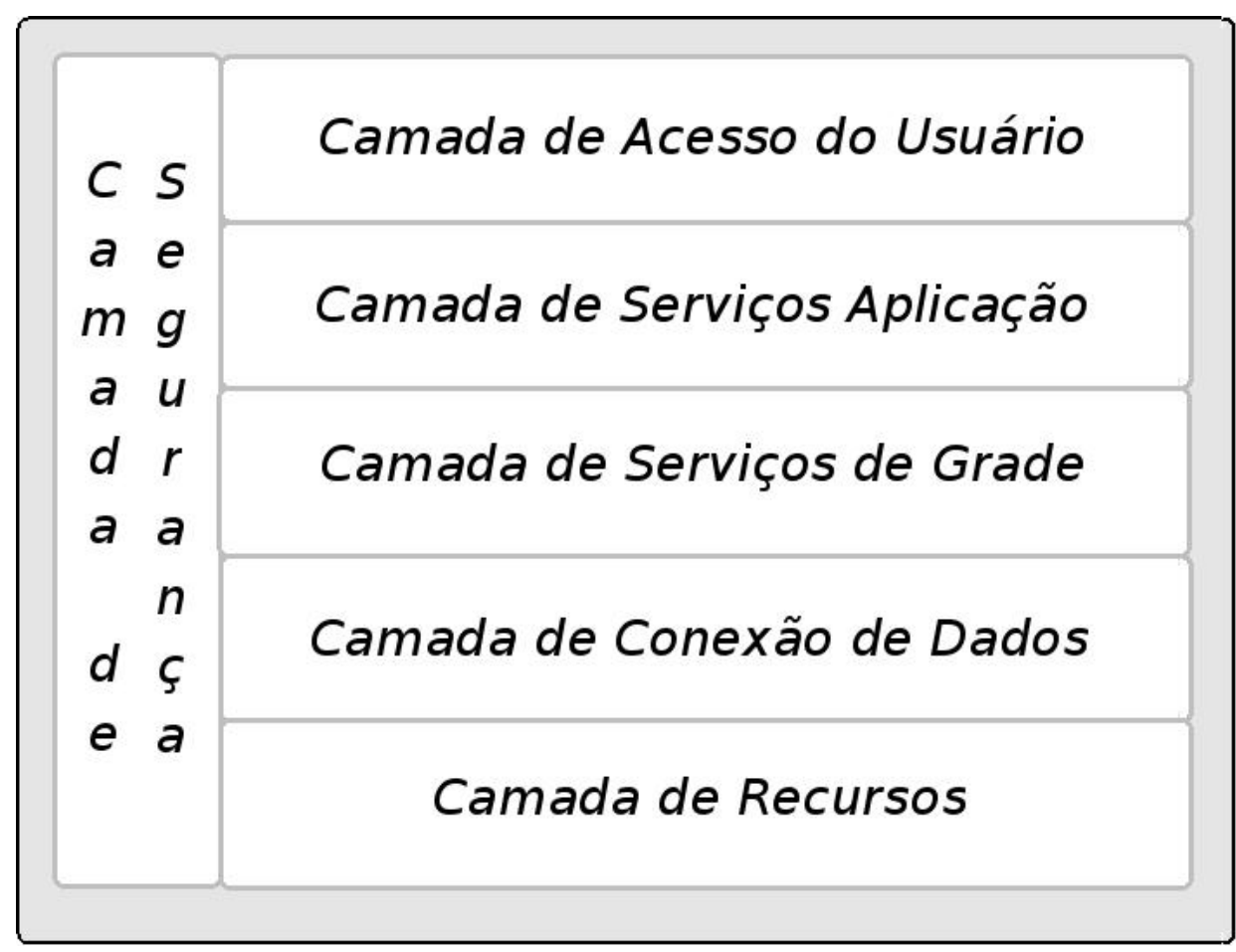

Figura 3.2: Camadas Funcionais do Oncogrid

Esta camada é baseada nos padrões GSI especificado pelo OGF e adotados posteriormente pelo OGSA, contemplando o uso de ferramentas para assinatura, renovação e revogação de certificados através da autoridade certificadora que irá fornecer uma Infraestrutura de Chaves Públicas ao ambiente.

A Figura 3.3 apresenta o processo realizado por uma AC para a assinatura de uma certificado da grade. O usuário deve gerar um certificado (1), enviar esse certificado para a AC (2), que deve assinar (3) e enviar para o usuário o certificado assinado (4).

Como já abordado, o Oncogrid oferece acesso do usuário ao ambiente através de Portal de Grade. Para isto o processo de autenticação e delegação serão integrados, possibilitando que após a autenticação, o usuário através do navegador web tenha permissões de acesso a todos os recursos do ambiente. O processo de autorização, é utilizado para atribuir as permissões de acesso de um usuário a determinado recurso.

Neste processo, ilustrado na Figura 3.4, o usuário deve informar a sua identificação e senha para o Portal de Grade (1), consultando um gerenciador de credenciais para autenticação do usuário (2) e delegada para o Portal de Grade através do navegador WEB a credencial do usuário (3). De posse da credencial de proxy, esta deve ser enviada para o sistema gerenciador de regras para que as permissões do usuário sejam anexadas a credencial (4), buscando em sua base de dados, as permissões do usuário e anexar na 


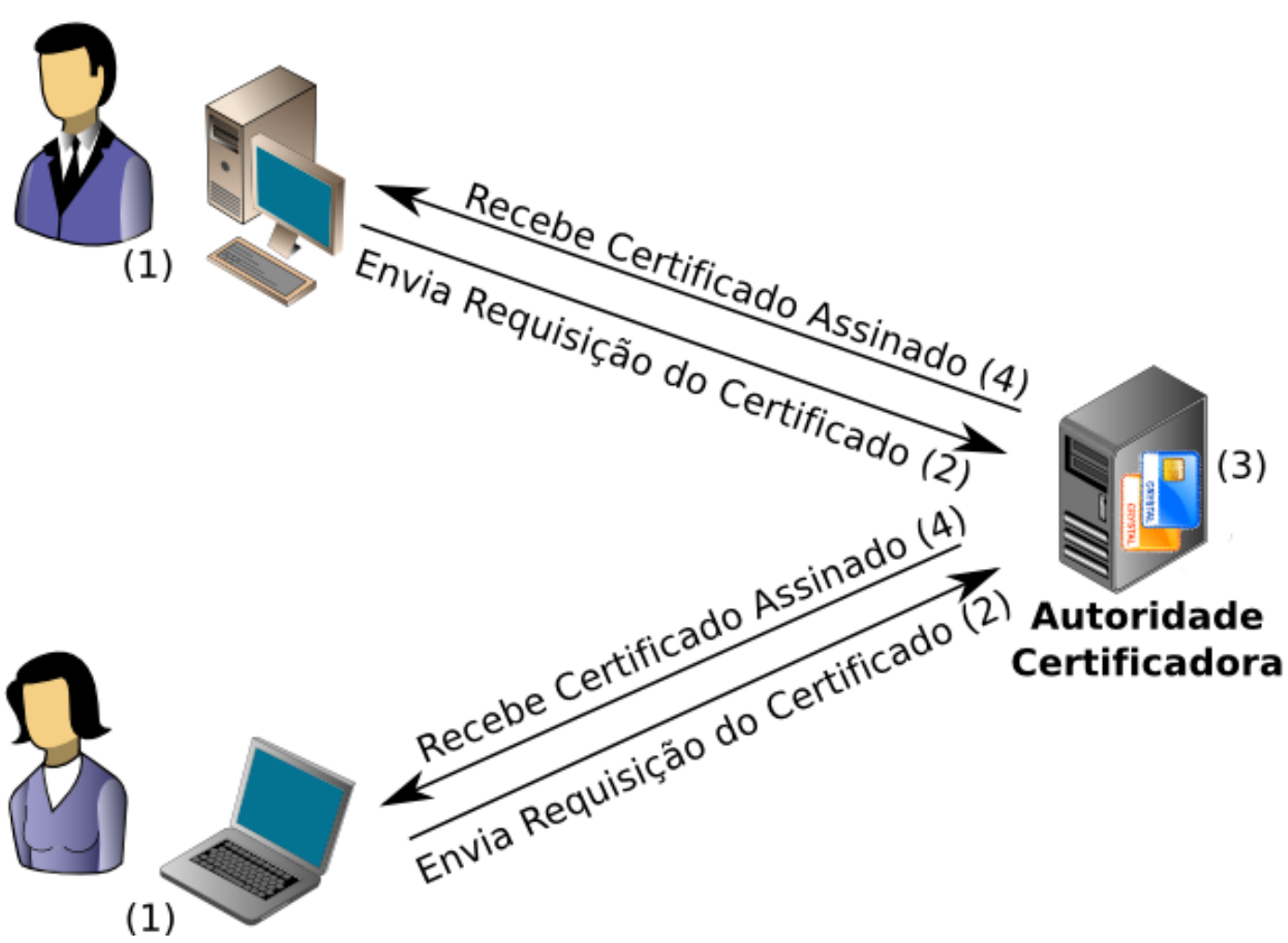

Figura 3.3: Processo de Assinatura de Certificado

credencial enviada (5), que deve ser enviada para o Portal de Grade (6) permitindo o acesso do usuário aos recursos da grade (7).

Após todo o processo de autenticação e autorização do usuário, o Portal de Grade através do navegador WEB permitirá acesso aos recursos e aplicações disponíveis no ambiente, os quais irão verificar a validade e confiabilidade da credencial utilizada no acesso.

\subsubsection{Camada de Acesso do Usuário}

Um ambiente de grade disponibiliza interfaces para interação do usuário com o ambiente. Análogo a infra estrutura de malha elétrica, o usuário da grade computacional deve utilizar os recursos disponibilizados de forma transparente, sem tomar conhecimento da complexidade empregada na composição do ambiente. Na primeira etapa deste projeto serão considerados dois métodos de interação do usuário com o ambiente: Aplicação WEB, conhecida como Portal de Grade, ou Aplicação Cliente.

A Aplicação WEB oferece maior mobilidade ao usuário, pois o único método de acesso ao ambiente será através de um navegador WEB, que estará acessando a versão mais atual da ferramenta, não necessitando se preoculpar com falhas de segurança ou atualizações de funcionalidades. A utilização deste modelo de interface possibilita maior mobilidade 


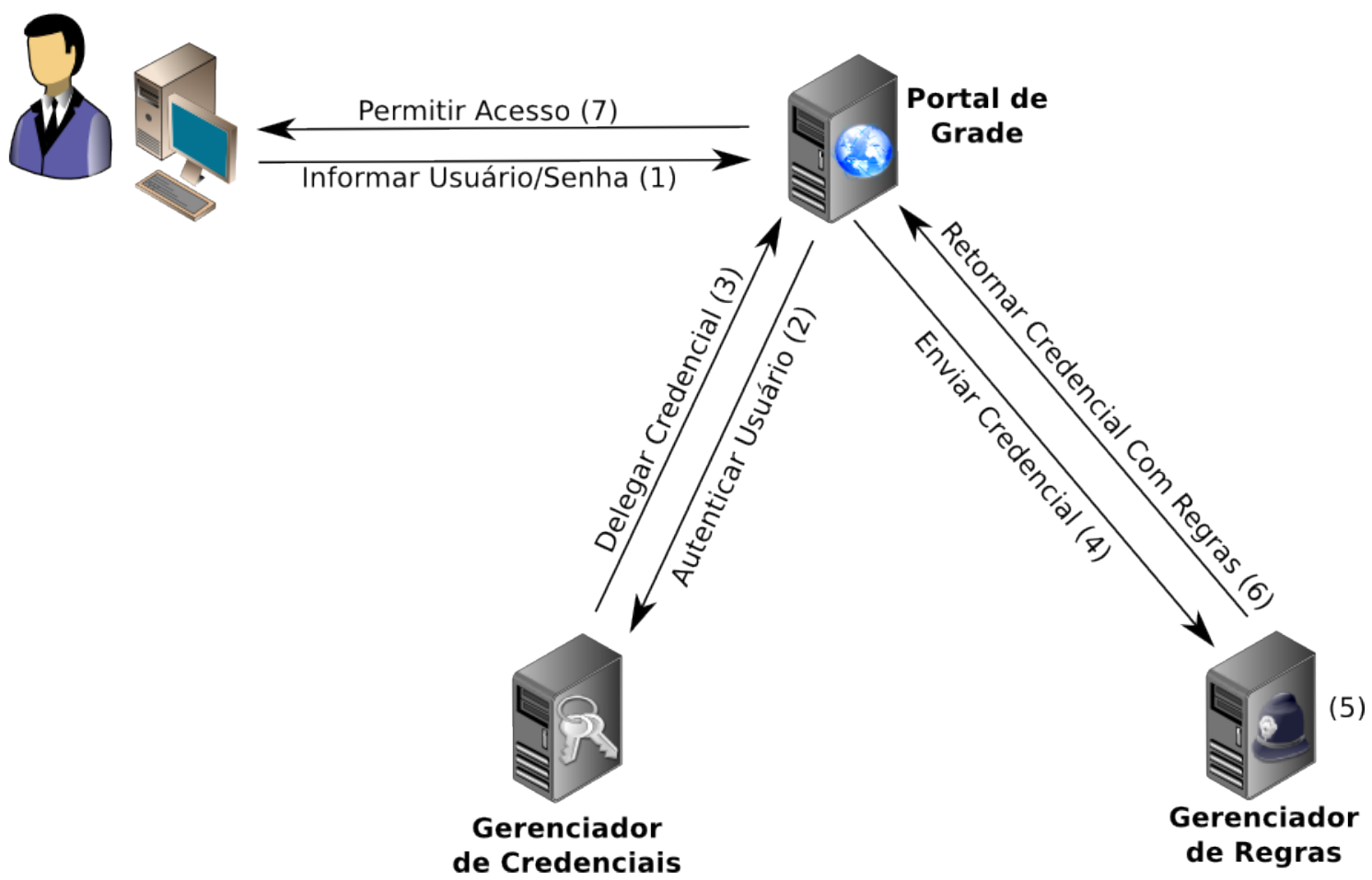

Figura 3.4: Processo de Autenticação e Delegação de Certificado

no acesso ao ambiente, sendo fundamental a utilização das abordagens de autenticação única e delegação de credenciais. A autenticação única como abordado é necessário pois permite que usuário exponha por um curto período de tempo a sua senha da credencial e uma única vez.

A Aplicação Cliente faz com que o usuário perca mobilidade, pois será necessário instalar uma aplicação em sua máquina para acesso ao ambiente e poderá tornar o desenvolvimento mais complexo pois deverão ser considerados múltiplos sistemas operacionais e o usuário terá que se preoculpar com as atualizações por causas de falhas de segurança ou de funcionalidades.

Tendo estas duas interfaces para a interação do usuário com à grade e a crescente oferta de aplicações WEB como por exemplo Suítes de Escritório (editor de textos e editor de planilhas eletrônicas) geradas pela WEB 2.0 faz com que o usuário a cada dia tenha maior contato com as aplicações tidas como On-Line.

Tendo este panorama e as vantagens encontradas na questão de atualização de versões utilizadas pelo usuário, o Oncogrid adotou a abordagem de Portal Web para prover seus serviços de grade, possibilitando que através de um navegador WEB em qualquer localidade o usuário consiga acessar o ambiente. 


\subsubsection{Camada de Serviços de Aplicação}

A Camada de Serviços de Aplicações é responsável por suportar os serviços no ambiente, seus componentes são servidores de aplicações que são responsáveis por prover os container's de serviços web que armazenam e disponibilizam os serviços de aplicação para os usuários. Estes serviços podem ser:

a. Aplicações matemáticas;

b. Serviços de busca de informações sobre recursos;

c. Aplicações para processamento de imagens e de informações genéticas;

d. Serviços para construção de bases de conhecimentos;

A importância desta camada é dada pelo motivo de possibilitar a inclusão de novos serviços voltados a saúde de forma padronizada e interoperável com os demais, a medida que se faça necessário. A interação com esta camada é realizada a partir dos portais de serviço e aplicações dispostas na Camada de Acesso do Usuário.

\subsubsection{Camada de Serviços de Grade}

A Camada de Serviço de Grade será responsável por oferecer componentes que contemplem essas funcionalidades. Para atender estes requisitos utilizamos as ferramentas MDS e Grid Resource Allocation Management (GRAM) (FOSTER, , 2005; SCHOPF et al., 2006; TANAKA et al., 1999).

O Oncogrid não oferecerá somente uma infra-estrutura para acesso a dados distribuídos e também ferramentas para processamento distribuído. Esta proposta de infraestrutura está voltada à integração e compartilhamento de dados.

A Figura 3.5 apresenta o processo de monitoramento e coleta de informações, no qual, o sistema de monitoramento deverá verificar o estado dos recursos disponíveis na grade (1)(2), armazenar em sua base de informações (3) e verificar a disponibilidade (4); permitindo que os administradores da grade sejam informados se o recurso estiver indisponível (5). 


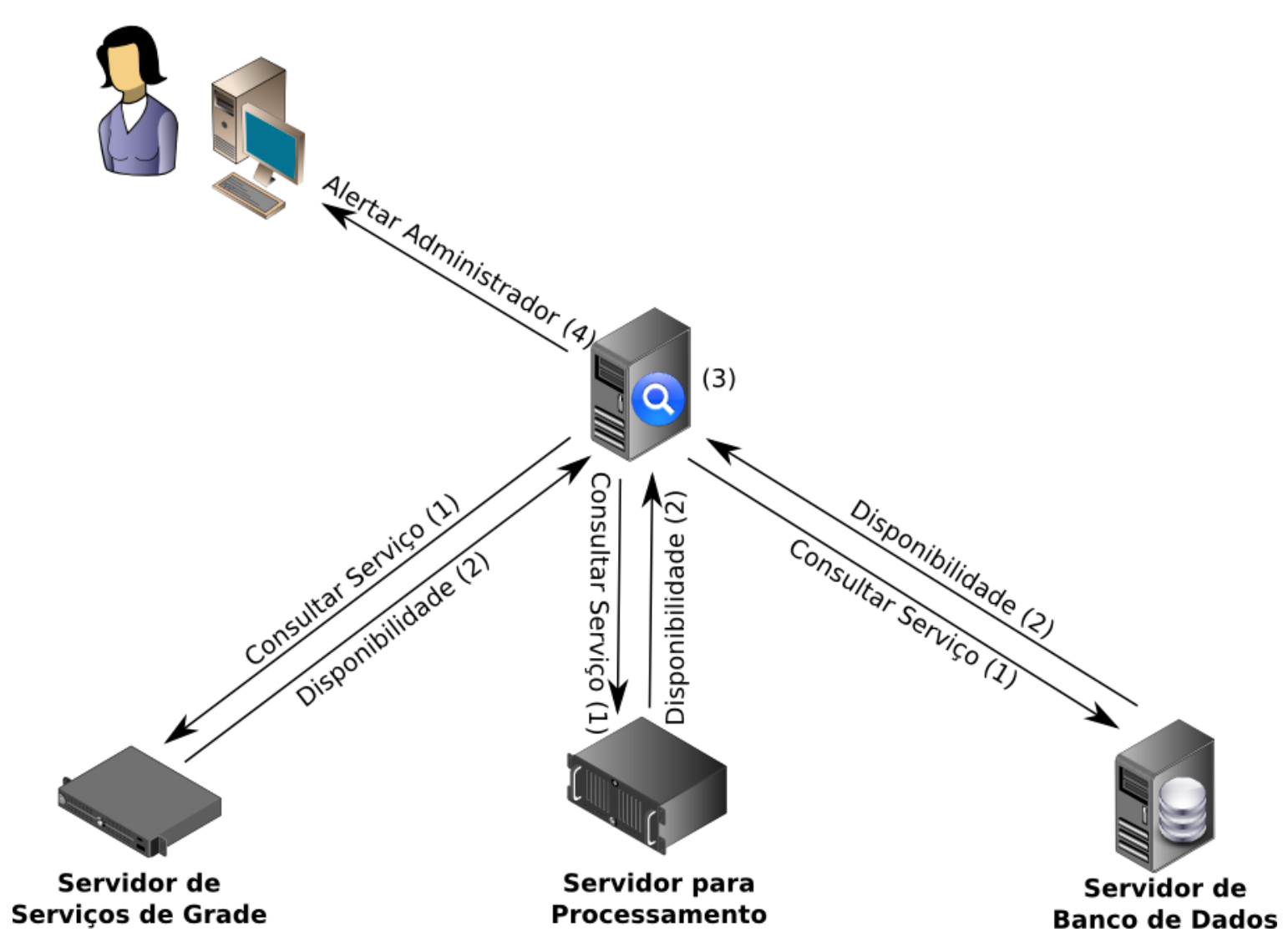

Figura 3.5: Processo de Monitoramento de Serviços e Recursos

\subsubsection{Camada de Serviços de Conexão de Dados}

Esta camada será responsável por oferecer os serviços para acesso aos recursos de dados disponíveis no ambiente.

A Figura 3.6 apresenta o processo realizado pelo usuário na utilização de recursos de dados. Vamos considerar que o processo de autenticação, delegação e autorização já foram realizados. O usuário deverá informar a aplicação qual o recurso que deseja utilizar (1); a aplicação irá consultar o sistema de monitoramento para verificar a disponibilidade do recurso (2), retornando para a aplicação (3); o usuário deverá especificar os parâmetros que deseja utilizar nos recursos de dados (4); a aplicação irá conectar no(s) serviço(s) de grade que oferece $(\mathrm{m})$ o(s) recurso(s) de dados requisitados (5); o serviço de dados deve verificar se o usuário tem autorização para acesso (6); após verificar o acesso ela deverá buscar os dados requeridos e enviar à aplicação (7); que apresentará para o usuário visualizar (8). 


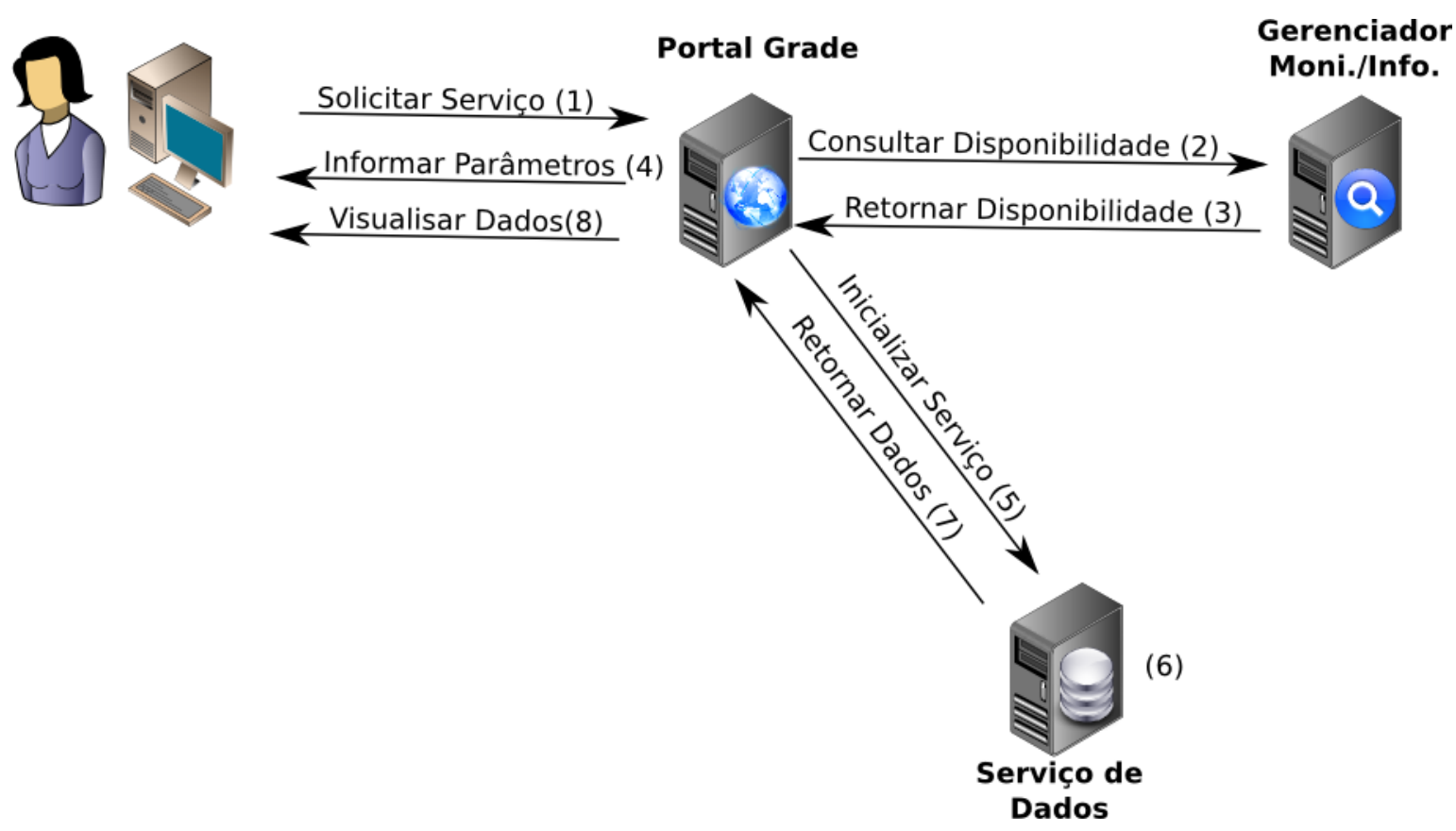

Figura 3.6: Processo de Utilização dos Serviços de Dados

\subsubsection{Camada de Recursos}

Os recursos em uma grade computacional pode ser caracterizados por equipamentos, armazenamento ou informaçoes e estão disponíveis dentro do ambiente para utilização colaborativa ou compartilhada.

Os recursos de equipamentos podem ser caracterizados por hardwares específicos como microscópios eletrônicos ou máquinas para processamento. Já os recursos para armazenamento são os diretórios compartilhados e as informações são caracterizadas através da colaboração de bancos de dados.

O Oncogrid disponibiliza na sua arquitetura os diretórios para armazenamento compartilhado e as bases de dados contendo dados médicos em oncologia para colaboração entre instituições de pesquisas. O suporte a disponibilização de recursos voltados para o processamento de informações estão sendo abordados por Moacir Alves de Campo Júnior em seu projeto de mestrado.

\subsection{Proposta de Validação do Oncogrid}

Os estudos realizados possibilitou a proposta do Oncogrid, que consiste de uma arquitetura de grade computacional para a integração e compartilhamento de dados médicos em oncologia. 
Tendo realizado a proposta da arquitura desta grade, abordando redes de interconexão, a arquitetura com seus requisitos, camadas, funcionalidades e interoperabilidade, foi necessário desenvolver uma aplicação de validação utilizando o método Kapla-Meier que identificou as dificuldades encontradas no desenvolvimento do ambiente como:

a. Restrições da rede de interconexão: Por utilizar uma rede que fora dos nossos domínios administrativos, é esperado que deve existir algumas restrições ou bloqueios como firewalls;

b. Integração dos componentes utilizados: Apesar da adoção de componentes que utilizem os padrões desejados, é esperado que as configurações destes componentes não sejam triviais;

c. Utilização das APIs disponíveis: Para o desenvolvimento das aplicações foi utilizada a linguagem de programação JAVA, devido a adoção o Globus Toolkit, a praticidade do desenvolvimento é proporcional a documentação das APIs;

d. Desenvolvimento de uma aplicação para validação e avaliação do ambiente: esta aplicação servirá para validar todos os pontos apresentados anteriormente, mostrando a viabilidade da arquitetura proposta.

\subsection{Resumo do Capítulo}

A arquitetura proposta para o Oncogrid, através da sua divisão de camadas possibilitará atender os requisitos apresentados e prover a escalabilidade e flexibilidade desejada para implantação desta tecnologia nos hospitais com poucos recursos computacionais disponíveis, pois as camadas poderão ser distribuídas na infra-estrutura computacional existente.

A camada de segurança conforme proposta tornou-se um ponto essencial na arquitetura do Oncogrid, pois ela será responsável por prover alguns dos principais recursos ao ambiente, que é a autenticação única e a delegação de credencial, sendo essencial para a utilização do ambiente a sua integração com as outras demais camadas.

Definir a utilização de um Portal de Grade para a Camada de Acesso do Usuário, possibilitou prover ao usuário uma método único e simples de acesso ao ambiente, através de uma navegador WEB. 
As Camadas de Aplicação e Serviço de Conexão serão responsáveis por atender as necessidades dos usuários, provendo aplicações e acesso as informações desejadas, que estarão armazenadas na Camada de Recurso, disponível na instituição.

A utilização de uma interface WEB para acesso ao Oncogrid, diferentemente de muitos projetos de Grade encontrados na literatura permitirá que o usuário possa acessar o ambiente de qualquer navegador WEB, simplificando a forma de acesso, permitimos que o usuário consiga acessar a grade computacional de qualquer local. 


\section{Implementação e Análise dos Resultados}

Este capítulo apresenta o projeto piloto e os trabalhos realizado entre o LSI/EPUSP e NUTES/UFPE para validar a arquitetura, componentes e funcionalidades propostos para o Oncogrid.

\subsection{Introdução}

Com a proposta da arquitetura e compomentes do Oncogrid, é necessário avaliar o trabalho desenvolvido, para isto foi desenvolvido um projeto piloto, possibilitando analisar as funcionalidades e assim validar a proposta do ambiente.

Para a validação dos conceitos que envolvem a arquitetura, foi desenvolvido uma aplicação de estudo de caso através da utilização do método Kaplan-Meier para realizar o cálculo da curva de sobrevida utilizando informações de bancos de dados geograficamente distribuídos.

No desenvolvimento desta avaliação foi firmada uma parceria entre o Núcleo de Saúde Digital do LSI-EPUSP e o NUTES-UFPE, possibilitando a implementação inicial do Oncogrid, com alguns dos componentes estudados, permitindo estudar o comportamento do ambiente e os requisitos das bibliotecas de desenvolvimento fornecidas pelos componentes.

Além de avaliar a viabilidade do sistema este projeto piloto possibilitou identificar em quais camadas funcionais da proposta do Oncogrid era necessário ajustes para tornar o ambiente mais funcional. 


\subsection{Estudo de Caso: Kaplan-Meier}

Para validar a arquitetura foi desenvolvido pelo LSI-EPUSP e NUTES-UFPE um serviço de grade que calcula a curva de sobrevida pelo método de Kaplan-Meier (KAPLAN; MEIER, 1958). Estes gráficos apresentam a expectativa de sobrevida dos pacientes ao longo da linha de tempo (IARC, 1991). A Figura 4.1 apresenta um exemplo de gráfico Kaplan-Meier.

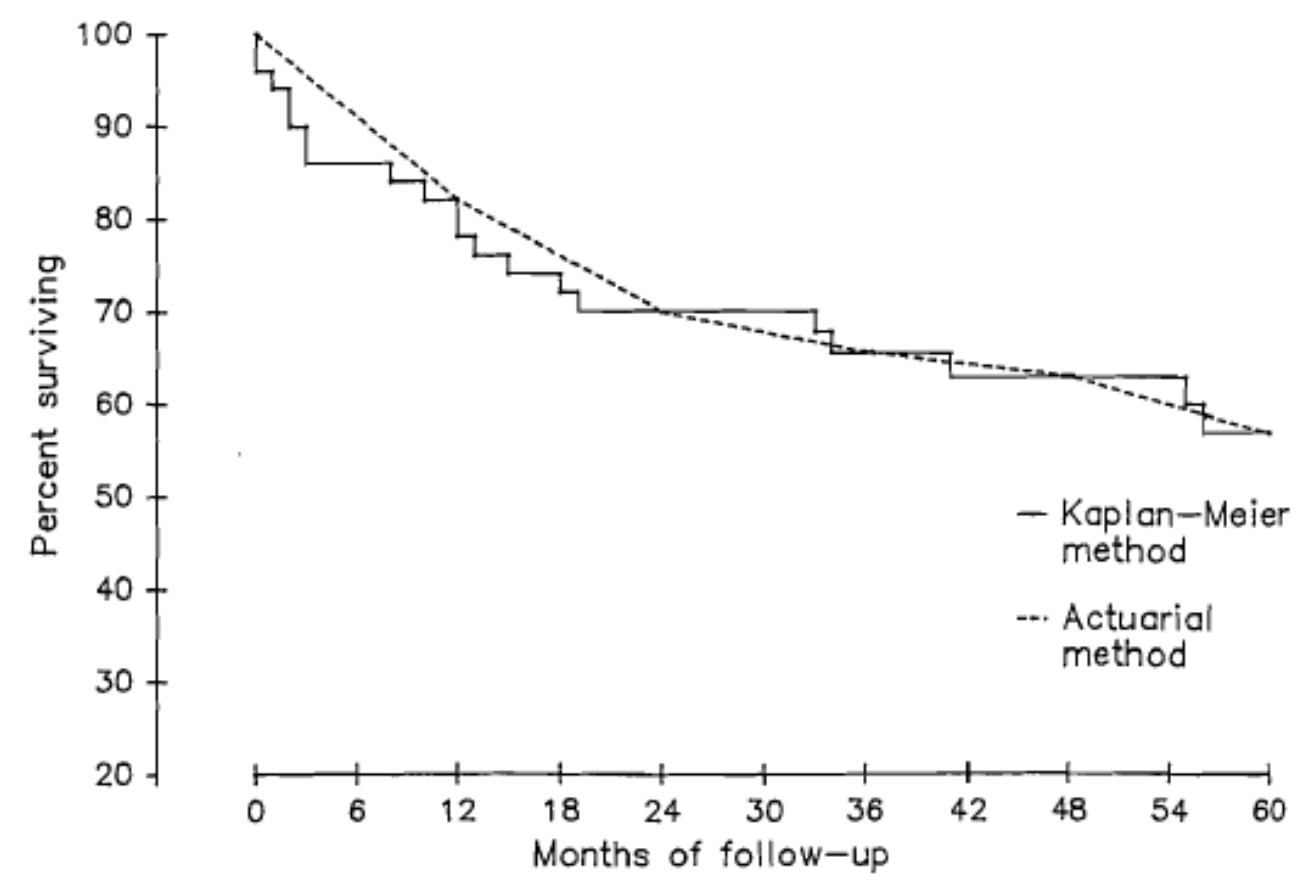

Figura 4.1: Curva de Sobrevida pelo método Kaplan-Meier (IARC, 1991)

Como exemplo do cálculo do estimador de Kaplan-Meier, supomos que exista um grupo de 100 pessoas a serem acompanhadas e que ao longo do primeiro ano morram 10. Para saber a porcentagem total de sobreviventes calcula-se 10\% dos 100\%. Sendo assim temos $90 \%$ de sobreviventes ao final do primeiro ano de observação. E, se ao final do terceiro ano, a curva atingir $60 \%$ e, ao longo do quarto ano mais $10 \%$ dos $60 \%$ morrerem, teremos ao final do quarto ano $90 \%$ de $60 \%$ sobreviventes, ou seja, 54\%, generalizando, a cada censo devemos calcular a percentagem de sobreviventes da percentagem do censo anterior em uma unidade de tempo.

A formulação matemática apresentada na fórmula 4.1 é conhecida como estimador produto limite de Kaplan-Meier, pois é o limite do produto dos termos até o tempo (t) (IARC, 1991; KAPLAN; MEIER, 1958). Onde $t$ é o tempo em meses, $l_{j}$ o tamanho da amostragem no início do mês e $d$ o número de obitos. 


$$
S(t)=\prod_{t=0}^{j} \frac{l_{j}-d}{l_{j}}
$$

As grades computacionais permitem que bases de dados com diferentes esquemas estruturais sejam disponibilizadas, possibilitando o desenvolvimento de aplicações como o Kaplan-Meier, conseguindo acesso a maior quantidade de informações sem a necessidade de consolidações ou homogeneização estrutural das bases de dados.

\subsection{Inclusão dos dados}

No projeto piloto os dados foram obtidos através do projeto Oncopediatria que oferece um sistema para auxílio ao tratamento de câncer infantil. Os dados fornecidos não continha as informações sensíveis do paciente, não sendo possível a sua identificação, possuindo apenas os dados clínicos e o seu CEP de origem. Atualmente estas informações estão centralizadas em uma base única para serem disponibilizadas pelo Oncogrid eles foram tratados e divididos em duas bases de dados distintas.

O tratamento realizado nos dados fornecidos antes de serem disponibilizados nas bases de dados das instituições, consistiu na divisão da base de dados em dois conjuntos de dados que possuiam um CEP em comum, neste caso os dois códigos de endereçamento postal correnpondia a cidade de Recife e São Paulo.

A proposta inicial do Oncogrid é utilizar a plataforma de grade computacional para integração e compartilhamento de informações médicas contidas nos bancos de dados dos hopitais que foram inseridas através de programas legados existentes na rotina do hospital, não abordando o processo de inclusão das informações. Os dados disponibilidados pelos hopitais podem estar na própria base de dados de informações médicas ou serem tratados formando um "depósito de dados"antes de serem colaborados pela grade.

\subsection{Implementação Inicial da Arquitetura}

A implementação do projeto piloto da arquitetura do Oncogrid, validou a integração entre alguns componentes que são vitais para realizar as funções que o Oncogrid se propôs, possibilitando avaliar:

a. A viabilidade de utilização da RNP como rede de interconexão; 
b. As funcionalidades do OGSA-DAI;

c. A complexidade no desenvolvimento de aplicações;

d. A integração entre componentes e sua complexidade;

e. Os componentes utilizados, permitindo melhor exploração das suas funcionalidades.

Para esta implementação foi proposto a utilização de alguns componentes, sendo eles:

a. OncogridCA: AC responsável pelo gerenciamento dos certificados utilizados no ambiente, utiliza as características da simple $C A$;

b. Globus Toolkit: utiliza dos padrões OGSI e OGSA e fornece uma infraestrutura de base flexível, possibilitando ao ambiente agregar diversas finalidades;

c. MyProxy: possibilita autenticação e delegação de credenciais, funcionalidades essenciais para utilização de portais de grade e é interoperável com o GT;

d. GridMap: o projeto inicial de avaliação da arquitetura consiste de poucos recursos e somente uma OV, não necessitando de uma ferramenta escalável para autorização, sendo interoperável com o GT;

e. OGSA-DAI: possibilita a utilização de diferentes bases de dados, utiliza padrões, baseada em serviços, maior utilizada em projetos de integração de dados e interoperável com o GT.

Os componentes considerados inicialmente para arquitetura do Oncogrid, possibilitaram a integração e interoperabilidade entre bases de dados homogêneas ou heterogêneos, autenticação única e delegação de certificados.

Apesar da possibilidade da utilização de bases de dados heterogêneas, como foi utilizada uma base única dividida em duas bases menores, acabou-se utilizando um esquema de base de dados homogêneas para a validação da proposta.

O serviço de grade desenvolvido para o cálculo da curva de sobrevida através o método Kaplan-Meier utiliza as bases de dados disponíveis na grade que são disponibilizadas através de serviços WEB possibilitando a colaboração e o desenvolvimento de aplicações para integração dos dados. 
A Tabela 4.1 apresenta a plataforma física e os recursos computacionais utilizados para a implementação inicial do ambiente.

\begin{tabular}{|c|c|c|}
\hline Localização & $L S I-E P U S P$ & NUTES-UFPE \\
\hline Qtd. Nó & 2 & 2 \\
\hline Modelo Processador & Dual Xeon $3.0 \mathrm{GHz}$ & Pentium D $2.8 \mathrm{GHz}$ \\
\hline Qtd. Memória RAM & $2 G B$ & $2 G B$ \\
\hline Discos & $2 x 80$ SATA & 2x80 SATA \\
\hline Rede Interna & 1 GB Ethernet & 1 GB Ethernet \\
\hline Rede Externa & $\begin{array}{l}10 \text { GB Ethernet } \\
\text { (Backbone RNP) }\end{array}$ & $\begin{array}{l}\text { 2.5 GB Ethernet } \\
\text { (Backbone RNP) }\end{array}$ \\
\hline Propósito & $\begin{array}{c}\text { Serviços de Grade, } \\
\text { Serviços de Seguranças e } \\
\text { Nó de Base de Dados }\end{array}$ & $\begin{array}{l}\text { Serviços de Grade e } \\
\text { Nó de Base de Dados }\end{array}$ \\
\hline
\end{tabular}

Tabela 4.1: Componentes Físicos do Oncogrid

O PostgreSQL foi definido como banco de dados padrão nesta avaliação e um conjunto de dados foi gerado com base na análise da base operacional do sistema de auxílio ao tratamento de câncer infantil disponível pelo portal www.oncopeditria.org.br. Os dados foram tratado para a exclusão dos campos de identificação do paciente como: nome, idade, nome da mãe, etc, antes de serem utilizados no Oncogrid, garantindo então a confidencialidade dos dados. O conjunto final de dados foi dividido em duas bases de dados, utilizando o Código de Endereçamento Postal (CEP) residencial do paciente como parâmetro. Uma base foi hospedada no LSI-EPUSP, nomeada Base de Dados LSI e uma outra no NUTES-UFPE, conhecida como Base de Dados NUTES, cada uma com aproximadamente 3000 registros.

Na organização dos componentes da arquitetura do Oncogrid, cada instituição disponibilizou as suas respectivas bases de dados, através dos serviços do OGSA-DAI. Dentre os componentes de grade utilizados, os contidos na Camada de Conexão de Dados foram diponibilizados nas duas instituições, sendo que o LSI/EPUSP disponibilizou também os componentes contidos na Camada de Segurança e hospedará o Portal de Grade.

Com esta distribuição organizacional, os componentes providos por cada instituição é ilustrada na Figura 4.2.

O NUTES-UFPE desenvolveu a aplicação para o cálculo da curva de sobrevida utilizando o método Kaplan-Meier, esta aplicação foi integrada ao Portal de Grade para a integração com os componentes das outras camadas do Oncogrid.

O Portal de Grade, foi disponibilizado para o usuário através do servidor de aplicativos WEB Tomcat, pois todo o desenvolvimento realizado no Oncogrid foi feito em linguagem 


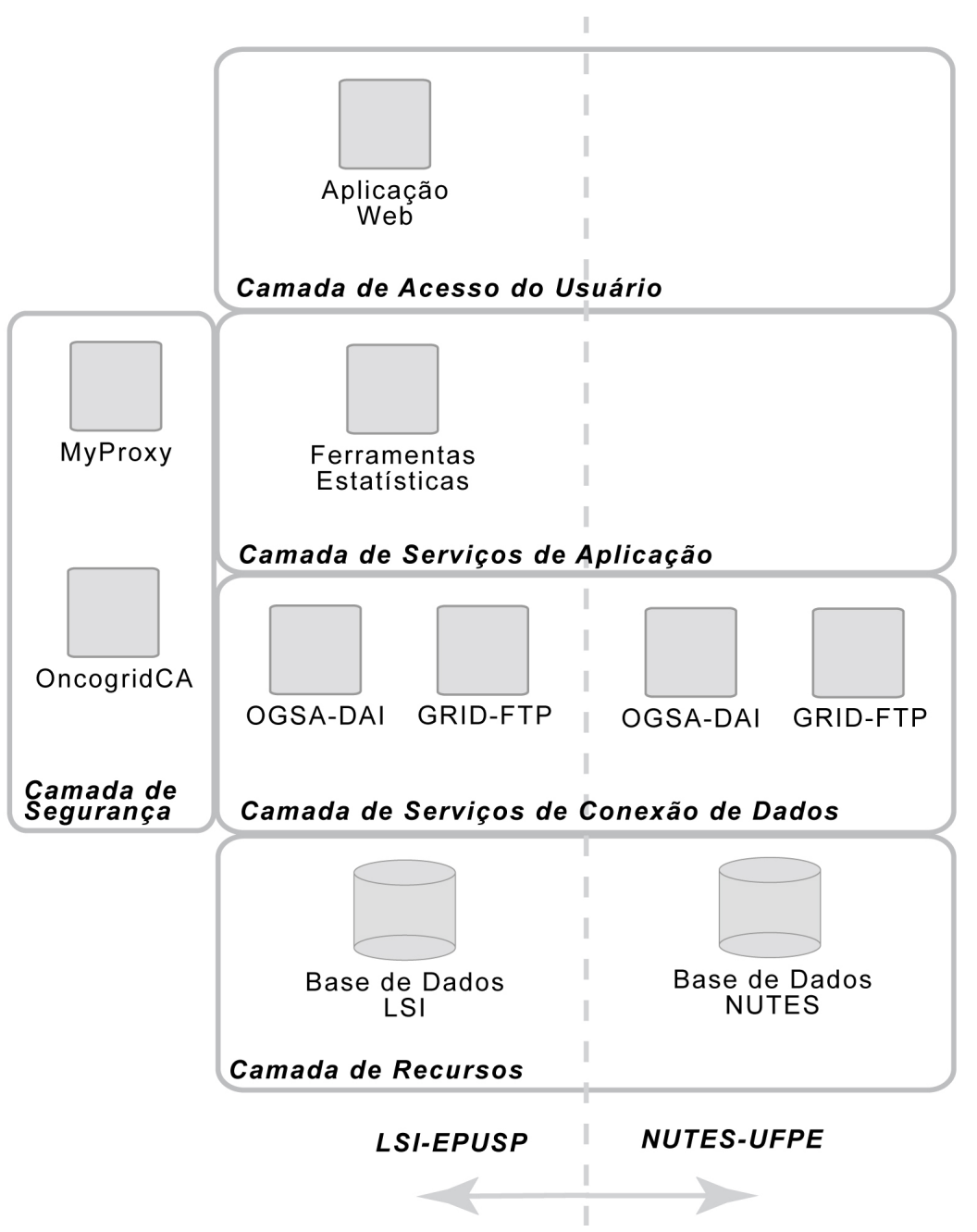

Figura 4.2: Implementação Inicial do Oncogrid

JAVA, que possi APIs para todos os componentes utilizados na proposta do Oncogrid.

Neste projeto piloto, os trabalhos de validação foram concentrados em duas funcionalidades principais do Oncogrid, o processo de autenticação, possibilitando a autenticação única e utilização dos recursos disponíveis na grade e o processo de integração de dados, o qual é o foco da proposta dessa arquitetura.

\subsubsection{Processo de Autenticação}

O processo de autenticação da grade necessitou da identificação dos usuários e hosts, para isto foi criada uma Autoridade Certificadora própria chamada OncogridCA, a qual ficou responsável pelo gerenciamento dos certificados utilizados dento do Oncogrid e manipulados para autenticação e acesso aos recursos.

Dentre as opções estudadas para a autenticação no ambiente, o MyProxy foi o compo- 
nente escolhido por ser integrada ao Globus Toolkit, componente escolhido para ser a base do Oncogrid, e devido as pesquisas realizadas na literatura apresentar melhor usabilidade, menor complexidade em implantação e atender as funcionalidades desejadas.

As funcionalidades desejadas neste processo de autenticação era permitir a autenticação do usuário através da utilização dos certificados da grade ou certificados proxy e possibilitar que utilizando estes certificados a implementação de um método de autenticação única ao ambiente.

A autenticação única elimina a necessidade de reautenticação para cada recurso disponível que o usuário utilizar. A delegação de credenciais permite ao usuário: delegar para outros componentes da grade as permissões de acesso a todos os recursos da grade computacional.

A Figura 4.3 ilustra o modelo desenvolvido no projeto piloto para o Oncogrid, no qual o usuário através do portal de grade, informando um login e senha, requisita sua credencial proxy para um servidor MyProxy, que busca em sua base de dados uma credencial válida, retornando para o usuário uma credencial com um determinado tempo de validade, que pode variar entre 1 ano quando obtidas as credenciais da grade ou 7 dias quando forem credenciais proxy. Permitindo que o usuário acesse os recursos do Oncogrid.

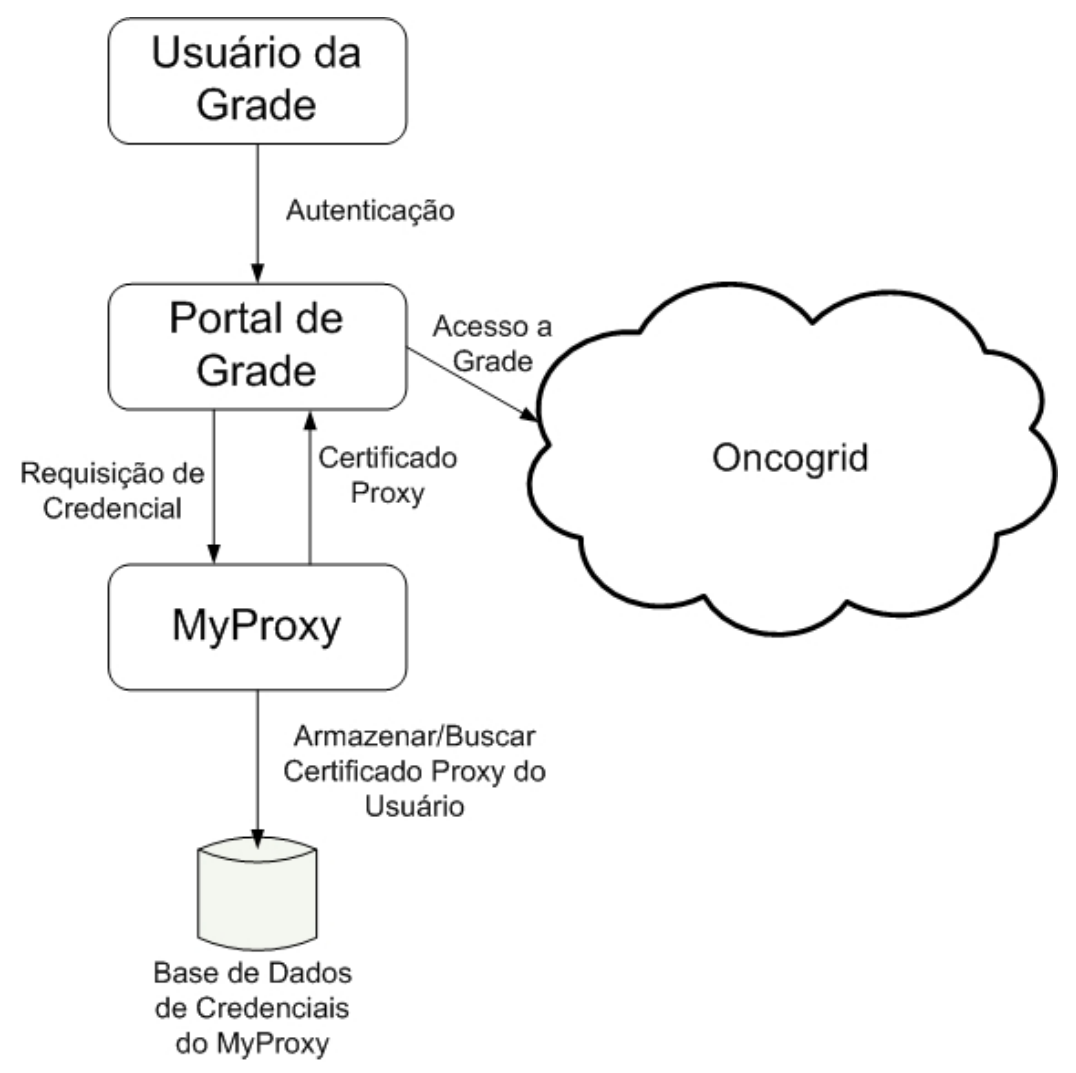

Figura 4.3: Modelo de autenticação e delegação 


\subsubsection{Processo de Integração de Dados}

A aplicação desenvolvida codifica um algoritmo que calcula a curva de sobrevida utilizando o Kaplan-Meier, adquirindo as informações em bases de dados distribuídas, através do middleware OGSA-DAI. Para tornar isso possível a conexão da aplicação com o ambiente, utilizamos as APIs das ferramentas para desenvolver a aplicação.

A Figura 4.4 apresenta o processo realizado na grade para gerar a curva de sobrevida. Neste passo, o usuário informa para aplicação a quantidade de meses que serão usados para gerar o gráfico e usa sua credencial obtida na autenticação do usuário.

A aplicação do portal utilizando a credencial proxy do usuário, acessa os recursos disponibilizados pelo OGSA-DAI que realiza as buscas nas bases de dados reais e retorna o valor da busca de forma padronizada para a aplicação.

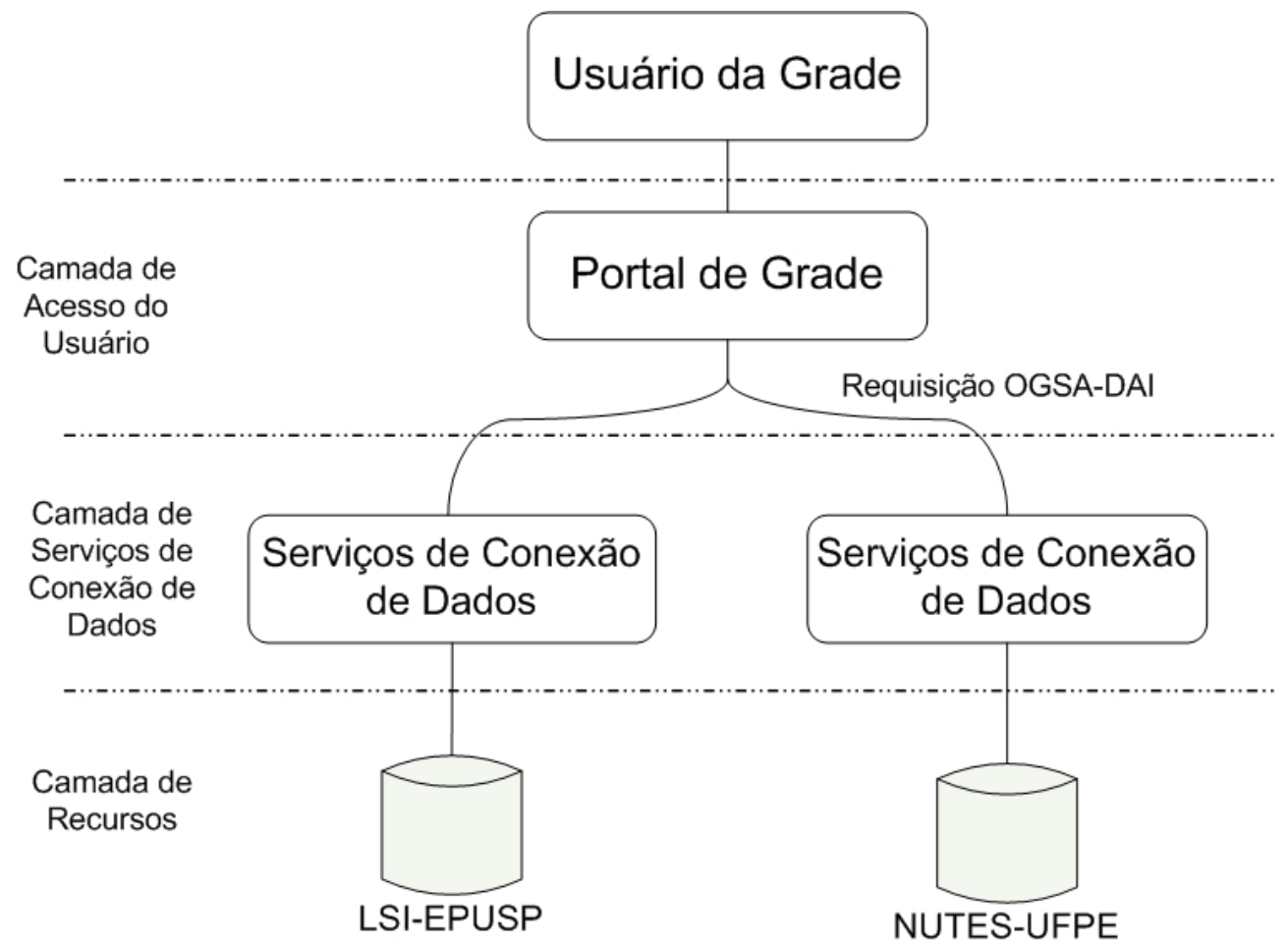

Figura 4.4: Modelo de Integração de Dados

\subsubsection{Integração do Ambiente}

Tendo o Oncogrid instalado, com os componentes citados e devidamente alocado em suas respectivas instituições, o primeiro teste realizado foi utilizando a transferência de arquivos entre as duas localidades através da utilização do GridFTP, o que oermitiu validar a utilização do MyProxy, proporcionando a autenticação única no ambiente, autorização 
de acesso através da utilização do arquivo GridMap e possibilitando a transferência de dados entre as instituições.

Após validar que acesso entre as instituições é viável e não encontramos muitas dificuldades de filtros ou barreiras na RNP durante a interconexão destes pontos. Passamos para a validar o acesso as bases de dados utilizamos um navegador de dados disponível junto com o OGSA-DAI para acessar as bases de dados locais e remotas, executando as consultas que seriam executadas pela aplicação para avaliação.

Apesar de alguns dos serviços utilizados proverem seu acesso através de serviços WEB, todos os testes realizados usaram as ferramentes disponíveis no Globus ou nos componentes utilizados para avaliar o ambiente.

Com esta avaliação do ambiente possibilitou o início do desenvolvimento de Portal de Grade utilizando as APIs disponíveis para levar a integração encontrada nos testes realizados para um ambiente WEB.

\subsubsection{Resultados Obtidos}

O resultados dos testes de integração do ambiente realizados, mostrou que é a proposta do Oncogrid é viável, mas quando portamos estes testes para um ambiente totalmente WEB passamos a encontrar algumas dificuldades na integração, os quais não ocorreram nos testes anteriores.

O ambiente implementado permitiu que a aplicação desenvolvida tivesse acesso as informações de bases de dados geograficamente distribuídas de forma homogênea e a utilização do MyProxy possibilitou a realização de autenticação no ambiente, mas com este processo desenvolvido não foi possível realizar o uso direto da credencial necessitando que fosse realizada manualmente a delegação da credencial, a qual é utilizada para a geração das curvas.

O processo de autenticação apresentou mais uma dificuldade foi em relação ao tempo de vida do certificado do usuário, pois se utilizado um certificado proxy com validade de 7 dias após este período era necessário criar um novo certificado, este caso não ocorreria com um certificado de grade que possui um 1 ano de validade, pois após esse período uma nova credencial terá que ser gerada para o usuário independentemente do MyProxy.

Após resolver manualmente as dificuldades encontrados com as credenciais foi possível realizar os testes com a aplicação Klaplan-Meier, que resultaram em três curvas: duas ger- 
adas de cada base de dados separadamente (LSI-EPSUP e NUTES-UFPE) e uma com os dados consolidados de ambas as bases. A Figura 4.5 mostra três curvas geradas em um único gráfico cartesiano, com o eixo horizontal representando o tempo e o eixo vertical, indicando a porcentagem de sobrevida.

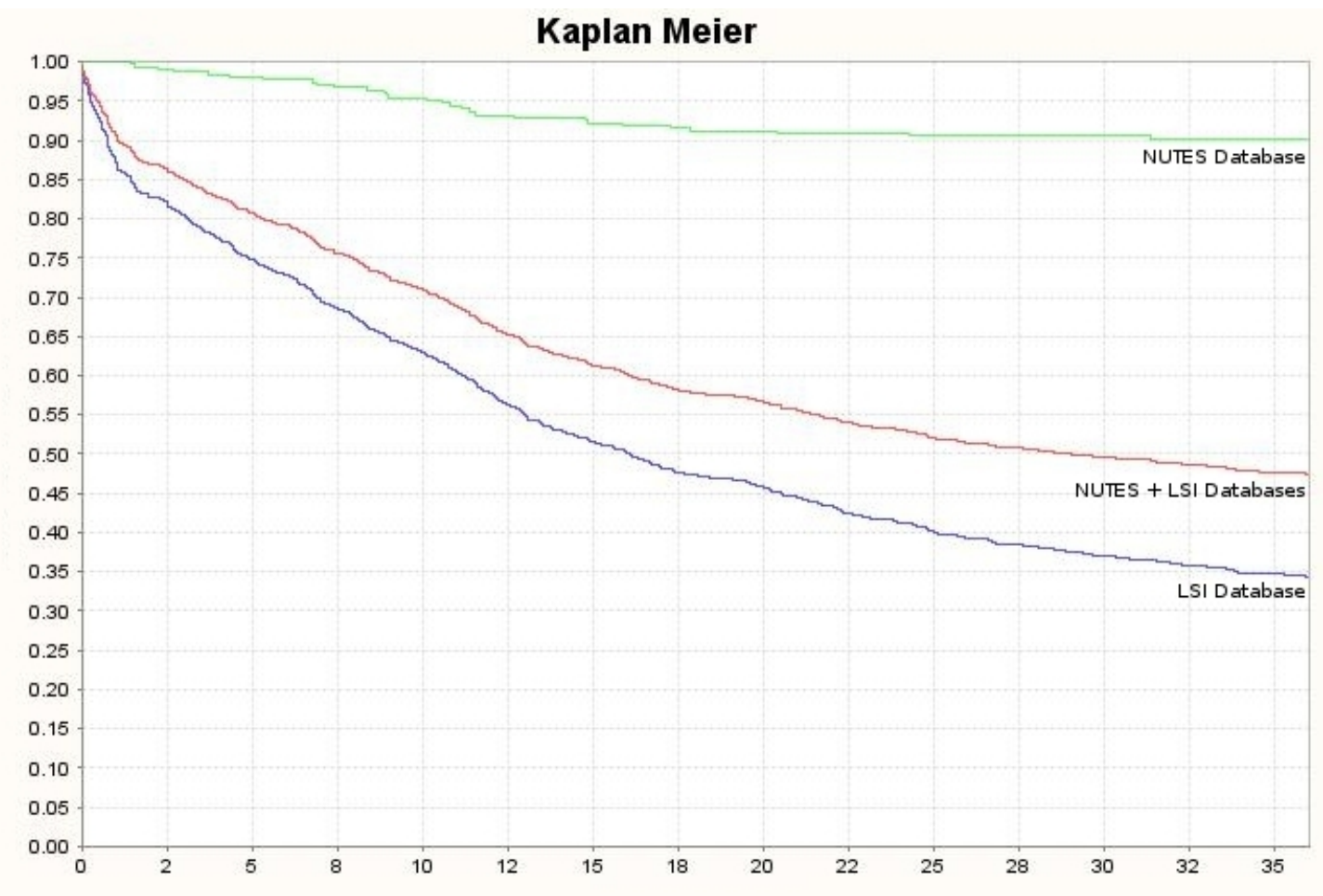

Figura 4.5: Curvas do Kaplan-Meier geradas no Oncogrid

É muito importante citar que as curvas mostradas na Figura 4.5 não podem ser consideradas como uma estatística da realidade brasileira, pois neste projeto piloto foi utilizado com um sub-conjunto de dados baseados nas informações do portal www.oncopediatria.org.br.

\subsubsection{Análise dos Resultados}

A implementação do projeto inicial possibilitou avaliar o Oncogrid, sua viabilidade, seus componentes, a complexidade no desenvolvimento de aplicações e as limitações encontradas na proposta.

A utilização de certificados proxy tem a vantagem de ter um tempo de vida curto, trazendo mais segurança se o ambiente possuir características amplas, provendo acesso por ferramentas que podem ser instaladas em qualquer local, em um ambiente mais restrito onde todo o acesso é realizado através de um Portal de Grade, acabamos oferecendo uma 
espécie de "encapsulamento"da plataforma.

O uso dos certificados proxy aplicado ao Oncogrid necessitará que o ambiente ofereça meios para que o usuário possa gerenciar a sua credencial, fazendo que o ambiente possua dois processos de gerenciamento de credenciais:

a. Externa realizada pelo usuário;

b. Interna realizada através do MyProxy.

Além dos dois processos de gerenciamento, devemos levar em consideração que os usuários que deverão utilizar o ambiente são médicos, enfermeiros, digitadores e outros profissionais da área da saúde, que podem não ter muito conhecimento de informática, tornando o processo do gerenciamento externo da credencial uma tarefa complexa.

Ao analizarmos o desenvolvimento de aplicações nesta plataforma, podemos afirmar que não é trivial devido a quantidade de fatores a serem considerados, como segurança, autorização, localização do recurso, métodos de acesso ao recurso e disponibilidade. Outro ponto identificado no desenvolvimento foi que algumas APIs disponibilizadas possuiam pouca documentação, como é o caso da API do MyProxy, sendo necessário o estudo de códigos fontes de outros aplicativos que utilizam esta API para melhorar a compreensão sobre os recursos de programação oferecidos.

O cenário encontrado no desenvolvimento utilizando as APIs do MyProxy é o reverso quando foi desenvolvida a aplicação utilizandos os recursos do OGSA-DAI, que possui uma API bem documentada.

Para obter maior eficiência no desenvolvimento de aplicações a melhor solução seria a oferta de um Kit de Desenvolvimento de Software (acrônimo de SDK, do inglês Software Development Kit), o qual ofereceria um conjunto completo de bibliotecas abrangendo todas os componentes utilizados, possibilitando que aplicações sejam desenvolvidas com maior eficácia.

Sem a oferta de um SDK, toda aplicação que for desenvolvida para o Oncogrid utilizará as bibliotecas dos componentes para prover a integração entre eles, causando retrabalho, pois com a existência de um arcabouço comum podemos obter a reutilização de código, tornando desenvolvimento mais eficiente.

Além de tornar o desenvolvimento mais eficiente podemos através do SDK avaliar se com sua utilização conseguimos reduzir a curva de aprendizado, incentivando o desenvolvimento de novas aplicações para o Oncogrid. 
Dentre as limitações encontradas no projeto inicial, podemos citar a integração de somente duas bases de dados homogêneas pelos recursos oferecido pelo OGSA-DAI, sendo que para utilizar mais bases de dados homogêneas é necessário fazer no desenvolvimento da aplicação e em relação a integração das credenciais com o ambiente WEB.

Apesar da utilização do MyProxy e suas vantagens em relação a delegação de credenciais e SSO, a integração desta ferramenta com um Portal de Grade e com os serviços do OGSA-DAI, ele não se comportou conforme o esperado, necessitando de intervenção para o gerenciamento dos certificados, como citado apresentados no início desta seção e em relação a delegação do certificado requisitada pelo OGSA-DAI.

Apesar das dificuldades encontradas, os resultados obtidos pelo projeto inicial foram animadores, pois os resultados obtidos com os experimentos mostraram que a proposta do Oncogrid viável.

O Oncogrid tona-se viável pois possibilitou a distribuição dos serviços entre computadores disponíveis na instituição, atendendo ao requisito de ser modular, oferece a possibilidade de um ambiente computacional geograficamente distribuído, utilizando a infra-estrutura de conexão da RNP para prover serviços de saúde. Os componentes propostos e utilizados nesta implementação inicial mostrou que é possível o compartilhamento de informações entre instituições médicas ou de pesquisa localizadas em diferentes estados, possibilitando aumentar o nível de colaboração no desenvolvimento de pesquisas e fornecendo uma alternativa para o acesso comum para que os dados sejam eles legados das instituições ou fornecidos por projetos de pesquisas.

\subsection{Estudo de Alternativas na Camada de Segurança}

A implementação do projeto piloto, identificou as dificuldades no processo de autenticação em relação aos certificados e a integração dos componentes, necessidando a manipulação dos certificados pertencentes ao usuário exigidos na autenticação do ambiente e a necessidade de intervenção para a delegação da credencial, que é necessária no acesso aos serviços de dados.

Identificando estas difuculdades foram realizados novos estudos para tornar o processo de autenticação mais simples, e foi encontrada duas opções, a utilização do MyProxy CA que consiste na criação dos usuários da grade no servidor MyProxy ou o desenvolvimento de uma aplicação que facilite o gerenciamento destes certificados pelos usuários. 
A utilização do MyProxy $C A$ fará com que o certificado utilizada pelo usuário possua validade de 1 ano o mesmo tempo que ele iria possuir em sua credencial de grade gerada pela OncogridCA.

O Gerenciador de Credencial de Grade é uma aplicação para possibilitar que usuários, possam utilizar gerenciar suas credenciais de acesso ao ambiente, permitindo criar certificados proxy com base em sua credencial de grade, armazenar a credencial de grade (certificado com vida longa) no servidor MyProxy, possibilitando sua utilização direta na autenticação na grade não necessitando a criação de certificados proxy (certificados com curto tempo de vida).

\subsubsection{MyProxy CA}

O MyProxy CA consiste na utilização do servidor MyProxy para criar as credenciais de grade dos usuários. Tais credenciais criadas utilizam informações da CA principal, a OncogridCA. Além de criar as credenciais de grade, elas são automaticamente armazenadas no servidor MyProxy.

O armazenamento automático das credenciais no diretório do MyProxy beneficia o usuário, pois ele não necessitará manipular suas credenciais para acesso ao Oncogrid, uma vez que já irá existir no servidor proxy. Estas credenciais têm validade padrão de um ano e possibilita que a senha de acesso seja trocado pelo administrador do servidor ou pelo usuário.

\section{Segurança de Armazenamento}

Garantir o acesso restrito e a integridade dos dados (certificados) armazenados é essencial para prover confiabilidade e segurança ao ambiente. Para isto, os certificados são armazenados no repositório do MyProxy e este repositório utiliza das regras de permissões de acesso somente para o usuário do sistema que está executando o serviço MyProxy, impedindo que outros usuários do sistemas não autorizados tenham acesso as informações dos certificados armazenadas.

\section{Administração do Servidor Proxy}

Esta opção transfere a responsabilidade de gerenciamento das credenciais para os administradores da grade, simplificando a utilização do sistema como um todo. Tomada as devidas medidas de segurança como já apresentadas, a tarefa dos administradores 
consistem na monitoração da disponibilidade do serviço e no gerenciamento das credenciais (criar, revogar, bloquear e desbloquear credenciais e alterar a senha dos usuários).

O MyProxy oferece um conjunto de ferramentas que possibilitam criar, revogar, alterar a senha, busca, apagar, travar e destravar uma credencial . O processo de revogação consiste na criação de uma nova credencial com o mesmo nome distinto (DN). Todas estas ações devem ser executadas pelo usuário de sistema que está executando o servidor MyProxy.

\subsubsection{Gerenciador de Credencial de Grade}

O principal objetivo do Gerenciador de Credencial de Grade é fornecer uma ferramenta intuitiva, onde o usuário pode gerenciar suas credenciais de acesso ao Oncogrid, mas para isto ele deve possuir uma interface simples, ser integrado ao portal de Grade e acessar dados na máquina do usuário quando solicitado. Estas são os principais requisitos desta ferramenta.

\section{Interface}

Para obter uma interface intuitiva a ferramenta é composta de uma interface de usuário única, onde é apresentada as opções disponíveis e, ao selecionar os campos requisitados pela opção são habilitados, permitindo que pessoas com menor conhecimento em informática possa utilizar e gerenciar os seus certificados. A figura 4.6 apresenta a interface desenvolvida.

Como observado na figura 4.6 o usuário possuirá inicialmente três ações, sendo que os dados informados nas ações 1 e 2 serão os mesmos, mas as funcionalidades finais serão diferentes. As ações são:

\section{Armazenar Certificado de Grade;}

2. Criar Certificado Proxy;

3. Apagar Certificados Armazenados.

Ao selecionar as ações 1 e 2, o usuário deverá informar o caminho para o seu Certificado da Grade (usercert.pem) e sua respectiva chave (userkey.pem), o usuário de conexão na grade e uma senha para poder restaurar e logar no sistema. 


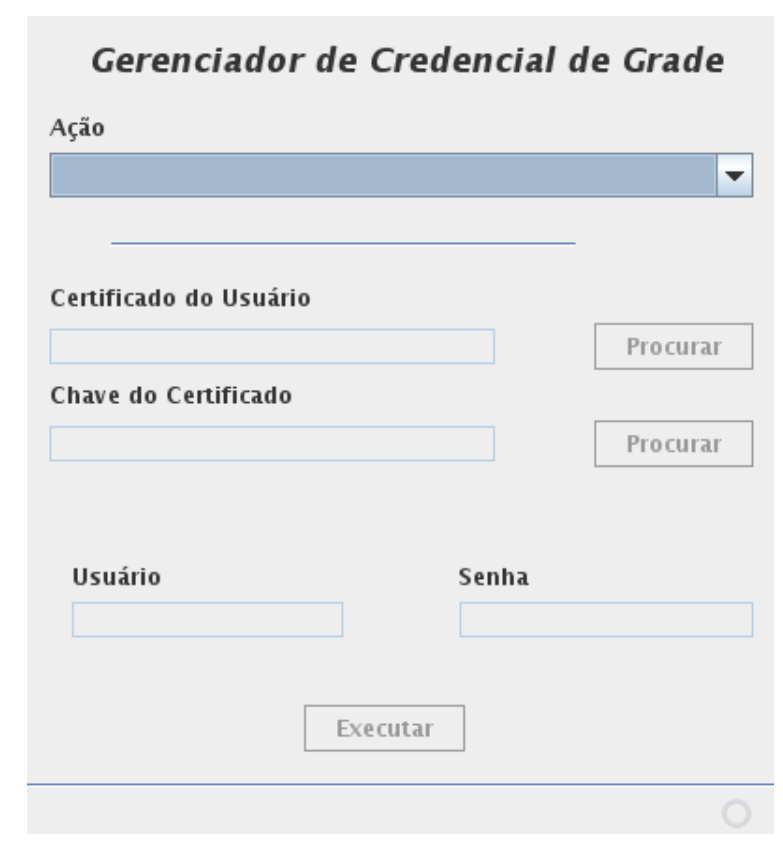

Figura 4.6: Modelo do Gerenciador de Credencial de Grade

Se selecionado a opção de "Armazenar Certificado de Grade", o usercert.pem será armazenado no servidor MyProxy, permitindo que o usuário tenha acesso ao ambiente enquanto a sua credencial de grade for válida, normalmente 1 ano.

Na ação "Criar Certificado Proxy"irá criar um certificado proxy, utilizando o Certificado de Grade e armazená-lo no MyProxy, o usuário e senha informados serão para reaver o certificado Proxy e login ao ambiente. Esta opção permite que o usuário tenha acesso ao ambiente enquanto a sua credencial de proxy for válida, normalmente 7 dias.

Já a opção "Apagar Certificados Armazenados"basta o usuário informar seu login e senha para remover os certificador armazenados no servidor MyProxy.

\section{Integração ao Portal de Grade}

O Oncogrid utiliza um Portal de Grade para prover as aplicações e serviços de grade ao usuário, evitando a instalação uma aplicação específica para acesso a grade computacional, pois através da utilização de um navegador padrão pode-se obter acesso ao ambiente.

Para desenvolver uma aplicação que atende este requisito, pode-se utilizar Java Applets amplamente utilizado em sites de Bancos ou o arcabouço Java Web Start.

Java Applet Um applet é um programa escrito em Java, que é incluido em uma página HMTL e possui sua execução realizada na máquina do cliente através da utilização de um plugin Java no navegador. O código do applet é transferido para a máquina 
do cliente e, então, executado localmente pelo navegador, possibilitando acesso aos dados localizados na máquina.

Arcabouço Java Web Start O arcabouço Java Web Start (JWS) é um framework desenvolvido pela Sun Microsystems que permite que uma aplicação Java seja iniciada diretamente pela Web e executada na máquina do cliente assim como o Applet, mas com o JWS podemos oferecer aplicações mais complexas.

A vantagem de ter uma aplicação que não está diretamente instalada na máquina do usuário é a questão de correção de falhas e atualização de funcionalidades, pois no caso do Applet e do JWS, o cliente sempre irá executar a última versão do aplicativo, facilitando a difusão de novas funcionalidades ou a correções de erros.

\section{Acesso aos dados do Usuário}

Para armazenar o Certificado Grade do usuário no MyProxy ou criar um Certificado Proxy para acesso ao Oncogrid, é necessário informar as credenciais da grade assinadas do usuário.

Estas credenciais ficam em posse do usuário e armazenadas em algum meio digital, como CD, SmartCard ou Token, para evitar a necessidade de trafegar essas credenciais para um servidor na grade, esta ferramenta prove acesso aos dados no ponto de acesso (computador público, computador pessoal, etc...) do usuário.

\section{Distribuição das Credenciais de Grade}

Atualmente a Infra-Estrutura de Chaves Públicas Brasileira (ICP-Brasil) utiliza Smartcards, tokens USB para a distribuição de certificados digitais.

A utilização destes meios digitais citados anteriormente para a distribuição das credenciais do Oncogrid, apresentaria um custo adicional ao projeto devido aos gastos envolvidos com mídia (smartcards) e hardware específico (leitoras de smartcard e token USB).Uma solução de baixo custo que poderá ser adotada em um projeto de larga escala é a utilização de $c d$-cards ou mini-cds, que além de conter as credenciais do usuário poderiam possuir, documentação como manuais de utilização do Oncogrid, informações sobre os tipos de tumores e informativos. 


\begin{abstract}
Abordagem de Uso
A utilização do MyProxy CA possibilita oferecer simplicidade e segurança ao usuário, uma vez que sua credencial será criada direto no Proxy e armazenada de forma segura pelo servidor. Além da simplicidade e segurança, é possível utilizar servidores de MyProxy CA distribuídos pelo ambiente, aumentando a disponibilidade no serviço, possibilitando a criação de servidores proxy regionais, por exemplo.
\end{abstract}

\title{
4.5.3 Análise das soluções
}

As duas opções apresentadas para o gerenciamento das credenciais dos usuário no processo de autenticação do ambiente de grade se mostraram eficientes, apresentando os seguintes pontos relevantes:

Gerenciador de Credencial de Grade: Dentre os benefícios desta ferramenta estão que o usuário tem posse de seu certificado, que será armazenada em algum meio óptico ou digital e utilizando uma aplicação disponível no Portal de Grade poderá utilizar este certificado para fazer a autenticação no ambiente, assim utilizando os recursos disponíveis e a utilização de uma ferramenta integrada ao portal de grade que acesse os dados na máquina do usuário.

Dentre os pontos negativos desta ferramenta, encontra-se na necessidade do usuário sempre ter em mãos sua credencial da grade para que possa acessar o ambiente e a necessidade de manipulação deste certificado à criação de um certificado proxy cada vez que sua credencial estiver inválida, necessitando expor suas credenciais de grade em computadores que podem não ser confiáveis.

MyProxy CA: Esta abordagem beneficia o usuário na gestão do seu certificado, não sendo necessário a criação de um novo certificado quando a existente estiver inválida, não tem a necessidade de investimento na aquisição de meios para armazenamento e hardwares específicos para utilização destes certificados e de levar sempre consigo a sua credencial, uma vez que ela já se encontra no servidor.

A desvantagem desta solução é que o gerenciamento destas credenciais ficam sob responsabilidade dos administradores do Oncogrid e por possuir um certificado com validade de 1 ano, o processo de login deve ser melhorado, para evitar que seja utilizado algum método para captura da senha do usuário, bem como garantir que 
mesmo com a senha capturada este usuário não consiga acessar o ambiente através da utilização de um login em duas fases.

Dentre as duas abordagens estudadas a utilização do MyProxy $C A$ utilizando um processo de login em duas fases, semelhante a utilizada em transações bancárias, mostrase a opção mais indicada para a utilização no Oncogrid, pois é uma solução que traz maior simplicidade no uso das credenciais quando comparado com o Gerenciador de Credencial de Grade e não obrigaria o usuário fazer investimento em um hardware específico que dependendo do meio utilizado para armazenar o seu certificado seria necessário carregá-lo consigo para poder ter acesso ao ambiente.

Outra vantagem para a utilização do MyProxy $C A$ é que o Oncogrid pode ser considerado um ambiente controlado, pois a única forma de acesso ao ambiente será através da utilização do navegador WEB, e oferecendo níveis de segurança no sistema que hospeda o serviço do MyProxy e priorizando o tráfego em canais seguro (HTTPS), proveria mais confiabilidade ao ambiente, quando comparado a distribuição das credenciais em meios ópticos ou digitais.

\subsection{Resumo do Capítulo}

Neste capítulo foram apresentados os trabalhos realizados no desenvolvimento de um projeto piloto para a validação da arquitetura proposta pelo Oncogrid, as dificuldades encontradas e as soluções estudadas para serem aplicadas durante o processo de autenticação.

A aplicação utilizada implementou o método de Kaplan-Meier para a geração de curvas de sobrevida e os resultados obtidos, mostraram que outros métodos estatísticos podem ser implementados, bem como aplicações mais complexas, pois o ambiente possibilita a colaboração de diferentes tipos de bancos de dados, abrindo a oportunidade para a colavoração de bases legadas. melhorar

O projeto piloto mostrou que os componentes utilizados na arquitetura proposta para o Oncogrid conseguem oferecer as funcionalidades desejadas para a arquitetura e que a integração destes componentes utilizando um ambiente totalmente WEB necessita de um pouco mais de estudo e desenvolvimento para alcançar os níveis de integração conseguidos nos primeiros testes utilizando as ferramentas disponíveis pelos componentes.

Dentre as dificuldades encontradas, o gerenciamento da credencial para autenticação 
foi a primeira a ser estudada, e dentre as opções avaliadas, a utilização do $M y$ ProxyCA com as devidas precauções de segurança que devem ser aplicadas pelos administradores do Oncogrid, esta solução é mais eficaz quando buscamos oferecer simplicidade ao usuário do Oncogrid. 


\section{Conclusão, Trabalhos Futuros e Contribuições}

Este capítulo apresenta as conclusões, trabalhos futuros e contribuições.

\subsection{Introdução}

O desenvolvimento do projeto piloto do Oncogrid possibilitou oferecer uma nova abordagem aos serviços de saúde oferecidos no Brasil, que ainda possui dificuldades na colaboração e integração de informações.

A dificuldade de colaboração e integração de dados deve-se à inexistência de uma plataforma computacional que possibilite que bases de dados espalhadas pelo território nacional, sejam acessadas remotamente com segurança, confiabilidade e integridade da informação. Fazendo com que as iniciativas de pesquisas se limitem em soluções que utilize a abordagem de consolidação em uma base única.

Com o projeto piloto podemos avaliar que a solução é viável, mas necessita de desenvolvimento e evolução da arquitetura para conseguir oferecer em um ambiente totalmente WEB as funcionalidades que podemos encontrar em aplicações de grade voltadas para serem executadas na máquina do usuário.

Além da evolução da arquitetura é necessário facilitar o desenvolvimento de aplicações, e a oferta de um kit de desenvolvimento seria o primeiro passo.

\subsection{Conclusão}

O desenvolvimento de um projeto de grade computacional não é um trabalho trivial, pois depende da integração dos componentes que compõem a sua arquitetura e da utilização de redes de interconexão rápidas que pode necessitar de investimentos na construção 
de uma rede dedicada.

O Oncogrid mostrou que é viável a utilização da RNP para o desenvolvimento de projetos que necessitam acessar informações que estão geograficamente distribuídas, utilizando a tecnologia de grades computacionais.

Os estudos realizados para propor a arquitetura do Oncogrid, mostraram que existem muitos componentes que podem ser considerados, sendo que nem todos utilizam os padrões propostos pelo OGF, sendo eles uma questão importante para facilitar a interoperabilidade entre os componentes e outros ambiente de grades computacionais.

A integração e compartilhamento de informações conseguidas com o projeto piloto do Oncogrid podem ser extendidas para abranger bases de dados legados possibilitando explorar uma nova abordagem no desenvolvimento de aplicações médicas, abrangendo as difilculdades encontradas pelo INCA na gestão do câncer no país e a necessidade de uma plataforma que possa auxiliar a comparação dos resultados dos tratamentos utilizando os protocolos colaborativos propostos pela SOBOPE e utilizados por diversas instituições no país como apresentado pelo Dr. Vicente Odone Filho.

Com os resultados alcançados com o desenvolvimento da arquitetura e a carência por um plataforma que ofereça essas características de distribuição e acesso a dados distribuídos para a área de saúde no Brasil, a continuação do desenvolvimento da arquitetura do Oncogrid pois permitirá a oferta de serviços que poderá auxiliar a gestão do câncer no país e melhorar o nível de colaboração entre as instituições médicas na avaliação da eficiência dos protocolos utilizados para tratamento.

\subsection{Contribuições}

O Oncogrid trouxe diversas contribuições para que pesquisas sejam desenvolvidas utilizando as tecnologias de grades computacionais. Essas contribuições são:

1. Apresentação uma abordagem voltada à saúde na integração e compartilhamento de informações para utilização de grades computacionais que são amplamente utilizadas para processamento de dados em larga escala;

2. Demonstrou que através do uso da RNP é possível construir uma grade computacional sem grandes investimentos na interconexão das organizações ou o uso de uma infra-estrutura de rede dedicada; 
3. Fez uma abstração do conceito que envolvem as grades computacionais, ilustrando através da sua arquitetura de camadas como as grades podem ser organizadas e quais componentes utilizados em cada uma destas camadas;

4. Disponibilizou uma plataforma de grade computacional para o Núcleo de Saúde Digital do LSI/EPUSP que poderá utilizar, modificar e aperfeiçoar os conceitos e a arquitetura proposta para o desenvolvimento de projetos na área de saúde;

5. Apresenção os componentes necessários à construção de uma grade e suas funcionalidades e a importância da padronização;

6. Os estudos realizados para a proposta da arquitetura resultou em um material contendo informações de como se construir um ambiente de computação em grade, sua arquitetura e componentes funcionais, material não encontrado nas pesquisas bibliográficas realizadas para o desenvolvimento deste projeto;

7. Gerou duas publicações em conferências: X Congresso Brasileiro de Informática em Saúde e 22nd IEEE International Paralles and Distributed Processing Symposium.

\subsection{Trabalhos Futuros}

As grades computacionais são utilizadas para o desenvolvimento de projetos entre instituições, possibilitando o compartilhamento de recursos como processamento e dados.

Com o desenvolvimento do Oncogrid, pode-se avaliar a importância de um SDK comum para o desenvolvimento de aplicações no ambiente, pois existe um grande conjunto de bibliotecas que devem ser utilizadas. Sendo que algumas não são bem documentadas, dificultando o estudo e desenvolvimento. Este SDK iria possibilitar maior eficácia no desenvolvimento de aplicações.

Um arcabouço de desenvolvimento deve contemplar todas as camadas e componentes propostos no Oncogrid. Dentre os requisitos que o SDK completo deve abranger estão:

- Camada de Serviços de Conexão de Dados:

permitir o uso de múltiplas bases de dados;

permitir o acesso a bases de dados;

prover métodos para sigilo dos dados dos pacientes;

prover métodos para integração entre camadas; 
- Camada de Serviços de Grades:

prover localização dos recursos e serviços;

prover disponibilidade dos recursos e serviços;

prover interfaces padrões para o desenvolvimento de novos serviços de grade;

prover métodos para integração entre camadas;

- Camada de Acesso do Usuário:

fornecer interfaces para o as aplicações que utilizam o Portal de Grade;

prover métodos para integração entre camadas;

- Camada de Segurança:

utilização do CAS;

prover para autenticação única;

prover métodos para o gerenciamento do certificado;

prover delegação dos certificados;

prover métodos para integração entre camadas.

Os estudos e implementações iniciais do Oncogrid mostraram que é possível utilizar um ambiente de grade computacional para integração e compartilhamento de informações entre organizações.

O uso desta tecnologia pela área médica pode ir muito além do compartilhamento de informações sobre tratamentos de câncer, podendo ser utilizado para outras áreas médicas e outros tipos de doenças, podendo ser utilizada também em áreas governamentais como prover auxílio a iniciativas como a do Cartão SUS.

Um exemplo de aplicação do modelo de grade computacional proposto pelo Oncogrid em outra área de saúde seria a comparação de imagens de exames médicos. Nesta aplicação, os hospitais iriam extrair as características das imagens dos exames realizados e estas informações seriam armazenadas em um banco de dados no hospital, utilizando a arquitetura proposta pelo Oncogrid, seria possível consultar os dados das imagens contidas nos bancos de dados, identificando casos semelhantes, auxiliando a prática médica na prevenção de doenças.

Um outro exemplo de aplicação desta tecnologia seria na bio-informática, onde instituições poderiam compartilhar suas bases de dados genéticas através da arquiteruta 
proposta, possibilitando que diferentes bases genéticas sejam compartilhadas entre as organizações para um bem em comum.

Os resultados alcançados por esta pesquisa mostra que a utilização da arquitetura proposta para o Oncogrid é extermamente promissora para a área da saúde, pois poderá ser utilizada como uma plataforma de colaboração de dados das instituições que utilizam os protocolos de tratamento da SOBOPE facilitando a análise dos dados, bem como poderá ser adaptada para prover uma plataforma para auxiliar a gestão do câncer. O Oncogrid é voltado para a integração e compartilhamento de dados médicos em oncologia, mas a arquitetura proposta pode ser utilizada para prover a integração de dados de para outras doenças. 


\section{Referências Bibliográficas}

ALEGRO, M. de C. et al. Rhcnet: Aplicação para consolidação nacional de registros hospitalares de câncer. X Congresso Brasileiro de Informática em Saúde CBIS'2006, 2006.

ALPDEMIR, M. et al. OGSA-DQP: A Service-Based Distributed Query Processor for the Grid. [S.l.]: UK e-Science All Hands Meeting, 2003.

ALPDEMIR, M. N. et al. Ogsa-dqp: A service for distributed querying on the grid. In: BERTINO, E. et al. (Ed.). EDBT. [S.l.]: Springer, 2004. (Lecture Notes in Computer Science, v. 2992), p. 858-861. ISBN 3-540-21200-0.

ALPDEMIR, M. N. et al. Service-based distributed querying on the grid. In: ORLOWSKA, M. E. et al. (Ed.). ICSOC. [S.l.]: Springer, 2003. (Lecture Notes in Computer Science, v. 2910), p. 467-482. ISBN 3-540-20681-7.

ALVES, H. A. V. et al. Oncogrid: A proposal of grid infrastructure for the establishment of a national health information system on childhood cancer. 22nd IEEE International Parallel and Distributed Processing Symposium, 2008. ISSN 1530-2075.

ANDERSON, D. P. Boinc: A system for public-resource computing and storage. In: GRID '04: Proceedings of the Fifth IEEE/ACM International Workshop on Grid Computing. Washington, DC, USA: IEEE Computer Society, 2004. p. 4-10. ISBN 0-7695-2256-4.

ANDRADE, N. et al. Peer-to-peer grid computing with the ourgrid community. Proceedings of the SBRC 2005 - IV Salão de Ferramentas (23rd Brazilian Symposium on Computer Networks - IV Special Tools Session ), 2005.

ANTONIOLETTI, M. et al. Ogsa-dai status report and future directions. Proceedings of the UK e-Science All Hands Meeting 2004, 2004.

ANTONIOLETTI, M. et al. The design and implementation of grid database services in ogsa-dai. Concurr. Comput. : Pract. Exper., John Wiley and Sons Ltd., Chichester, UK, UK, v. 17, n. 2-4, p. 357-376, 2005. ISSN 1532-0626.

ARAúJO, E.; CIRNE, W.; MENDES, G. Hiding grid resources behind brokers. Proceedings of the 2nd International Workshop on Middleware for Grid Computing, 2004.

BASNEY, J.; HUMPHREY, M.; WELCH, V. The myproxy online credential repository. In: Software: Practice and Experience. [S.l.: s.n.], 2005. v. 35, n. 9, p. 801-816.

BOINC. Projeto BOINC. último acesso em Junho 2008. http : //boinc.berkeley.edu/. 
BRADY, M. et al. eDiamond: a grid-enabled federated database of annotated mammograms. [S.l.]: Wiley, 2002.

BRASIL, M. da Saúde do. Portaria $n^{0}$ 3535, de 02 de setembro de 1998. [S.l.]: Ministério da Saúde do Brasil, 1998.

CABIG. caBIG Primer:An Introduction to caBIG. [S.l.], 2006.

CABIG. Cancer Biomedical Informatics Grid. último acesso em Junho 2008. http : //cabig.nci.nih.gov/.

CADSUS. Portal de Cadastros Nacionais. último acesso em Junho 2008. http : //cartaonet.datasus.gov.br/.

CATLETT, C. Teragrid architecture. Second IEEE/ACM International Symposium on Cluster Computing and the Grid, 2002.

CHAKRABARTI, A. Grid Computing Security. [S.l.]: Springer, 2007. ISBN 3540444920.

CIRNE, W. et al. Running bag-of-tasks applications on computational grids: The mygrid approach. icpp, IEEE Computer Society, Los Alamitos, CA, USA, v. 00, p. 407, 2003. ISSN 0190-3918.

CNGRID. China National Grid Project. último acesso em Junho 2008. http : //i.cs.hku.hk/ clwang/grid/CNGrid.html.

COSTA, L. B. et al. Mygrid: A complete solution for running bag-of-tasks applications. Proceedings of the SBRC 2004 - Salão de Ferramentas (22nd Brazilian Symposium on Computer Networks - III Special Tools Session ), 2004.

CROMPTON, S. et al. Data integration in bioinformatics using ogsa-dai. Proceedings of the UK e-Science All Hands Meeting 2005, 2005.

DATASUS. Departamento de Informática do SUS. último acesso em Junho 2008. http : //w3.datasus.gov.br/datasus/datasus.php.

EDIAMOND. eDiaMoND - Diagnostic Mammography National Database Project. último acesso em Junho 2008. http: //www.ediamond.ox.ac.uk/index.html.

FENSTERMACHER, D. et al. The cancer biomedical informatics grid (cabig $\left.{ }^{t m}\right)$. Engineering in Medicine and Biology Society, 2005. IEEE-EMBS 2005. 27th Annual International Conference of the, p. 743-746, 2005.

FERREIRA, L. et al. Introduction to Grid Computing with Globus. [S.l.]: IBM RedBooks, 2003. ISBN 0738499889.

FOSTER, I. Globus toolkit version 4: Software for service-oriented systems. In:

Conference on Network and Parallel Computing. [S.l.]: Springer-Verlag, (LNCS, 3779). p. $2-13$.

FOSTER, I. Globus toolkit version 4: Software for service-oriented systems. In: JIN, H.; REED, D. A.; JIANG, W. (Ed.). NPC. [S.l.]: Springer, 2005. (Lecture Notes in Computer Science, v. 3779), p. 2-13. 
FOSTER, I.; KESSELMAN, C. The Grid: Blueprint for a New Computing Infrastructure. [S.l.]: Morgan-Kaufman, 1999. ISBN 1558604758.

GOBLE, C. et al. The myGrid project: services, architecture and demonstrator pages. [S.l.]: UK e-Science All Hands Meeting, 2003.

GRAHAM, P. J. et al. Firstdig: Data investigations using ogsa-dai. Proceedings of the UK e-Science All Hands Meeting 2004, 2004.

HASTINGS, S. et al. Distributed data management and integration framework: The mobius project. Proceedings of the Global Grid Forum 11 (GGF11) Semantic Grid Applications Workshop, 2004.

HIRA, A. Y. Telesaúde sobre tecnologias livres: Um sistema de informação em saúde para gestão da atenção em Oncologia Pediãtrica. Dissertação (Mestrado) — Escola Politécnica da Universidade de São Paulo, 2005.

IARC. Cancer Registration: Principles and Methods. [S.l.]: International Agency for Research on Cancer, 1991. ISBN 9789283211952.

INCA. Estimativa 2008 - Incidência do Câncer. [S.1.]: Ministério da Saúde, 2007. ISBN 978-85-7318-126-5.

INCA. Registro Hospitalar de Câncer. último acesso em Junho 2008. http : //cartaonet.datasus.gov.br/.

JACKSON, M. J.; LLOYD, A. D.; SLOAN, T. M. Enabling access to federated grid databases: An ogsa-dai odbc driver. Proceedings of the UK e-Science All Hands Meeting 2005, 2005.

JR., B. S. et al. Neesgrid: A distributed collaboratory for advanced earthquake engineering experiment and simulation. 13th World Conference on Earthquake Engineering, 2004.

JR., M. A. C. et al. Computação em grade na saúde: Proposta de uma arquitetura para integração e informações médicas. X Congresso Brasileiro de Informática em Saúde, 2006 .

KAPLAN, E. L.; MEIER, P. Nonparametric estimation from incomplete observations. In: Journal of the American Statistical Association. [S.l.: s.n.], 1958. v. 53, n. 282, p. 457-481.

KARASAVVAS, K. et al. Introduction to ogsa-dai services. Lecture Notes in Computer Science, v. 3458, p. 1-12, 2005.

KRAUTER, K.; BUYYA, R.; MAHESWARAN, M. A taxonomy and survey of grid resource management systems for distributed computing. Software Practice and Experience, v. 32, n. 2, p. 135-164, 2002.

LANGELLA, S. et al. A distributed data management middleware for data-driven application systems. Proceedings of the 2004 IEEE International Conference on Cluster Computing, 2004. 
LANGELLA, S. et al. The cancer biomedical informatics grid (cabig ${ }^{\mathrm{TM}}$ ) security infrastructure. Proceedings of the 2007 AMIA Annual Symposium, 2007.

MENEZES, A. J.; VAnSTONE, S. A.; OORSCHOT, P. C. V. Handbook of Applied Cryptography. Boca Raton, FL, USA: CRC Press, Inc., 1996. ISBN 0849385237.

MINOLI, D. A Networking Approach to Grid Computing. [S.1.]: Wiley. ISBN 978-0-471-68756-6.

MOBIUS. Projeto Mobius. último acesso em Junho 2008. http : //projectmobius.osu.edu/.

MYGRID. Projeto ${ }^{\text {my }}$ Grid. último acesso em Junho 2008. http : //www.mygrid.org.uk/.

NEFEDOVA, V. et al. Automating climate science: Large ensemble simulations on the teragrid with the griphyn virtual data system. In: E-SCIENCE '06: Proceedings of the Second IEEE International Conference on e-Science and Grid Computing. Washington, DC, USA: IEEE Computer Society, 2006. p. 32. ISBN 0-7695-2734-5.

NESS. Projeto Network for Earthquake Engineering Simulation. último acesso em Junho 2008. http: //www.opensciencegrid.org.

NG, M. H. et al. Biosimgrid: grid-enabled biomolecular simulation data storage and analysis. Future Gener. Comput. Syst., Elsevier Science Publishers B. V., Amsterdam, The Netherlands, The Netherlands, v. 22, n. 6, p. 657-664, 2006. ISSN 0167-739X.

NOVOTNY, J.; TUECKE, S.; WELCH, V. An online credential repository for the grid: Myproxy. In: Proceedings of the Tenth International Symposium on High Performance Distributed Computing (HPDC-10), IEEE. [S.l.]: Press, 2001. p. 104-111. ISSN 1082-8907.

OGF. Open Grid Fórum. [S.l.]: Open Grid Forum, último acesso em Junho 2008. http : //www.ogf.org.

OSG. Networking and the Open Science Grid. [S.1.]: Open Science Grid, último acesso em Junho 2008. http: //www.opensciencegrid.org/images/brochures/ins5.pdf.

OSG. Projeto Open Science Grid. [S.l.]: Open Science Grid, último acesso em Junho 2008. http: //www.opensciencegrid.org.

OSTER, S. et al. cagrid 1.0: A grid enterprise architecture for cancer research. 2007.

OURGRID. Projeto OurGrid. último acesso em Junho 2008. http : //www.ourgrid.org/.

PEARLMAN, L. et al. A community authorization service for group collaboration. In: Policies for Distributed Systems and Networks, 2002. [S.l.: s.n.], 2002. p. 50-59. ISBN 0-7695-1611-4.

PENNINGTON, R. Terascale clusters and the teragrid. In: Proceedings for HPC Asia. [S.l.: s.n.], 2001. p. 407-413.

POWER, D. et al. A relational approach to the capture of dicom files for grid-enabled medical imaging databases. In: SAC '04: Proceedings of the 2004 ACM symposium on Applied computing. New York, NY, USA: ACM, 2004. p. 272-279. ISBN 1-58113-812-1. 
RNP. A rede Ipê. [S.l.]: Rede Nacional de Ensino e Pesquisa, último acesso em Junho 2008. http : //www.rnp.br/_arquivo/documentos/div0089a.pdf.

RNP. Redes Integradas. [S.l.]: Rede Nacional de Ensino e Pesquisa, último acesso em Junho 2008. http://www.rnp.br/redes/.

SALTZ, J. et al. cagrid: design and implementation of the core architecture of the cancer biomedical informatics grid. Bioinformatics, p. 1910-1916, Dec 2006.

SALTZ, J. et al. cagrid: design and implementation of the core architecture of the cancer biomedical informatics grid. Bioinformatics, v. 22, n. 15, p. 1910-6, 2006. Disponível em: <http://dx.doi.org/10.1093/bioinformatics/btl272>.

SCHOPF, J. M. et al. Monitoring and discovery in a web services framework: Functionality and performance of globus toolkit mds4. Technical Report, Mathematics and Computer Science Division, Argonne National Laboratory, 2006.

SHIBBOLETH. Projeto Shibboleth. último acesso em Junho 2008. http : //shibboleth.internet2.edu/.

SOUTTER, J. et al. Grid-Based Mammography Training. [S.l.]: UK e-Science All Hands Meeting, 2003.

STEVENS, A. R. R.; GOBLE, C. mygrid: Personalised bioinformatics on the information grid. Proceedings of 11th International Conference on Intelligent Systems in Molecular Biology, 2004.

TANAKA, Y. et al. Resource manager for globus-based wide-area cluster computing. In: IWCC '99:1st IEEE Computer Society Int. Workshop on Cluster Computing. Washington, DC, USA: IEEE Computer Society, 1999. p. 237. ISBN 0-7695-0343-8.

TERAGRID. Projeto TeraGrid. último acesso em Junho 2008. http : //www.teragrid.org.

TOHSATO, Y. et al. Heterogeneous database federation using grid technology for drug discovery process. In: KONAGAYA, A.; SATOU, K. (Ed.). LSGRID. [S.l.]: Springer, 2004. (Lecture Notes in Computer Science, v. 3370), p. 43-52. ISBN 3-540-25208-8.

TUECKE, S. et al. Open Grid Services Infrastructure (OGSI), Version 1.0. [S.1.], 2003.

UKNGS. UK National Grid Services. último acesso em Junho 2008. http : //www.grid-support.ac.uk/.

WU, B. et al. A web / grid portal implementation of biosimgrid: A biomolecular simulation database. In: ITCC '04: Proceedings of the International Conference on Information Technology: Coding and Computing (ITCC'04) Volume 2. Washington, DC, USA: IEEE Computer Society, 2004. p. 50. ISBN 0-7695-2108-8.

WU, B. et al. Biosimgrid: a distributed database for biomolecular simulations. In: UK e-Science All Hands Meeting. [s.n.], 2003. p. 412-419. Disponível em: $<$ http://www.osc.ox.ac.uk/events/conference2003.html>.

ZANIKOLAS, S.; SAKELLARIOU, R. A taxonomy of grid monitoring systems. Future Gener. Comput. Syst., Elsevier Science Publishers B. V., Amsterdam, The Netherlands, The Netherlands, v. 21, n. 1, p. 163-188, 2005. ISSN 0167-739X. 